SANDIA REPORT

SAND97-2405 • UC-510

Unlimited Release

Printed October 1997

\title{
RHOBOT: Radiation Hardened Robotics
}

P. C. Bennett, L. D. Posey

DISTRIDUTION OF THIS DOCUMENT IS UNUTTED h

Prepared by

Sandia National Laboratories

Albuquerque, New Mexico 87185 and Livermore, California 94550

Sandia is a multiprogram faboratory operated by Sandia

Corporation, a Lockheed Martin Company, for the United States

Department of Energy under Contract DE-AC04-94AL85000.

Approved for public release; distribution is unlinited.

\section{Iin Sandia National Laboratories}


Issued by Sandia National Laboratories, operated for the United States Department of Energy by Sandia Corporation.

NOTICE: This report was prepared as an account of work sponsored by an agency of the United States Government. Neither the United States Government nor any agency thereof, nor any of their employees, nor any of their contractors, subcontractors, or their employees, makes any warranty, express or implied, or assumes any legal liability or responsibility for the accuracy, completeness, or usefulness of any information, apparatus, product, or process disclosed, or represents that its use would not infringe privately owned rights. Reference herein to any specific commercial product, process, or service by trade name, trademark, manufacturer, or otherwise, does not necessarily constitute or imply its endorsement, recommendation, or favoring by the United States Government, any agency thereof, or any of their contractors or subcontractors. The views and opinions expressed herein do not necessarily state or reflect those of the United States Government, any agency thereof, or any of their contractors.

Printed in the United States of America. This report has been reproduced directly from the best available copy.

Available to DOE and DOE contractors from Office of Scientific and Technical Information

P.O. Box 62

Oak Ridge, TN 37831

Prices available from (615) 576-8401, FTS 626-8401

Available to the public from

National Technical Information Service

U.S. Department of Commerce

5285 Port Royal Rd

Springfield, VA 22161

NTIS price codes

Printed copy: A04

Microfiche copy: A01 
SAND97-2405

\title{
RHOBOT: Radiation Hardened Robotics
}

\author{
P. C. Bennett \\ Intelligent Systems and Robotics Center \\ L. D. Posey \\ Radiation Effects Experimentation Department \\ Sandia National Laboratories \\ P.O. Box 5800 \\ Albuquerque, NM 87185-1176
}

\section{Abstract}

A survey of robotic applications in radioactive environments has been conducted, and analysis of robotic system components and their response to the varying types and strengths of radiation has been completed. Two specific robotic systems for accident recovery and nuclear fuel movement have been analyzed in detail for radiation hardness.' Finally, a general design approach for radiation-hardened robotics systems has been developed and is presented. This report completes this project which was funded under the Laboratory Directed Research and Development program. 


\section{DISCLAIMIER}

Portions of this document may be illegible in electronic image products. Images are produced from the best available original document. 
1. Introduction

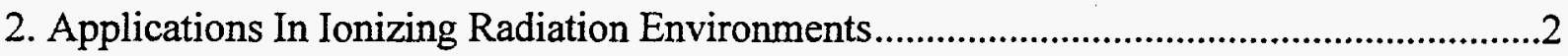

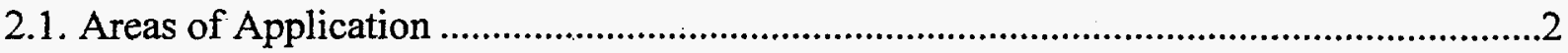

2.1.1. Civilian High Level Radioactive Waste Management .....................................................2

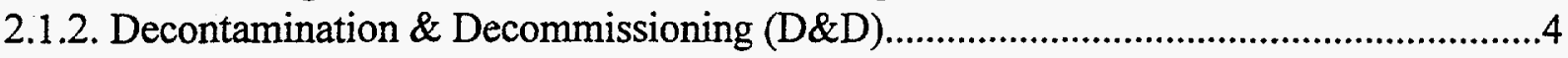

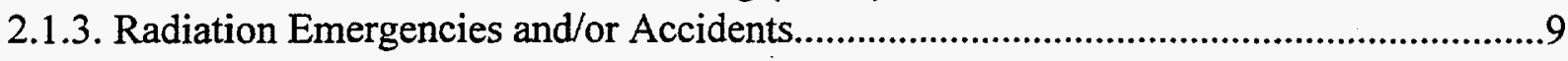

2.1.4. Environmental Restoration and Waste Management ..................................................10

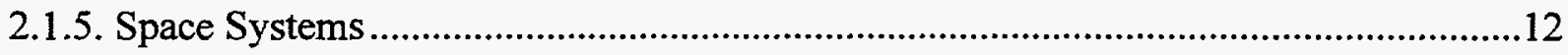

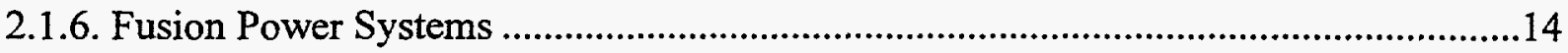

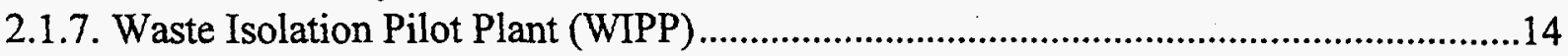

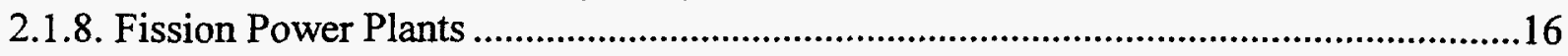

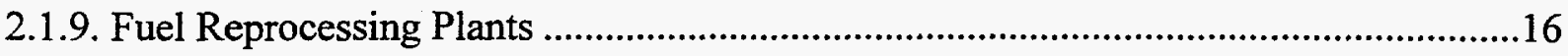

3. Robotic System Categories and Components ..................................................................18

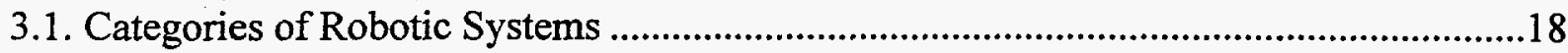

3.1.1. Fixed/Tracked Robotic Systems with or without Manipulator Arms ...........................18

3.1.2. Mobile Tethered Robotic Systems with or without Manipulator Arms..........................18

3.1.3. Mobile Semi-Autonomous or Autonomous Robotic Systems ......................................19

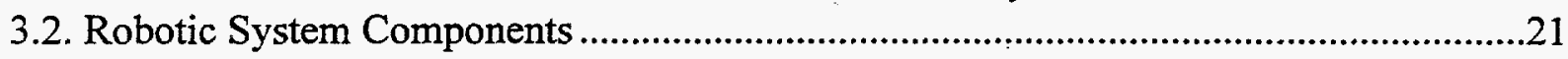

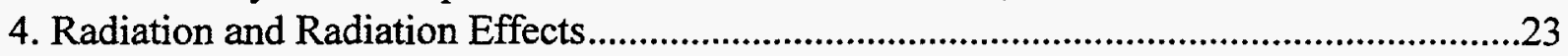

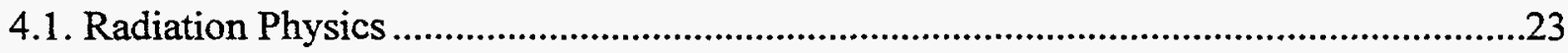

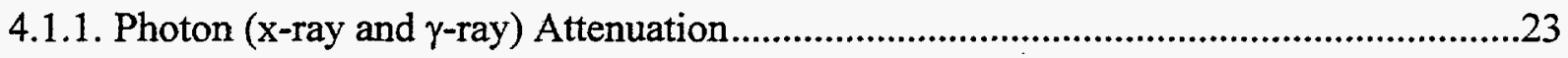

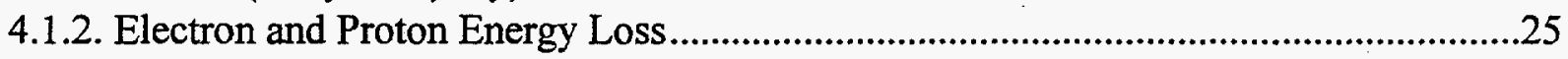

4.1.3. Heavy Charged Particle Interactions ...............................................................................28

4.1.4. Neutron and Proton Displacements Damage................................................................28

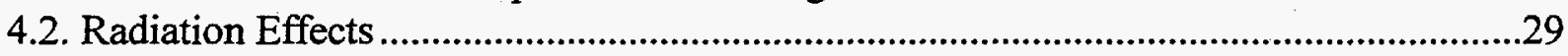

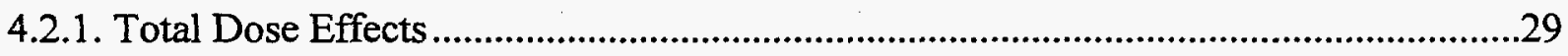

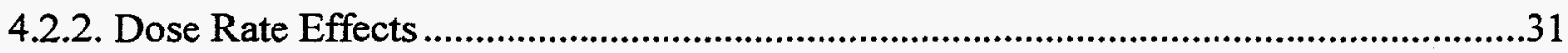

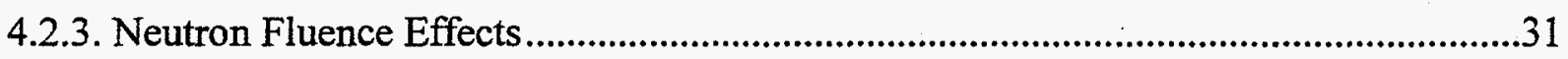

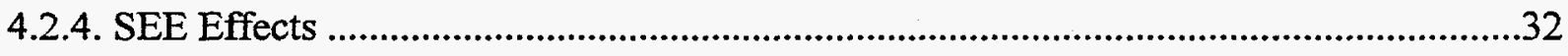

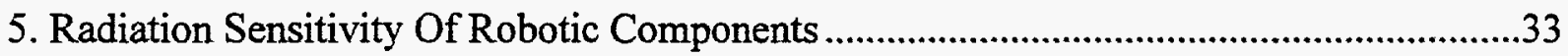

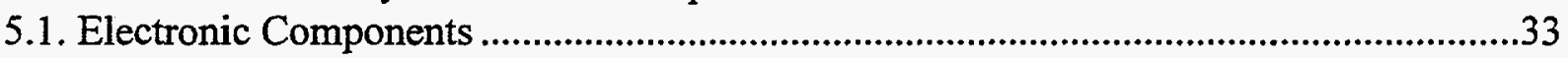

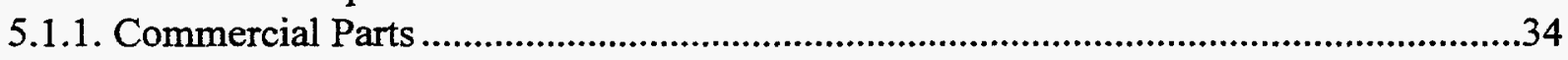

5.1 .2. Hardened Parts ............................................................................................................37

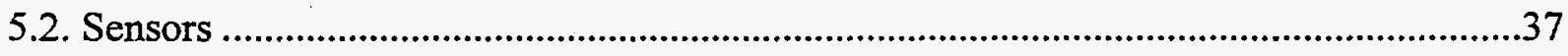

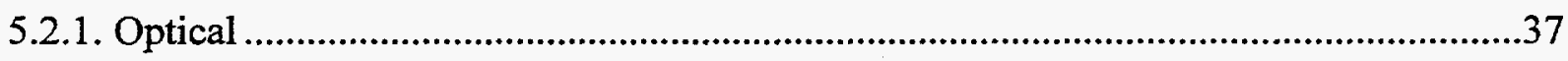

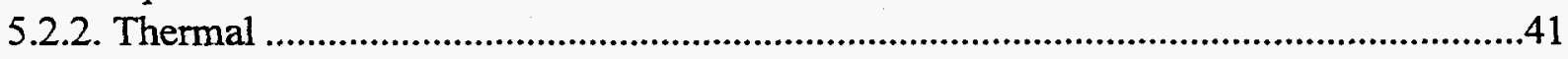

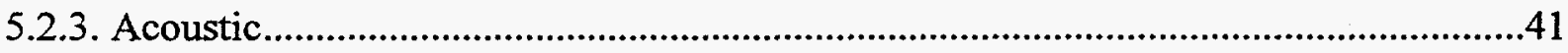

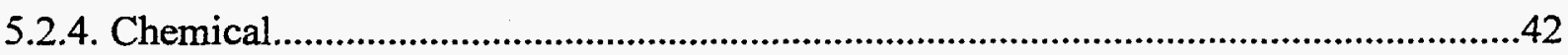

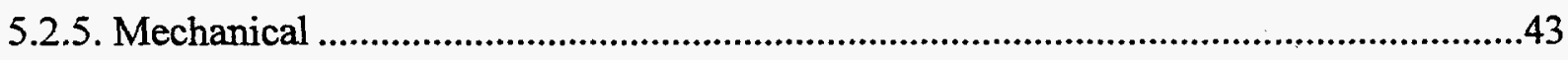

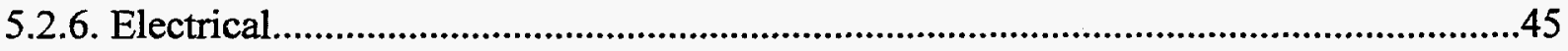

5.3. Materials and Miscellaneous Components........................................................................46 

5.3.1. Materials.

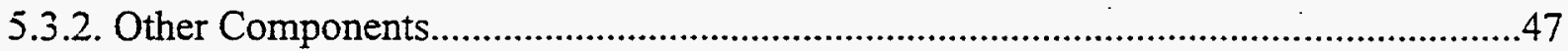

6. Robotic System Survivability In Radiation Fields: Two Examples....................................49

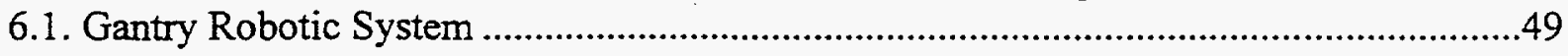

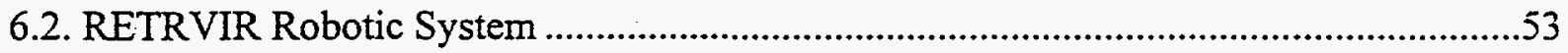

7. Radiation Hardened Robotic Design Approach. ...............................................................59

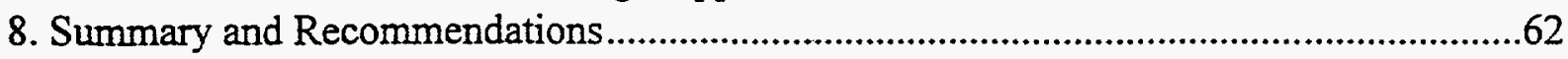

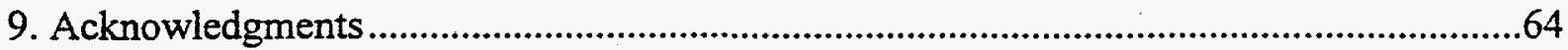

10. Appendix-A Radiation Hardness of Electronic Components...........................................65

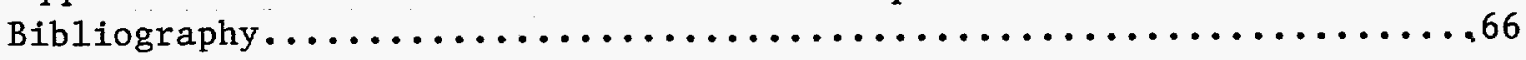


figure 2-1 model of the mrs conceptual design based on a 1992 conceptual design.......................................................... 3

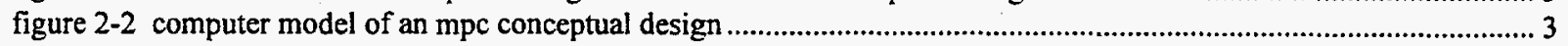

figure 2-3. artist's rendition of a mined geologic repository at yucca mountain, nevada................................................... 4

figure 2-4. the trojan nuclear power plant is preparing for $d \& d$ operations..................................................................... 5

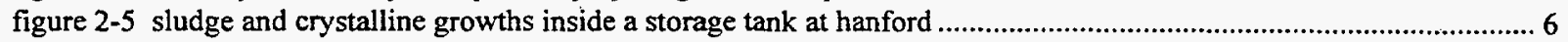

figure 2-6. multiple robots and tools operated as a system in the underground storage tank integrated demonstration at

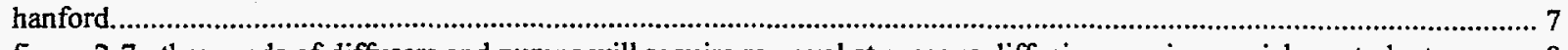

figure 2-7. thousands of diffusers and pumps will require removal at gaseous diffusion uranium enrichment plants. .......... 8

figure 2-8. molten fuel passed through sand barriers and self-vitrified in chambers under chernobyl unit 4 , forming this

highly-radioactive "elephant's foot."..

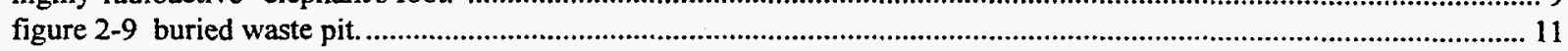

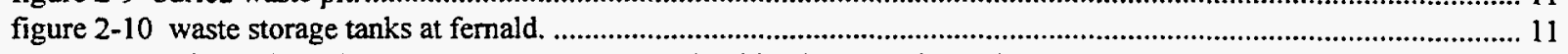

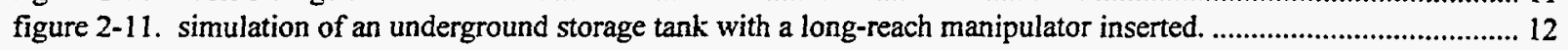

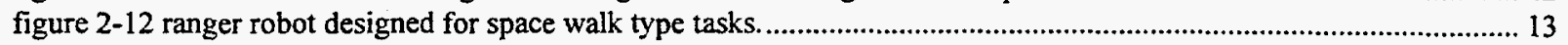

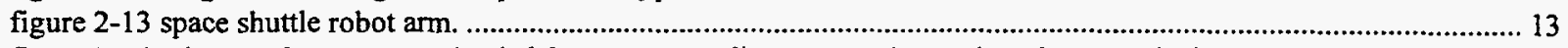

figure 2-14. drums of waste are unloaded from a trupact-ii transportation cask at the waste isolation pilot plant for

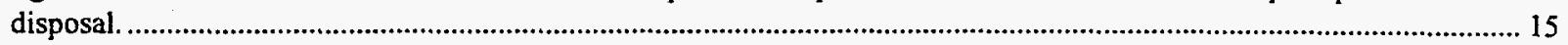

figure $2-15$ specially designed machine for remote emplacement of containers at wipp................................................ 15

figure 3-1. the retrvir robot at sandia national laboratories integrates on-board intelligence and sensors with a commercially

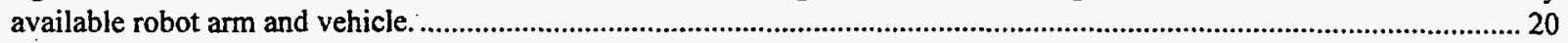

figure 4.1 mass absorption coefficient for $\mathrm{pb}$ as a function of photon energy...........................................................24

figure 4. 2 mass absorption coefficient for si as a function of photon energy. ............................................................. 25

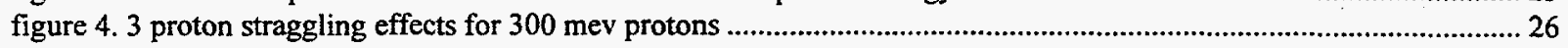

figure 4.4 dependence of electron energy deposition profiles upon the atomic number of the target material...................... 27

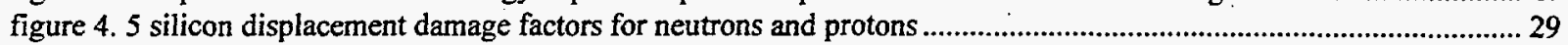

figure 4. 6 ic failure level dependentcy on dose rate (a.h. johnston et, ieee trans. on nucl. sci., ns-31, p. 1427, 1984)........ 30

figure 4. 7 threshold-voltage shift vs. dose at varying dose rates (p.s. winokur et. al., ieee trans on nucl. sci., ns-33, p. 1343,

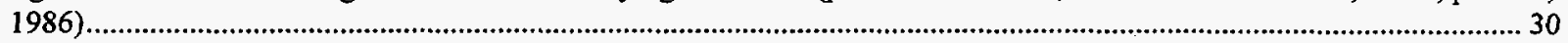

figure 4.8 input offset voltage vs. total dose for the $\operatorname{lm} 324 \mathrm{op}$-amp at various dose rates (a. h. johnston et. al., ieee trans. on

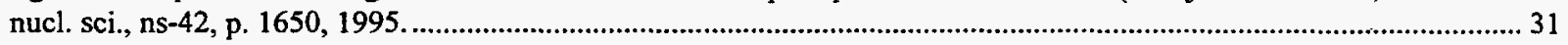

figure 4.9 nomograph for prediction of annealing factors, at room temperature. ...................................................... 32

figure 5-1 $a$ and $b$ tid and neutron/proton fluence hardness for various electron piece-part type ...................................... 35

figure 5-2 energy dependence of the ratio of proton-to-neutron damage constants for selected transistors a function of

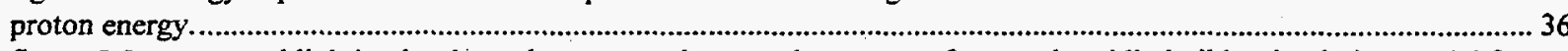

figure 5-3. structured lighting has been demonstrated as a tool to scan surfaces and rapidly build a simulation model for robot programming and control.

figure 5-4. force/torque sensors are used extensively in robotic systems throughout the u.s. doe complex....................... 44

figure 5-5. whole arm protection (whap) sensors are capacitive based, and have been envisioned as part of a collision avoidance system on robots in unstructured environments.

figure 5-6. the mast sensor, also capacitive based, has been demonstrated to be useful in seam tracking, and is being examined as a stand-off sensor for plasma arc cutting.

figure d. 1 industry standard eia resolution chart \#1956.industry grid.

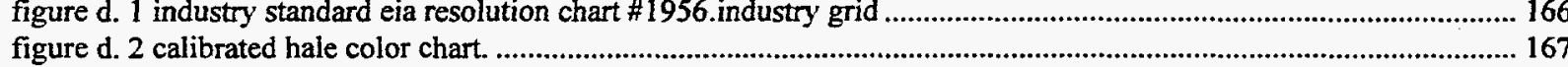

figure d. 3 experimental hardware setup for the testing of the sony $x c-999$, toshiba $i k-c 40 a$, and the elmo mn $401-e$ camera

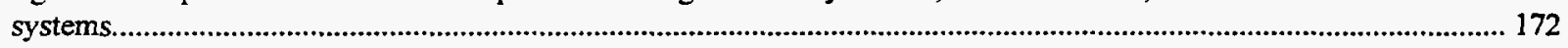

figure d. 4 experimental hardware setup for the testing for the electrim edc-1000c camera system................................... 173

figure d. 5 experimental setup for the gif testing of the cidtec cid2221d camera system. ............................................. 174

figure d. 6 reproduction of eia resolution chart \#1956 and hale color chart for sony Xc-999 camera sn13295 prior to tid exposure.

figure d. 7 reproduction of eia resolution chart \#1956 and hale color chart for sony xc-999 camera sn 13295 with irradiated

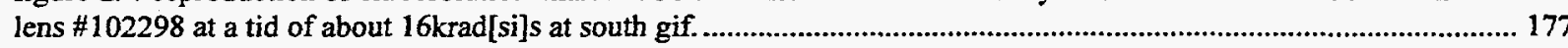

figure d. 8 reproduction of eia resolution chart and hale color chart for sony xc-999 camera sn 13295 with unirradiated lens

$\# 102534$ at a tid of about $16 \mathrm{krad}[\mathrm{si}] \mathrm{s}$ at south gif.

figure d. 9 reproduction of eia resolution chart \#1956 for sony xc-999 camera sn13295 with irradiated lens \#102298 seconds before failure at a tid of about $19 \mathrm{krad}[\mathrm{si}] \mathrm{s}$ at south gif. 
figure d. 10 reproduction of eia resolution chart for sony xc-999 camera sn 13295 with un-irradiated lens \#102534 after recovery at south gif.

figure d. 11 reproduction of eia resolution chart \#1956 for sony xc-999 camera sn13295 with un-irradiated lens \#102534 at

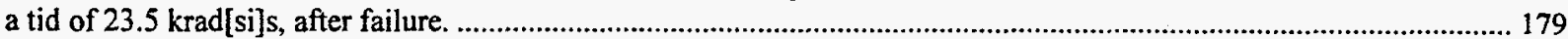
figure d. 12 reproduction of resolution chart and hale color chart for sony xc-999 camera sn 13297 prior to tid exposure at south gif. . 180 figure d. 13 reproduction of eia resolution chart \#1956 and hale color chart for sony xc-999 camera sn13297 with unirradiated lens $\# 102534$ at a tid of $13.9 \mathrm{krad}$ [si]s at south gif..

figure d. 14 reproduction of eia resolution chart \#1956 and hale color chart for sony xc-999 camera sn13297 with unirradiated lens \#102534 at a tid of $22.7 \mathrm{krad}[\mathrm{si}] \mathrm{s}$ at south gif.

figure d. 15 eia resolution chart \#1956 for sony xc-999 camera sn13296 with unirradiated lens \#103990 prior to proton exposure at uc davis. .

figure d. 16 reproduction of eia resolution chart \#1956 for sony xc-999 camera sn13296 with irradiated lens \#103990 at end of run $\# 105,1.49 \mathrm{p} / \mathrm{cm}^{2}$ at uc davis.

figure d. 17 reproduction of eia resolution chart and hale color chart for toshiba ikc40a camera sn 76510905 prior to tid exposure on south gif.

figure d. 18 reproduction of eia resolution chart and hale color chart for toshiba ikc40a camera sn 76510905 with irradiated

tamron lens \#2 at a tid exposure of $120 \mathrm{krad}[\mathrm{si}] \mathrm{s}$ at the south gif. ........................................................................... 184 figure d. 19 reproduction of eia resolution chart for toshiba ikc40a camera sn 76510905 with unirradiated tamron lens \#2 at a tid of $100 \mathrm{krad}[\mathrm{si}] \mathrm{s}$ on south gif.

figure d. 20 reproduction of eia resolution chart for toshiba ikc40a camera sn 76510905 with irradiated $1 / 2$ " format lens at a

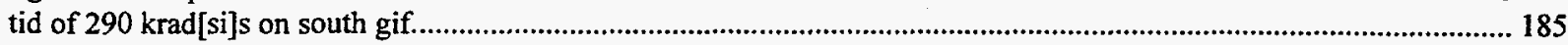
figure d. 21 reproduction of eia resolution chart for toshiba ikc40a camera sn 0824 at uc davis prior to proton exposure.. 186 figure d. 22 reproduction of eia resolution chart for toshiba ikc $40 \mathrm{a}$ camera sn0824 at uc davis at $5.2 \mathrm{e} 11 \mathrm{p} / \mathrm{cm}^{2}$ tamron lens

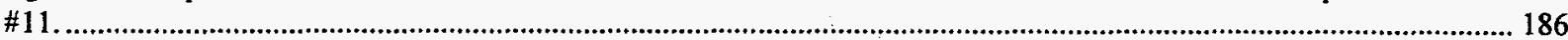
figure d. 23 reproduction of eia resolution chart for toshiba ikc40a camera sn0824 at uc davis just prior to failure at $7.76 \mathrm{e} 11 \mathrm{p} / \mathrm{cm}^{2}$ tamron lens \#11.

figure d. 24 reproduction of eia resolution chart $\$ 1956$ and hale color chart for elmo mn401-e sn97764 camera prior to tid exposure at south gif.

figure d. 25 reproduction of eia resolution chart \#1956 and hale color chart for elmo mn401-e sn97764 camera at $100 \mathrm{krad}[\mathrm{si}] \mathrm{s}$ tid exposure with $1 / 2$ " format lens $\# 2$ at south gif. figure d. 26 reproduction of eia resolution chart \#1956 for elmo mn401-e sn97764 camera at $200 \mathrm{krad}$ [si]s tid exposure with $1 / 2$ " format lens $\# 3$ at south gif.

figure d. 27 reproduction of eia resolution chart \#1956 for elmo mn401-e sn97764 camera just prior to failure at about $250 \mathrm{krad}[\mathrm{si}] \mathrm{s}$ tid exposure with $1 / 2$ " format lens \#3 at south gif.

figure d. 28 reproduction of eia resolution chart \#1956 and hale color chart for electrim edc-1000c camera on south gif prior to tid exposure...

figure d. 29 reproduction of eia resolution chart $\# 1956$ for electrim edc-1000c camera on south gif at a tid exposure of $11.3 \mathrm{krad}[\mathrm{si}] \mathrm{s}$ figure d. 30 reproduction of eia resolution chart $\# 1956$ for electrim edc-1000c camera on south gif at a tid exposure of $14.8 \mathrm{krad}[\mathrm{si}] \mathrm{s}$. figure d. 31 reproduction of eia resolution chart \#1956 for cidtec cid2221d sn v908747 with unirradiated $2 / 3$ " format lens \#3 (f stop=f8) prior to tid exposure on the south gif..........................................................................................193 figure d. 32 reproduction of eia resolution chart $\$ 1956$ for cidtec cid2221d sn v908747 with unirradiated $2 / 3$ " format lens \#3 (f stop $=f 8$ ) at a tid exposure of about $200 \mathrm{krads}[\mathrm{si}]$ on the south gif. 193 figure d. 33 reproduction of eia resolution chart \#1956 for cidtec cid2221d sn v908747 with unirradiated 2/3" format lens $\# 2$ (f stop $=8$ ) just prior to failure at a tid exposure of about $275 \mathrm{krads}$ [si] on the south gif............................................. 194. figure d. 34 reproduction of eia resolution chart \#1956 for cidtec cid2221d sn v908744 with unirradiated 2/3" format lens \#11 prior to proton exposure at uc davis. figure d. 35 reproduction of eia resolution chart \#1956 for cidtec cid2221d sn v908744 with unirradiated $2 / 3$ " format lens $\# 12$ at $1 \mathrm{e} 12 \mathrm{p} / \mathrm{cm}^{2}$ at uc davis. figure d. 36 reproduction of eia resolution chart \#1956 for cidtec cid2221d sn v908744 with unirradiated 2/3" format lens $\# 12$ just prior to failure at $1.56 \mathrm{e} 12 \mathrm{p} / \mathrm{cm}^{2}$ at uc davis.

figure e. 1 contaq ultrasonic proximity sensor test locations in the north gif cell. .........................................199 figure e. 2 contaq ultrasonic proximity sensor test setup in the north gif cell................................................................. 200 figure e. 3 contaq ultrasonic proximity sensor tld locations and dose rates on the north gif cell...................................... 201 figure e. 4 spatial profiles for the two exposures in the north gif cell............................................................................205 figure $f .1$ experimental test setup of the cat $24 \mathrm{c02}$ pi eeprom . 
figure g. 1 experimental setup for the tid testing of the adg506a and ad7503 multiplexers.

figure g. 2: (top left) adg506a at $10 \mathrm{rad} / \mathrm{s}$ (bottom left) adg506a at $3 \mathrm{rad} / \mathrm{s}$ (top right) ad7503 at $10 \mathrm{rad} / \mathrm{s}$ (bottom right) ad7503 at $3 \mathrm{rad} / \mathrm{s}$. t-on as a function of dose.

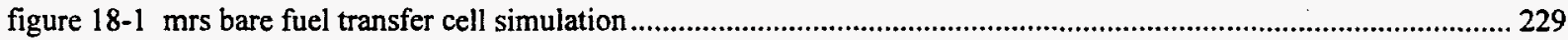

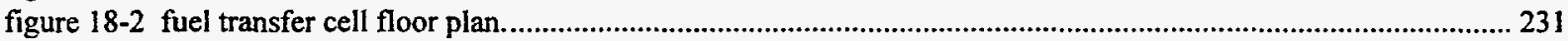

figure 18-3 dose map for gamma radiation with fuel raised over a transfer station................................................... 232

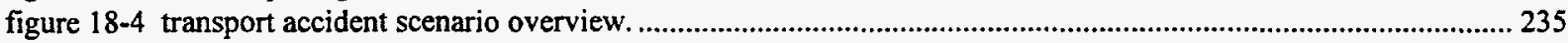

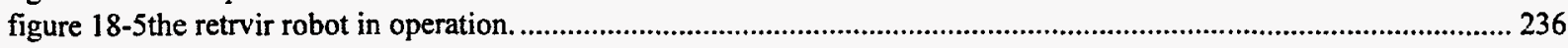

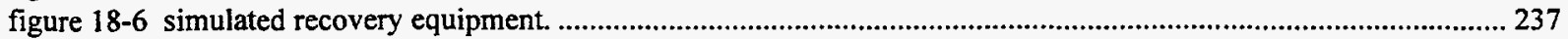

figure 18-7 interface menu for selection of robots and sources for radiation dose tracking.........................................238

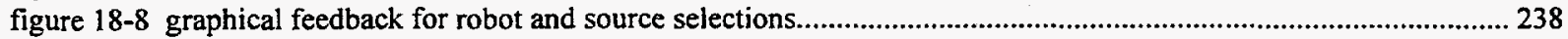

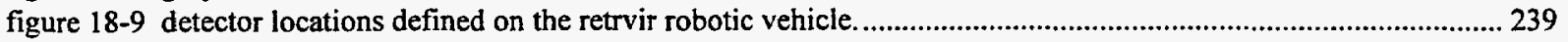

figure 18-10 retrvir attaches a shield plate support cover to the open cask end.......................................................... 240

figure 18-11 trojan nuclear power plant. (courtesey portland general electric) ...................................................... 242

figure 18-12 simulation of the trojan reactor containment building. ........................................................................2. 243 
table 6. 1 gantry robot subsystems/sensors

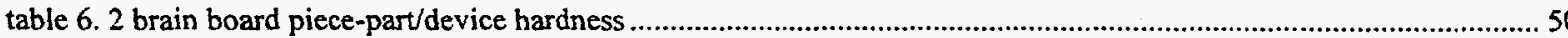

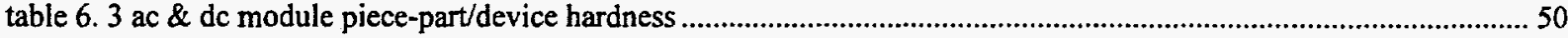

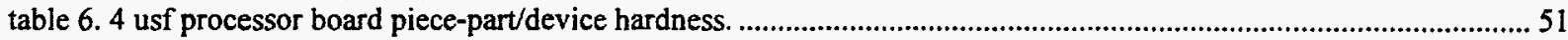

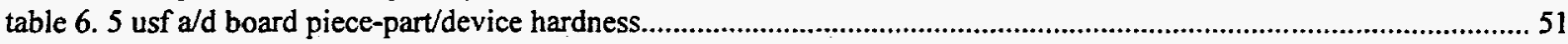

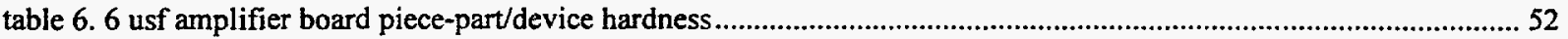

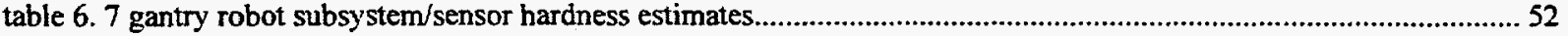

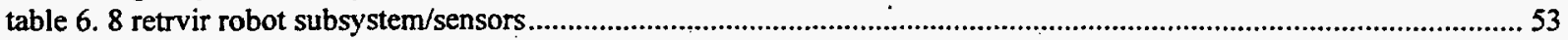

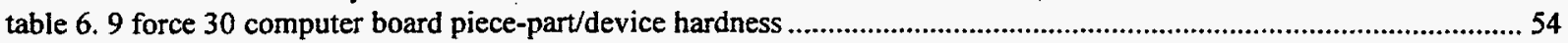

table 6.10 force 33 computer board piece-part/device hardness .................................................................................5 55

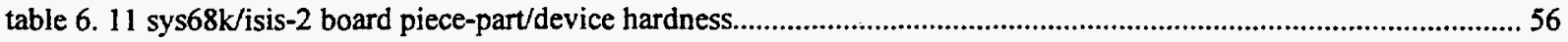

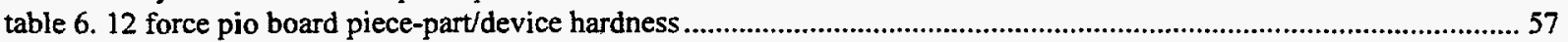

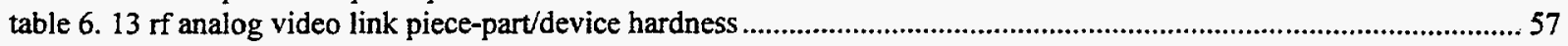

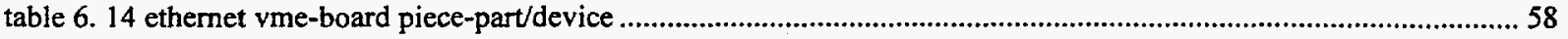

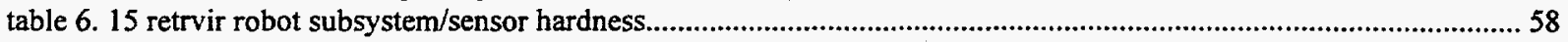

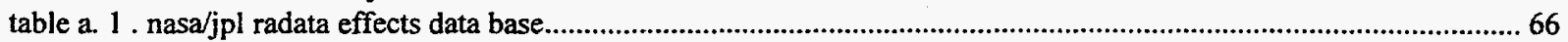

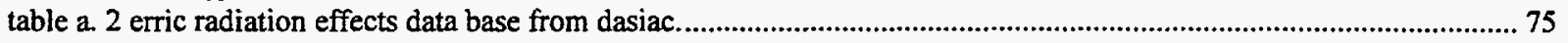

table a. 3 . snl "whitestar" data base

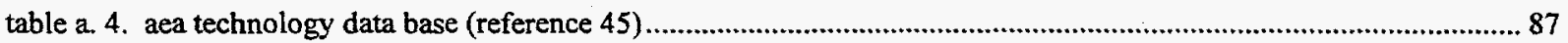

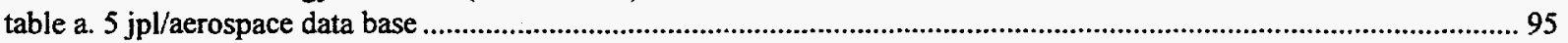

table b. 1. manufacturers of hardened piece parts with listing of part types and associated target hardness parameters .... 128

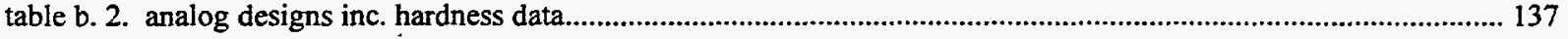

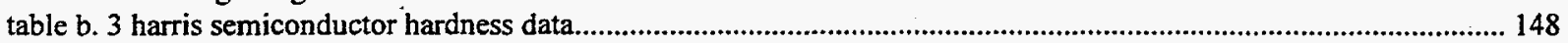

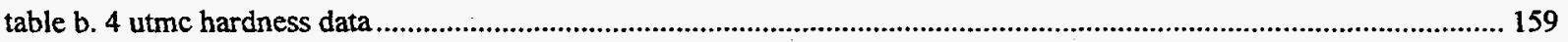

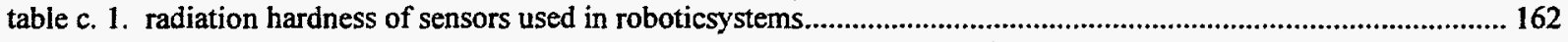

table c. 2. radiation hardness of materials and other components used in robotic systems............................................ 163

table d. 1 summary of step-stress exposure increments and camera response for the tid testing of selected ccd-type and cid-

type cameras on the gif.

table d. 2 summary of step-stress exposure increments and camera response for the proton fluence testing of selected ced-

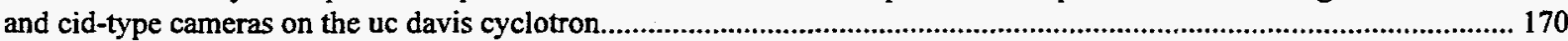

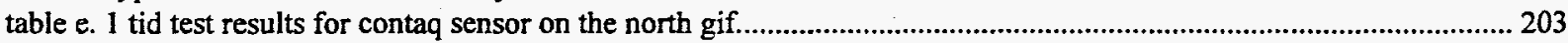

table e. 2 voltage readings from digital voltage meter during irradiation on north gif. .................................................204

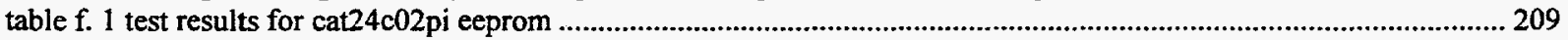

table g. 1 : exposure increments used for the tid testing of the adg506a and the ad7503 at $10 \mathrm{rad} / \mathrm{s}$ on the north gif....... 212

table g. 2: exposure increments used for the tid testing of the adg506a and the ad 7503 at $3 \mathrm{rad} / \mathrm{s}$ on the north gif.......... 212

table 18.1. dose tracking results for spent fuel transfer operations at a simulated mrs............................................... 234

table 18-2. dose tracking results for transport accident scenario ............................................................................. 241 


\section{Introduction}

Robotic technologies and associated systems are used widely in industrial ${ }^{1}$, entertainment and, to a lesser degree, research applications. This results from considerations such as (1) their unique capabilities (2), economic advantages and (3) improved safety in the conduct of operations.

In recent years there has been increased interest in the use of robotic systems in hazardous environments especially where sources of radiation are present (i.e., from nuclear power plant maintenance to operations conducted in the space environment). In the late 1980 s many off-the-shelf robotic systems were available 2,3 for use in applications where ionizing radiation was present. Most of the applications considered at that time were for use in relatively low field strengths; i.e., up to hundreds of $R / h r$. The scope of the work presented in this report concentrated on robotic system applications with field strengths up to 30 to $50 \mathrm{kR} / \mathrm{hr}$, which are characteristic for many of the applications described in Section 2 . The primary advantage of using robots for operations in radiation field is to replace human workers.

Radiation workers are presently limited to $5 \mathrm{Rem} / \mathrm{yr}$ by federal regulations. Future limits are sure to be lower, and will likely continue to decline, as evidenced by new engineering designs being required to achieve 1 to $2 \mathrm{R} / \mathrm{hr}$ and as a result of the general philosophy of ALARA (indeed, an acute dose of 350R will lead to a $50 \%$ mortality rate for an average worker). This low dose limit means that a large number of personnel would have to be used to perform functions in high radiation-field situations. Robotic systems, appropriately "hardened" against the deleterious effects produced by ionizing radiation, can offer a cost-effective solution in the performance of these functions. In the nuclear power industry a "rule-of-thumb" is that a robotic system is a viable alternative to humans if its equivalent cost is less than $\$ 10 \mathrm{~K} /$ person Rem eliminated.

In this report Section 2 will discuss some of the potential applications of robotic systems in activities/operations where radiation is encountered. However, this discussion is not exhaustive. A limited number of robotic systems are described in Section 3 for illustration and the important components of robotic systems are discussed. The types of radiation and their basic mechanisms of interaction with materials are dealt with in Section 4 . Then detailed consideration is given to the radiation response of robotic system components and materials in Section 5.

Two SNL-developed robotic systems, a Gantry Robot and the RETRVIR, were evaluated in detail concerning their hardness in select environmental scenarios and the results are presented in Section 6.

Section 7 presents a general design approach that should be employed when developing robotic systems to operate in high radiation fields (i.e., up to 30 to $50 \mathrm{krad}[\mathrm{Si}] / \mathrm{hr}$ ).

Finally the findings of this work are summarized in Section 8 and recommendations are made relative to future work as well as to viable robotic system applications. 
At present there is a great deal of interest in the potential of using robots to limit human exposure to ionizing radiation in the case of routine radiological operations as well as to perform functions that would be very hazardous to human beings such as an emergency response to a radiological accident. Although conceptual studies and prototype demonstrations are being performed for such applications as the Idaho National Engineering Laboratory (NNEL) waste burial sites, the Hanford underground storage tanks, the disassembly of weapons at Pantex, the waste drum sampling and handling at the Savanah River Site (SRS), etc.; there has been only limited activity devoted to radiation vulnerability considerations of such robotic systems in light of their early stages of development. This area is beginning to receive increased emphasis and the work reported on herein is a part of this effort.

\subsection{Areas of Application}

Potential applications involving the use of robotic systems in ionizing radiation environments are listed, and briefly discussed, below. This includes most of the present areas of expressed interest, but is not meant to be an exhaustive summary.

\subsubsection{Civilian High Level Radioactive Waste Management}

The United States Department of Energy (USDOE) has the responsibility to develop and operate a Civilian Radioactive Waste Management System (CRWMS) that will remove approximately 86,000 metric tons of spent nuclear fuel (SNF) from commercial reactors in the United States and dispose of the fuel in a permanent geologic repository. Elements of the CRWMS may include temporary storage facilities, transport capabilities, and the repository facilities. TRW Environmental Safety Systems, Inc. (TESS), the CRWMS Management and Operating Contractor, has developed conceptual designs for a Multi-Purpose Canister (MPC) system to simplify SNF handling through these elements, a Monitored Retrievable Storage (MRS) facility for the interim storage of SNF, and is engaged in characterization efforts for a geologic repository.

\subsubsection{Monitored Retrievable Storage (MRS)}

Most commercial reactor fuel storage facilities will reach capacity before a permanent geologic repository can be opened. While some utilities are investing in local independent spent fuel storage installations to provide extended storage capacity, the CRWMS is planning a interim storage facility for the fuel. This facility, called a Monitored Retrievable Storage facility, or MRS, would accept and store fuel from the utilities until a repository is opened. Transport casks containing the fuel would be processed and unloaded, with bare or canisterized fuel moved to a storage mode such as storage casks or vaults. A conceptual model of the MRS is shown in Figure 2-1.

A high volume facility such as an MRS facility, processing up to 400 casks per year, will have high cumulative doses to operators, even with low dose rate $(120-700 \mathrm{mrem} /$ cask is anticipated) routine cask and fuel handling operations. In a regulatory environment of low dose limits and pressure to reduce limits even further under an ALARA operating philosophy, it is essential to explore all reasonable means to reduce radiation exposure. In an analysis of four MRS work cells ${ }^{4}$ it was determined that a potential 5400 rem can be eliminated at the MRS facility. This dose can be eliminated, not only without significant cost but with substantial savings potential. All of the indicators for the examined workcells show a potential facility lifetime savings of up to $\$ 148$ Million over manually operated counterparts when automated. 


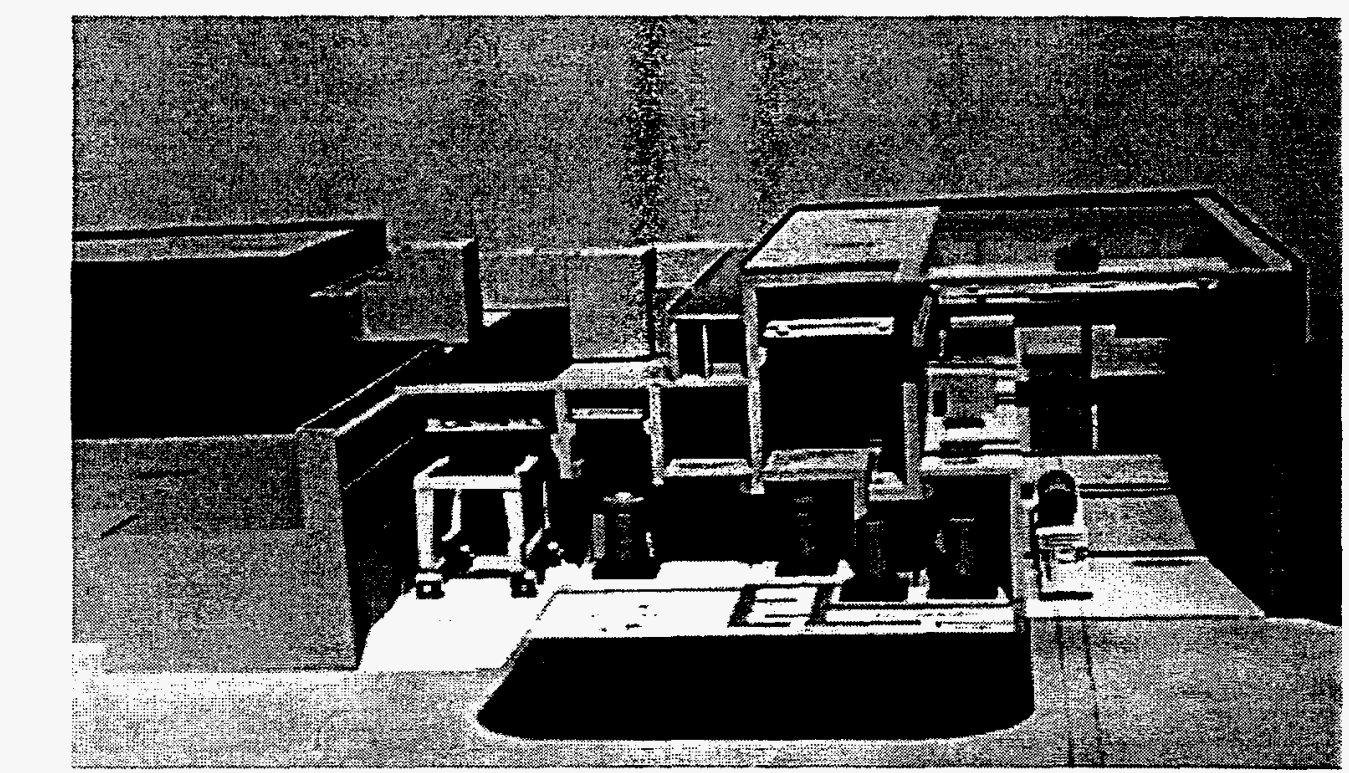

Figure 2-1 Model of the MRS conceptual design based on a 1992 conceptual design

\subsubsection{Multi-Purpose Canister (MPC)}

To simplify operations in the Civilian Radioactive Waste Management System (CRWMS), the USDOE and TESS have chosen to develop the MPC. The MPC is a sealed metallic container which could be used for storage, transportation and disposal of spent nuclear fuel (SNF) assemblies throughout the CRWMS (Figure 2-2). MPCs are intended to be loaded and sealed at commercial reactor sites to provide a dry, inert environment for SNF, and are over-packed separately and uniquely for the various system elements of storage, transportation, and geologic disposal.

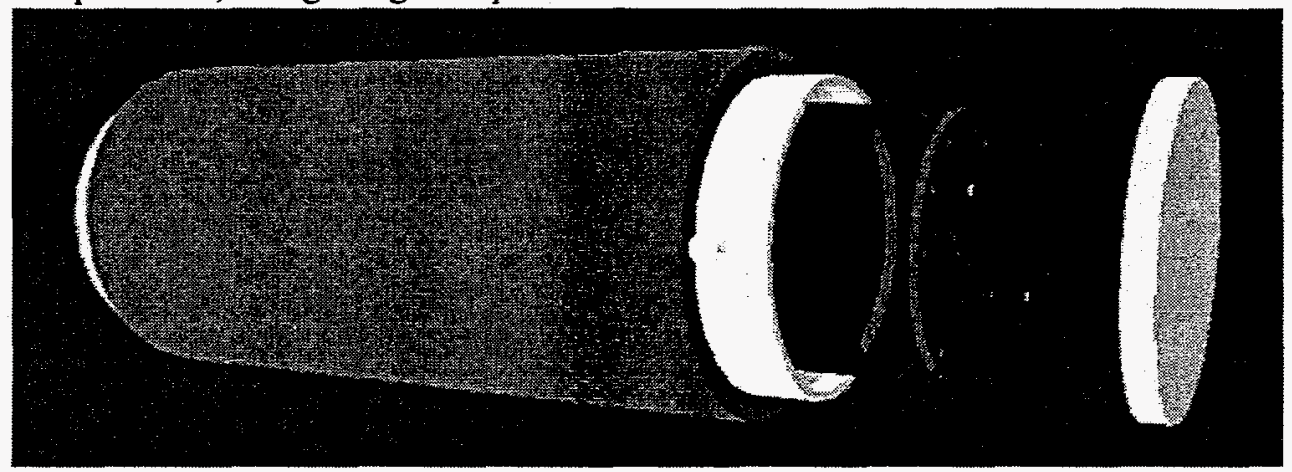

Figure 2-2 Computer model of an MPC conceptual design

One difficulty with the MPC concept is the relatively high radiation dose imparted to workers during the closure and welding operations at the nuclear utility reactor sites. Closure operations of a single 125 ton MPC may result in a combined exposure of over $10 \mathrm{mSv}$ (1 rem) using available manual and remote techniques, with about $60 \%$ of this exposure taken by welding personnel. With anticipated MPC loading rates of up to nearly 400 per year, substantial radiation doses may be imparted at the sites. Further, with continuously-decreasing administrative dose limits (10 person-mSv/year or $1 \mathrm{rem} /$ year for CRWMS facilities), strains on the available labor force may result and associated labor rates may become unstable.

As a result, alternative means of closing and welding MPCs consistent with the ALARA philosophy have been sought. Robotic closure and welding is one potential solution, removing the workers from the radiation fields and potentially eliminating $85 \%$ of the doses associated with these operations. Further, the radiation environments are minimal for robotic equipment. 
Simulation of the robotic MPC closure and welding indicated the technical feasibility of automating these operations. Throughput tracking in the simulation indicated the possibility of doubling the through-put over current manual and remote methods for the operations examined, reducing handling time from 38 to 15 hours.

Benefit/cost analysis (see Reference 4) indicated the possibility of saving $\$ 28.3$ Million to $\$ 274$ Million over approximately 30 years of at-reactor MPC loading. Payback on simulated systems ranges from 1-9 years and results in a reduction in doses of over $61 \mathrm{~Sv}(6100 \mathrm{Rem})$ during the 30 year expected operational life.

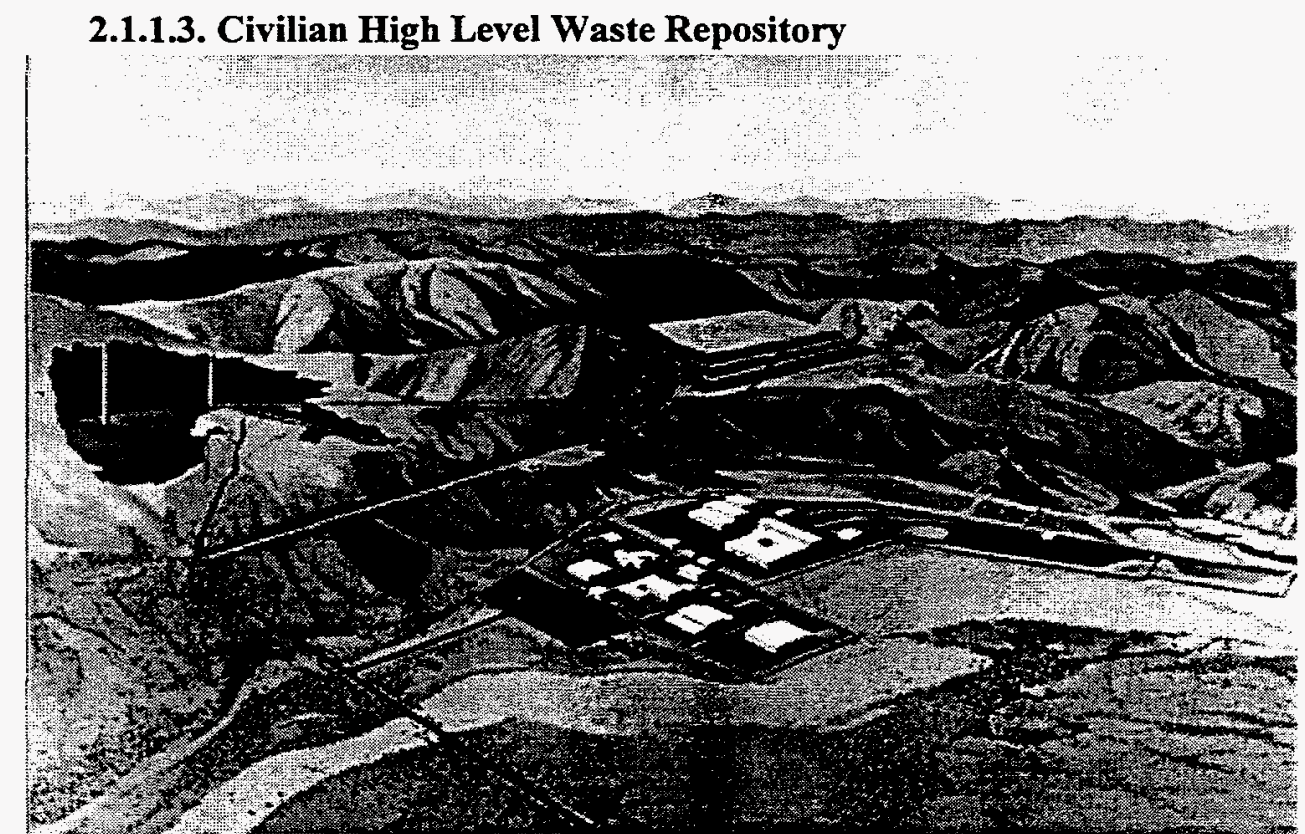

Figure 2-3. Artist's rendition of a mined geologic repository at Yucca Mountain, Nevada

DOE plans to send high-level waste, whether civilian or military spent nuclear fuel, to a proposed Federal repository after the Year 2000. Yucca Mountain, located 100 miles northwest of Las Vegas, Nevada, is being characterized to determine its suitability for a deep geologic repository for the permanent disposal of high-level waste (see Figure 2-3 for an Artist's rendition of such a repository). This work is being performed under the Yucca Mountain Site Characterization Project (YMP) ${ }^{5}$.

Major site characterization activities include (1) fault characterization including historical data, (2) volcanism studies at Crater Flat, (3) field monitoring of water resources in the Yucca Mountain area which includes monitoring 34 wells and 5 springs, (4) the extensive drilling programs, and (5) construction of the Exploratory Studies Facility (ESF).

The ESF is an underground laboratory designed to facilitate examination, at depth, of the geologic, hydrologic, geo-engineering and geothermal characteristics of the potential repository host rock. The ESF will consist of two mined ramps, both excavated down to various levels, 14 miles of tunnels and 70 acres of surface facilities. Potential robotic applications are presently being evaluated for the activities to be carried out in the ESF.

\subsubsection{Decontamination \& Decommissioning (D\&D)}


When an industrial enterprise and its resources are transitioned from an operating mission to an end-state, the process has become known as "D\&D." The process may actually involve five "Ds": Deactivation, Decontamination, Disassembly, Disposition, Decommissioning. Deactivation stabilizes a nuclear facility, placing it in "SAFESTOR" condition. Decontamination is the reduction of radioactive and chemical contaminants to levels defined as "safe" for the chosen end-state of the facility or materials. The disassembly phase removes equipment and building components to the degree deemed necessary. The end-state of all components, facilities, sites and workers associated with a given facility is known as disposition, and decommissioning is the final statement that all liabilities have been removed and the facility and its resources no longer exist.

\section{Commercial Nuclear Power Plants}

One-hundred nine commercial power plants are currently operating in the United States, most of which will undergo D\&D within the next 30-40 years. The current cost estimate (in 1992 USD) for one utility with three units beginning $D \& D$ in 2026 is $\$ 440-460$ Million per unit: a substantial $\$ 1.4$ Billion for the utility. A projected cost increase of $55 \%$ over the last five years has driven some nuclear utilities to consider premature shutdown.

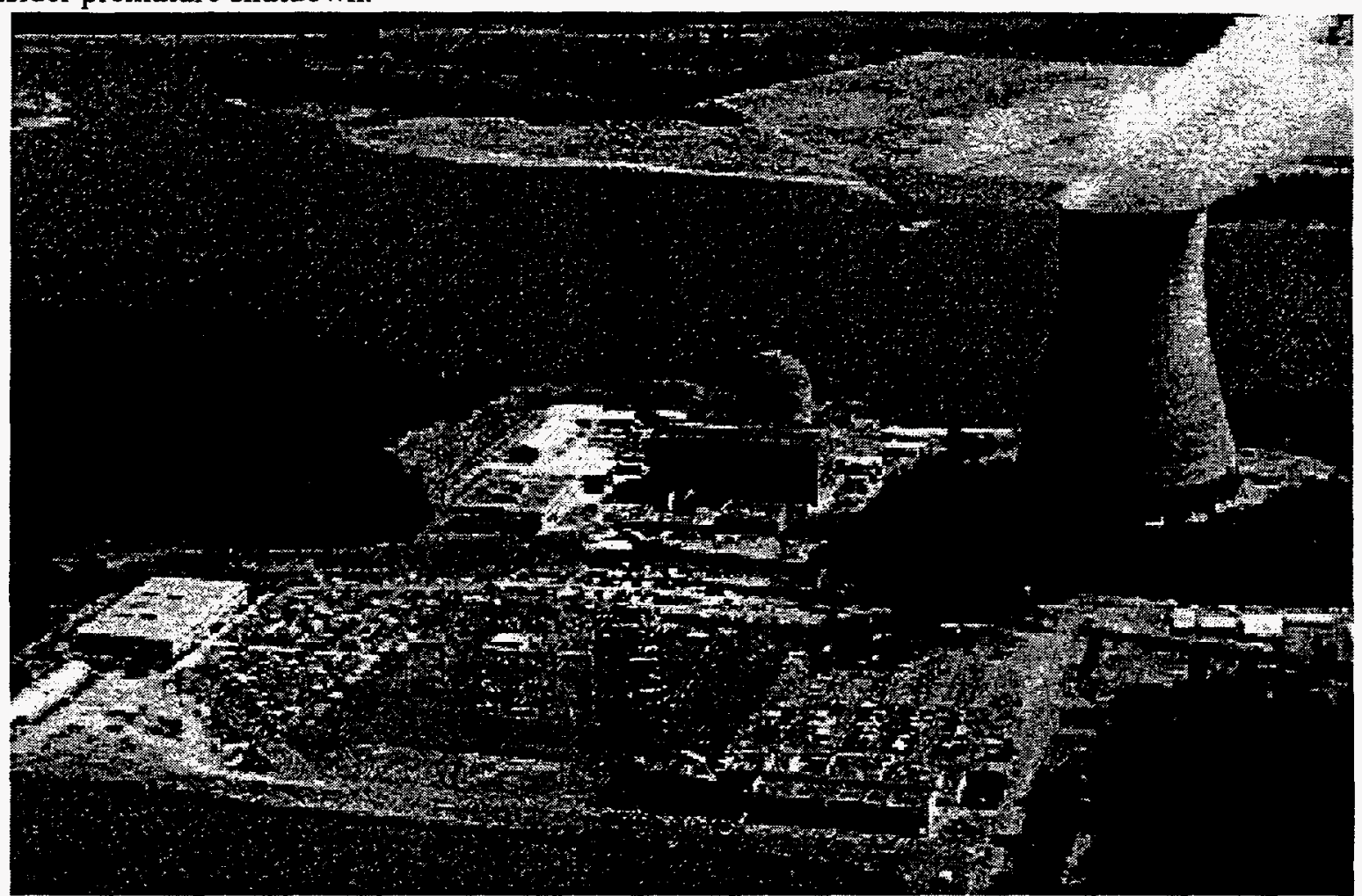

Figure 2-4. The Trojan nuclear power plant is preparing for D\&D operations

Portland General Electric chose to shut-down the Trojan power plant in 1992, less than half-way through its design lifetime, and to begin D\&D operations for economic and political reasons. (Photo) The Trojan plant began D\&D preparatory activities in 1993. Examples of areas where robots would be useful are near the reactor pressure vessel, steam generators, piping, and RTD bypass lines. Removal of the RTD lines at Trojan in 1994-95 resulted in a dose of approximately 4 Rem, a dose that theoretically could have been eliminated by using robotic equipment. Current industrial practice is to spend an average of approximately $\$ 10,000$ to eliminate each person-rem of radiation exposure in plant operations. Thus, elimination of the 4 Rem from the single Trojan RDT line operation would have been worth $\$ 40,000$. 
Spent fuel handling and interim storage on-site will be carried out to allow D\&D of the spent fuel storage areas, and may benefit from robotic operations similar to those described for the MPC. With major D\&D operations expected from 1998 through 2001, many more opportunities may exist to reduce radiation doses and costs using robotic systems.

DOE defense facilities

Rocky Flats

Until 1989, the DOE' s Rocky Flats plant processed material containing plutonium and fabricated plutonium metal into components for nuclear weapons. About 12.8 metric tons of plutonium are stored at the plant in metallic, oxide, liquid and residue forms. Plutonium is both radioactive and highly toxic. It emits primarily alpha radiation, which may be easily shielded. However, airborne plutonium contamination can be a serious hazard if particles are lodged in living tissue, and may seriously damage materials of machines working in contaminated environments. Further, decay products, such as americium-241, can reach significant proportions and emit gamma radiation, a more penetrating and more difficult radiation to shield. Plutonium also reacts with oxygen, hydrogen and water vapor, forming fines and hydrides that are pyrophoric, having the potential to spontaneously ignite. Under these hazards, multiple facilities will undergo D\&D, with much of the plutonium material requiring retrieval, packaging or repackaging, and storage. For many of these operations, robotic and telerobotic devices could be safer and more economical than hands-on techniques.

\section{Hanford Site}

Since 1944, processing of spent nuclear fuel for recovery of plutonium and uranium at the USDOE Hanford Site has produced high-level radioactive waste 6 . Approximately $140,000 \mathrm{~m}^{3}$ of waste material now lies in 149 underground single-shell storage tanks (SSTs), which range in capacity from $208 \mathrm{~m}^{3}$ to $3785 \mathrm{~m}^{3}$. The SSTs have exceeded their 20-year design life, with 67 tanks known to leak or suspected of leaking into the environment. The primary radioactive waste components are cesium and strontium, with some quantities of uranium, plutonium and americium. ${ }^{7}$ Materials are in liquid, crystalline and sludge form, as illustrated in Figure 2-5. Radiation levels in one tank are approximately 450 $\mathrm{Rad}[\mathrm{Si}] /$ hour, with a water-cooled temperature of $142^{\circ} \mathrm{F}$. Other tanks have temperatures ranging up to $240^{\circ} \mathrm{F}$.

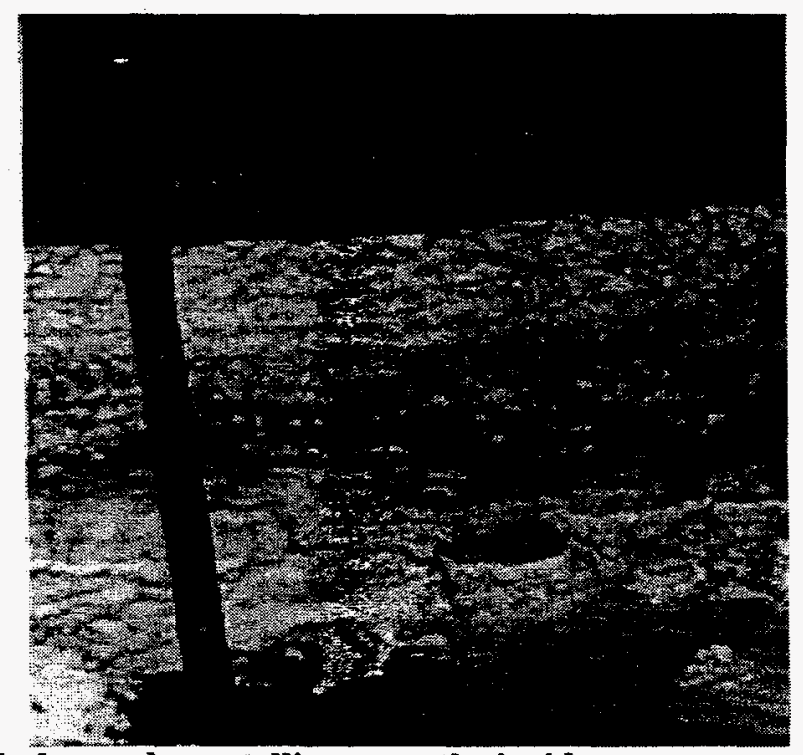

Figure 2-5 Sludge and crystalline growths inside a storage tank at Hanford 


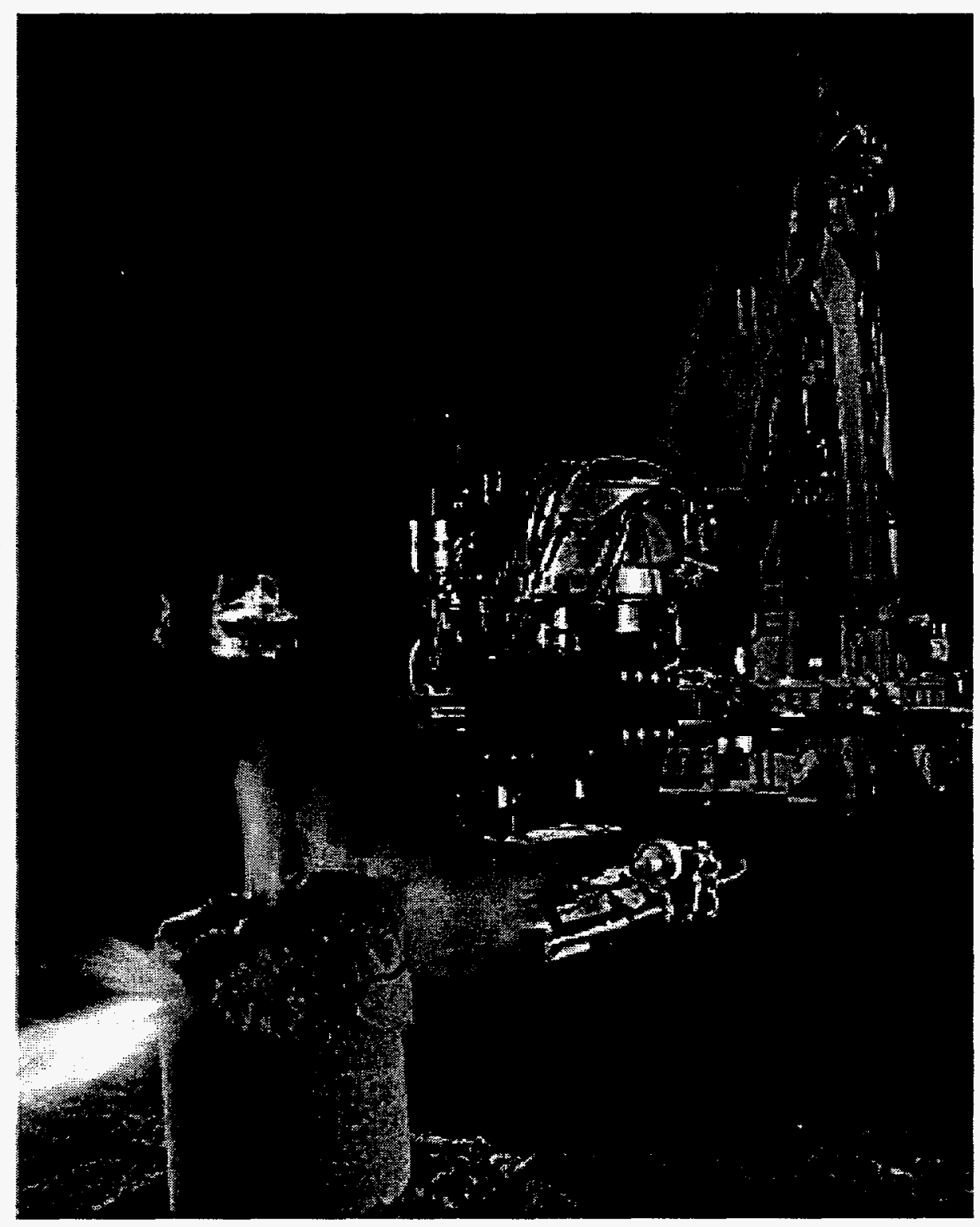

Figure 2-6 Multiple Robots and Tools Operated as a System in the Underground Storage Tank Integrated Demonstration at Hanford. 
Robotic and telerobotic systems are being developed to remove waste from the tank. During demonstrations in 1991, 1992, and 1994, feasibility of sensor-based control, graphical programming, and supervisory control of prototypic robotic systems was demonstrated for waste characterization and removal (see Figure 2-6). The alternative to robotic systems is either human entry into the waste environment or the use of conventional remote manually operated mechanisms. The presence (frequently in poorly characterized quantities and conditions) of radioactive materials, explosives, toxins, and other hazardous materials precludes human entry into the waste tanks. In many cases, existing remotely operated devices, such as, teleoperated manipulators could be adapted for ER\&WM applications. However, these technologies are frequently slow (dramatically decreased productivity results) and fatiguing to the human operator (resulting in decreased operational safety and/or frequent operator changes). Advanced sensor-based, model-directed robotic technologies provide faster, safer, and cheaper remediation operations.

\section{Enrichment Facilities}

Three major gaseous diffusion facilities have been operated in the United States to enrich uranium for nuclear fuel. The first, of these, the K-25 facility at Oak Ridge, TN, has been shut-down and awaits D\&D tentatively scheduled for 2003. (K25 David Neiswander 615-241-3639 576-8082(proj ofc), V. Pasupathi 615-220-4019) The two operational plants are in Paducah, KY and Portsmouth, $\mathrm{OH}$, and are operated by the United States Enrichment Corp. (USEC), a government corporation. The USEC produces and markets uranium enrichment services to more than 60 utilities that own and operate commercial nuclear power plants in the United States and 11 other countries. Gaseous diffusion plants include enrichment equipment covering many square kilometers. Cascades of more than 1000 large diffusers, pumps and associated piping are required to efficiently produce enrichments of approximately $4 \% \mathrm{U}-235 .{ }^{8}$ (See Figure 2-7) These facilities have produced enrichments of over $90 \%$, with many thousands of cascade units. Early planning for the D\&D of the remaining gaseous diffusion plants projected $D \& D$ to begin sometime between 2010 and 2020 .

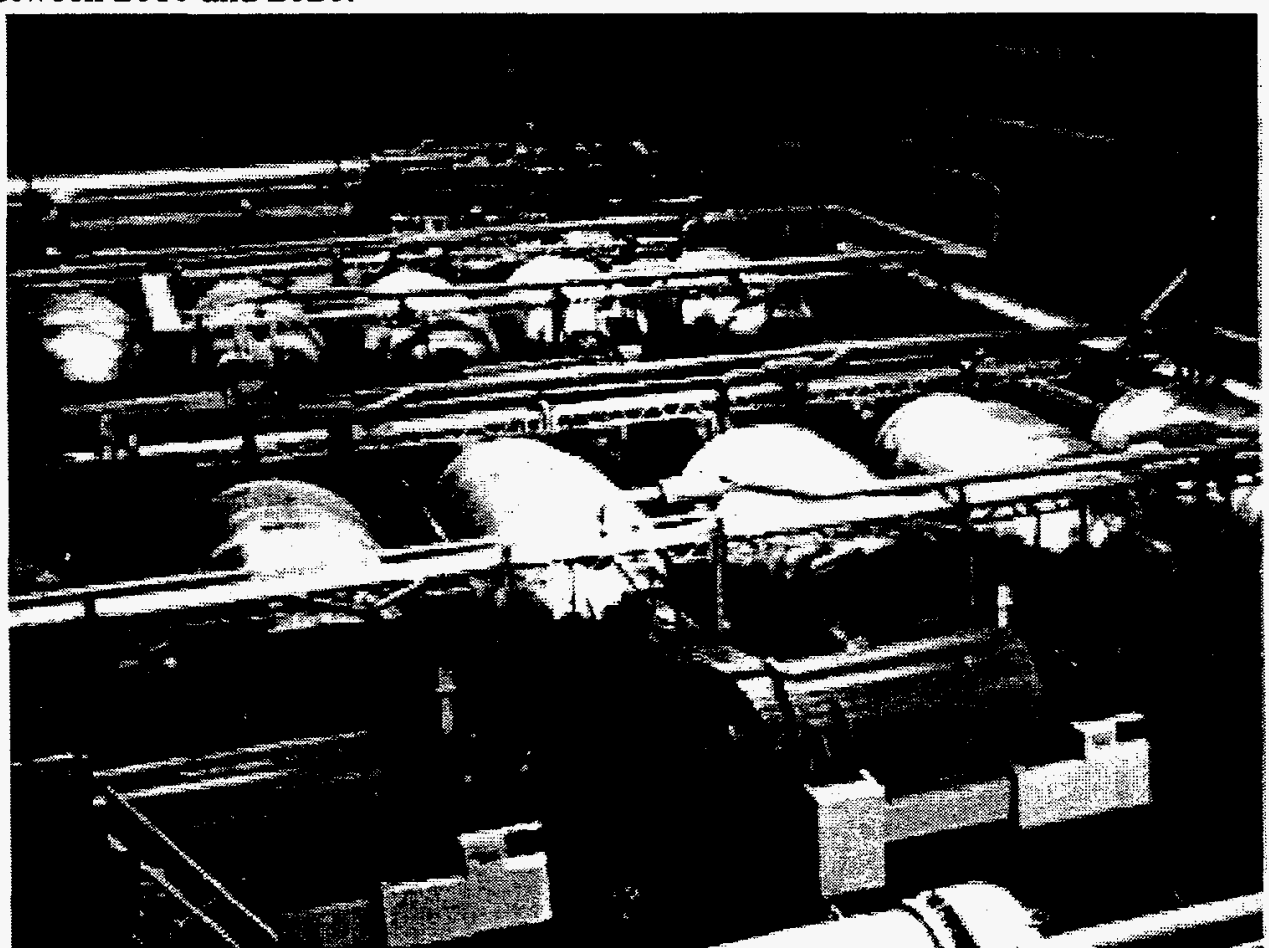

Figure 2-7. Thousands of diffusers and pumps will require removal at gaseous diffusion uranium enrichment plants. 
D\&D operations will be carried out in the presence of both radioactive and non-radioactive hazards. Substantial PCB-containing materials and electrical equipment, such as ventilation gaskets and transformers must be removed, as well as significant volumes of asbestos materials. Removal of the cascade units will involve protection against airborne uranium contamination, surface decontamination and removal of highly-enriched uranium deposits from equipment. Accountability and safety are issues in deposit removal. While the majority of the radioactive hazard may come from uranium, some equipment is contaminated with fission products, resulting from processing contaminated fuel. This results in a raised gamma radiation level and complicates the D\&D process.

\subsubsection{Radiation Emergencies and/or Accidents}

In March of 1986, Chernobyl reactor unit 4, near the now Ukrainian city of Kiev, experienced a power surge causing a major steam explosion, destroying the reactor and sending massive radioactive contamination into the environment. By November 1986, a concrete Sarcophagus had been completed, surrounding the destroyed reactor facility as a biological shield ${ }^{9}$. It is estimated that $180 / 190.2$ tonnes of uranium dioxide fuel remain within the Sarcophagus in various forms. Large amounts of fuel assemblies, fragments of individual fuel rods, and graphite moderator thrown to distances of 150 meters. Molten fuel passed through sand barriers and self-vitrified in chambers under Unit 4, some of which is shown in Figure 2-8. Thousands of tonnes of sand, dolomite, clay, lead and boron-containing materials were dumped on the ensuing fire and now lie in the Central Hall making surveys difficult.

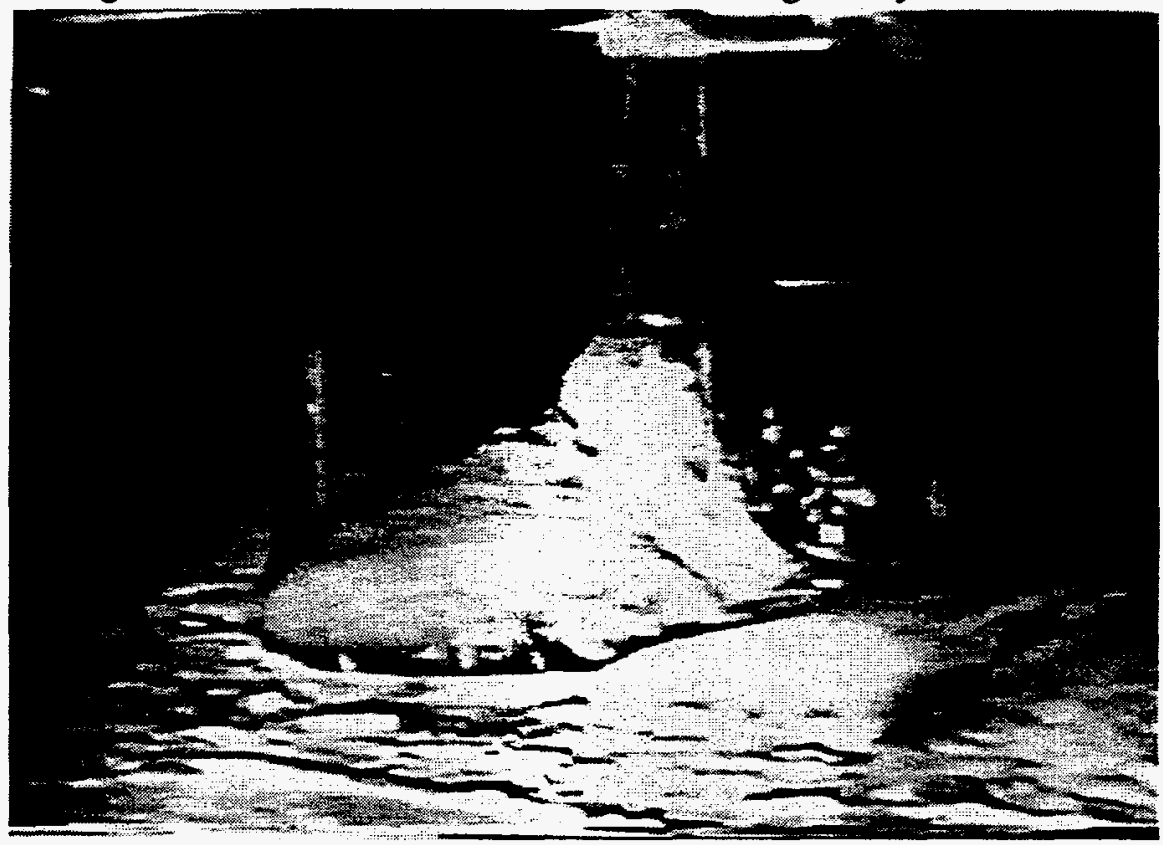

Figure 2-8. Molten fuel passed through sand barriers and self-vitrified in chambers under Chernobyl Unit 4, forming this highly-radioactive "elephant's foot."

Initially it was necessary to account for all the fuel, and to characterize condition of the fuel and the facility. Manned reconnaissance found areas within the sarcophagus measuring several thousand $\mathrm{R} / \mathrm{hr}$, preventing further manned entry. Several goals were established for continued characterization and recovery initialization. These included clearing debris and decontamination of strategic areas to allow manned entry, installation of drilling machinery to drill access holes into the reactor region for instrumentation, and to install inspection equipment for data collection on location and condition of fuel.

Sophisticated robotic machinery was tried initially. Electronic equipment failed, video equipment burned out, robot machinery stuck in debris, and one robot careened out of control until eventually burning out in 
a high radiation area. Simple toy tanks fitted with flashlights, dosimeters and thermometers assisted in mapping, collecting information for implementation of the next generation of robots.

A family of robots has been designed for use at Chernobyl with interchangeable parts and common vehicle platform. Dust suppression, bore hole sampling, grasping, air sampling, sawing, loading crane, and scoop samples are some of the demonstrated functions. These robots are currently in use, but difficulties remain with operational mistakes, breakdowns and decontamination. A second generation is currently under design, improving upon original designs. Prototype designs are expected by the end of 1995. Future goals include removing the fuel for safe storage from within a second Sarcophagus (hermetically sealed), construction of which is planned in the near future. This activity must clearly be done by remote means, offering opportunities for robotics applications at Chernobyl for perhaps several decades.

Another example of power plant emergencies is Three Mile Island Unit 210. In 1978, Three Mile Island Unit 2 suffered a loss of coolant accident, resulting in substantial contamination of reactor facilities. Remote and robotic equipment was utilized in some operations and considered for others. Operations in which robotic equipment was used included radiation surveys and smear samples, high-pressure water flushing for contamination reduction, concrete scarification using ultra-high-pressure water spray, and concrete scabbling. This latter operation, in conjunction with a grout cover, reduced rad levels from 20$100 \mathrm{R} / \mathrm{h}$ to $1 \mathrm{R} / \mathrm{h}$. The reactor core sustained substantial damage, reducing parts of the core to rubble and preventing standard removal of the fuel. A robotic mining and shredding device was considered for fuel removal. The device would have shredded the entire core, vacuumed it out of the pressure vessel, and transferred debris directly to the fuel handling building. Due to 3-year development effort and concerns about loss of spatial information on fission products and control materials, this option was not pursued.

These examples indicate a need for accident recovery capabilities, including robotic equipment capable of entering high-dose-rate areas, characterizing the area, and executing debris removal and decontamination tasks.

\subsubsection{Environmental Restoration and Waste Management}

The DOE has substantial environmental restoration and waste management responsibilities within its production complex. Examples of restoration challenges include plumes of contamination slowly advancing through geologic strata and ground water under and near facilities, substantial landfills where insufficient barriers may allow buried wastes to contaminate the environment, and large volumes of waste stored in tanks, some of which are leaking. DOE faces a contaminant plume clean-up problem of $>600$ billion gallons of contaminated ground water and $>200$ million cubic yards of contaminated soil. Most of the plumes contain both radioactive and hazardous contaminants. Handling of concentrated wastes removed from the plumes will require remote methods. Within the DOE complex there are 3 million cubic meters of radioactive and hazardous buried waste, and 30 million cubic meters of contaminated soils from these buried wastes. Waste has been buried in trenches with little or no engineered barrier, as shown in Figure 2-9. Environmentally effective, safe and cost efficient technologies for remediating and managing these sites is needed, including the removal and handling of containers. Three-hundred thirtytwo (332) tanks at Hanford, Oak Ridge, Savannah River, Idaho and Fernald contain over 100 million gallons of radioactive and mixed waste (Figure 2-10). Many have exceeded their life span, and at least 67 single-shell tanks at Hanford are known or assumed to have leaked. Some of the tanks are also potentially explosive. Environments inside the tanks prohibit manned entry; for example, one Hanford tank exceeds $500 \mathrm{Rad}[\mathrm{Si}] /$ hour at the waste surface. Robotic manipulators are currently being designed to retrieve tank waste. 


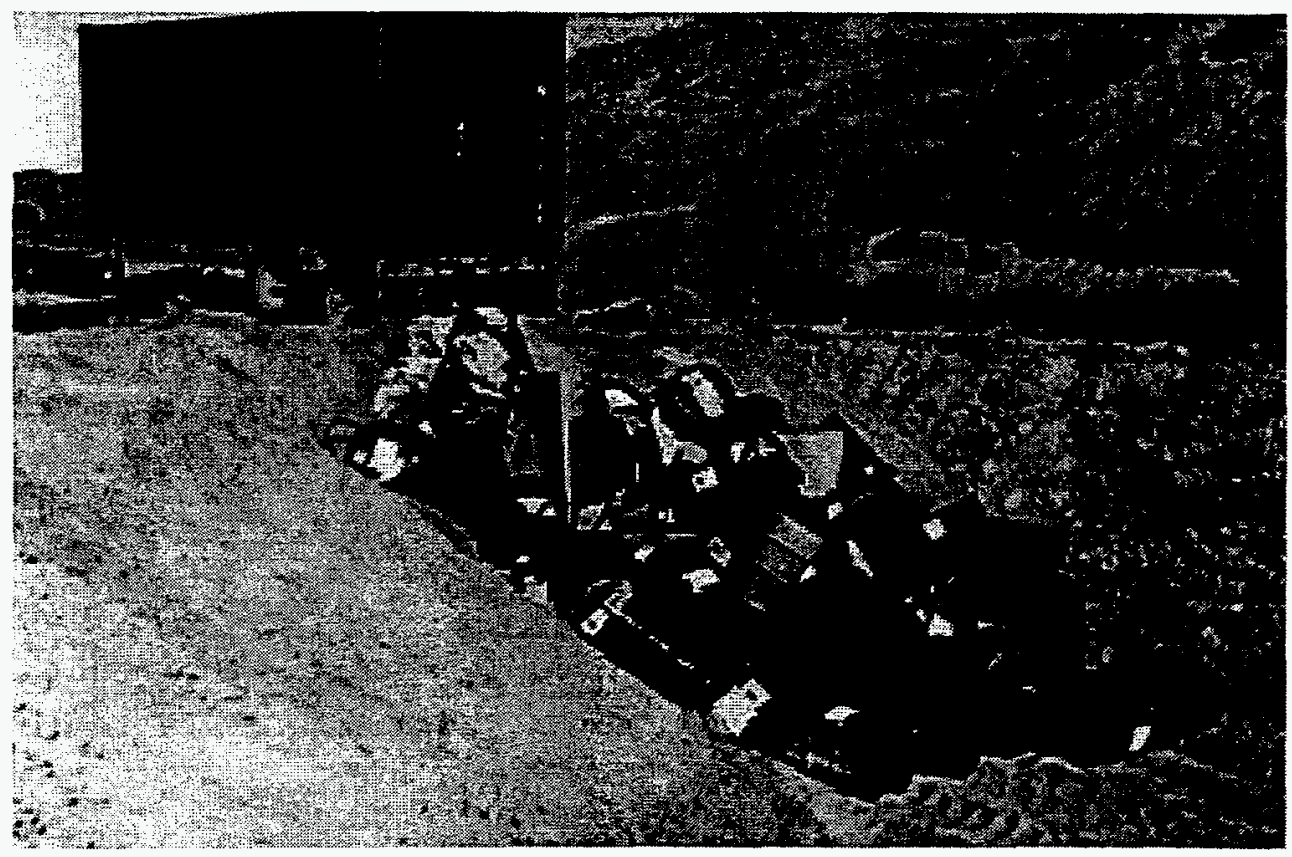

Figure 2-9 Buried Waste Pit.

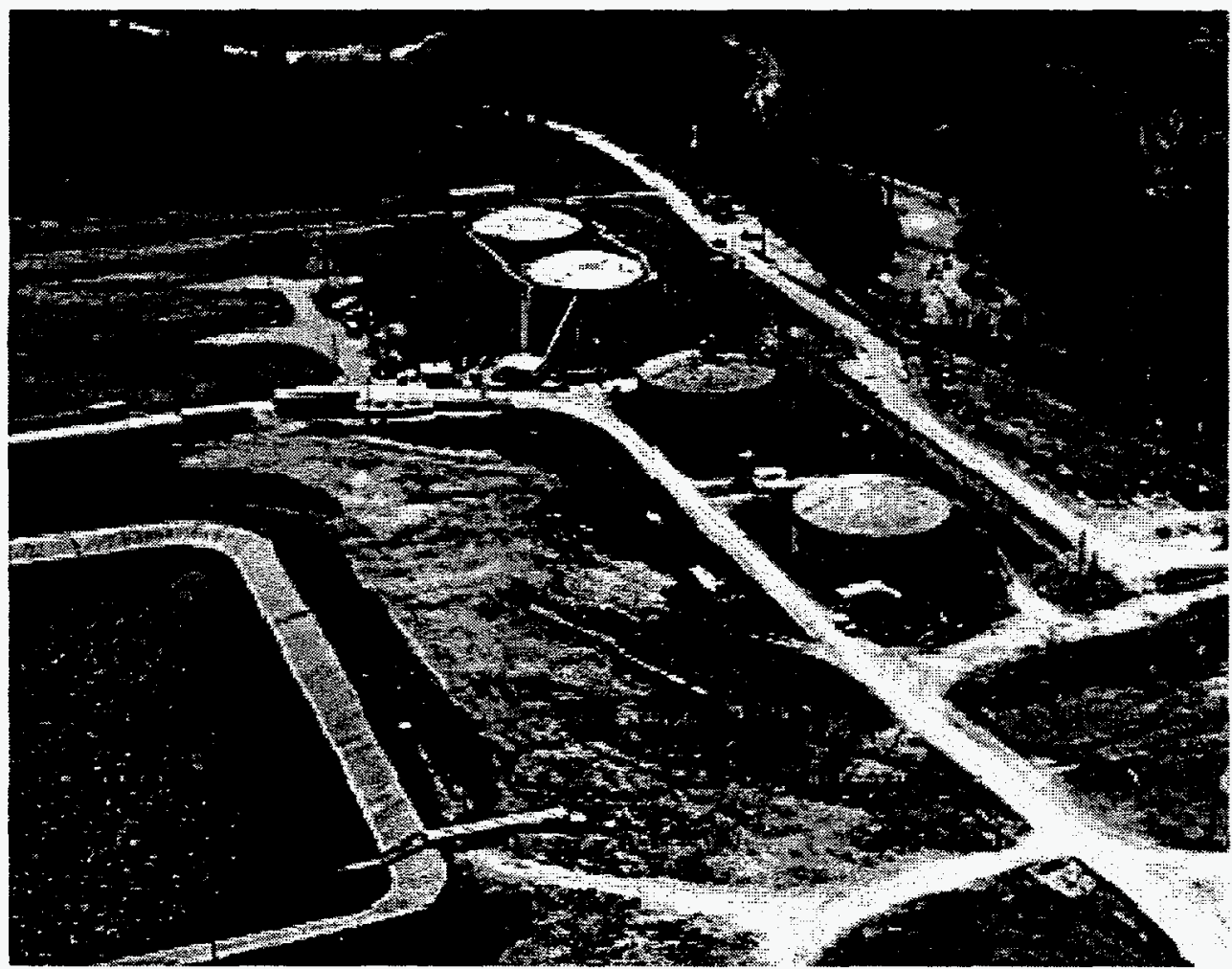

Figure 2-10 Waste Storage Tanks at Fernald 
Concerns about access, safety and cost efficiency have led DOE's Office of Technology Development to establish the Robotics Technology Development Program to coordinate development of appropriate technologies for these and D\&D activities. For example, in the tank remediation area, the Long Reach Manipulator for waste removal is under development (Figure 2-11), a Light-duty utility arm for tank characterization and operational support has also been supported. Examples of activity in the buried waste area include mobile robots for characterized buried waste; a remote excavation system for hot spot excavation, and remote size reduction capabilities exploring robotic fielding of various cutting tools in hazardous environments.

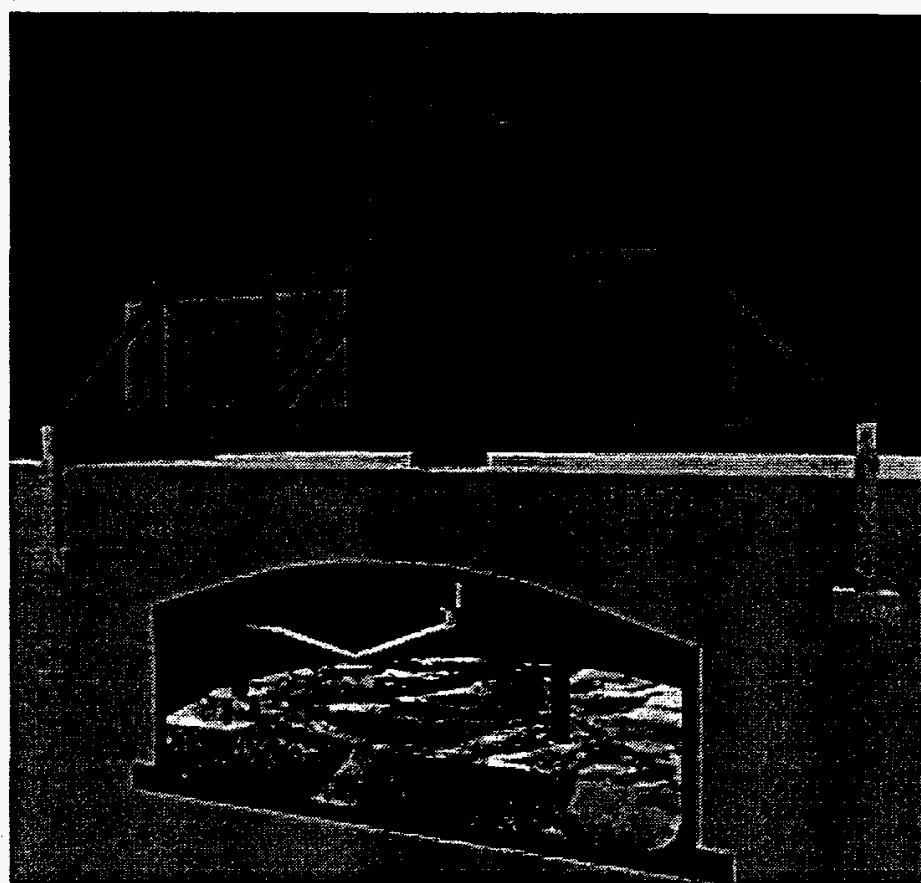

Figure 2-11. Simulation of an underground storage tank with a long-reach manipulator inserted.

\subsubsection{Space Systems}

Although hazardous tasks in space are still, for the most part, performed manually due to inadequate dexterity and sensing abilities of present-day robotic systems, the time will come when they will be used routinely. The Ranger space robotic system (see Figure 2-12) is being developed to perform space-walk type tasks with potential applications such as space station support. In this event, radiation hardness of these robotic systems will become more important. Although the radiation requirements of manned missions will continue to be minimal, in-orbit unmanned missions could result in more severe radiation environments depending upon the orbit. In orbits that pass through the electron and proton belts, doses approaching a Mrad[Si]/yr. are possible depending upon the degree of shielding around the sensitive electronics and sensors. Should the electron belts be pumped up, the yearly dose. This could be significantly higher. It is likely, that whenever possible, orbits will be selected to minimize the yearly dose as has been the case for manned orbital missions where the shuttle robot arm (see Figure 2-13) and has proven to be very valuable. However, such minimized levels are still likely to stress commercial parts, at least in some instances. Since the ionizing particles are electrons and protons, displacement damage effects should be insignificant at dose levels that are acceptable. Even for those orbital missions where the dose can be minimized, the presence of cosmic rays can present a radiation effects problem (i.e., SEE) similar to that encountered in the case of interplanetary missions. However, standard space certification procedures should account for this eventuality. 


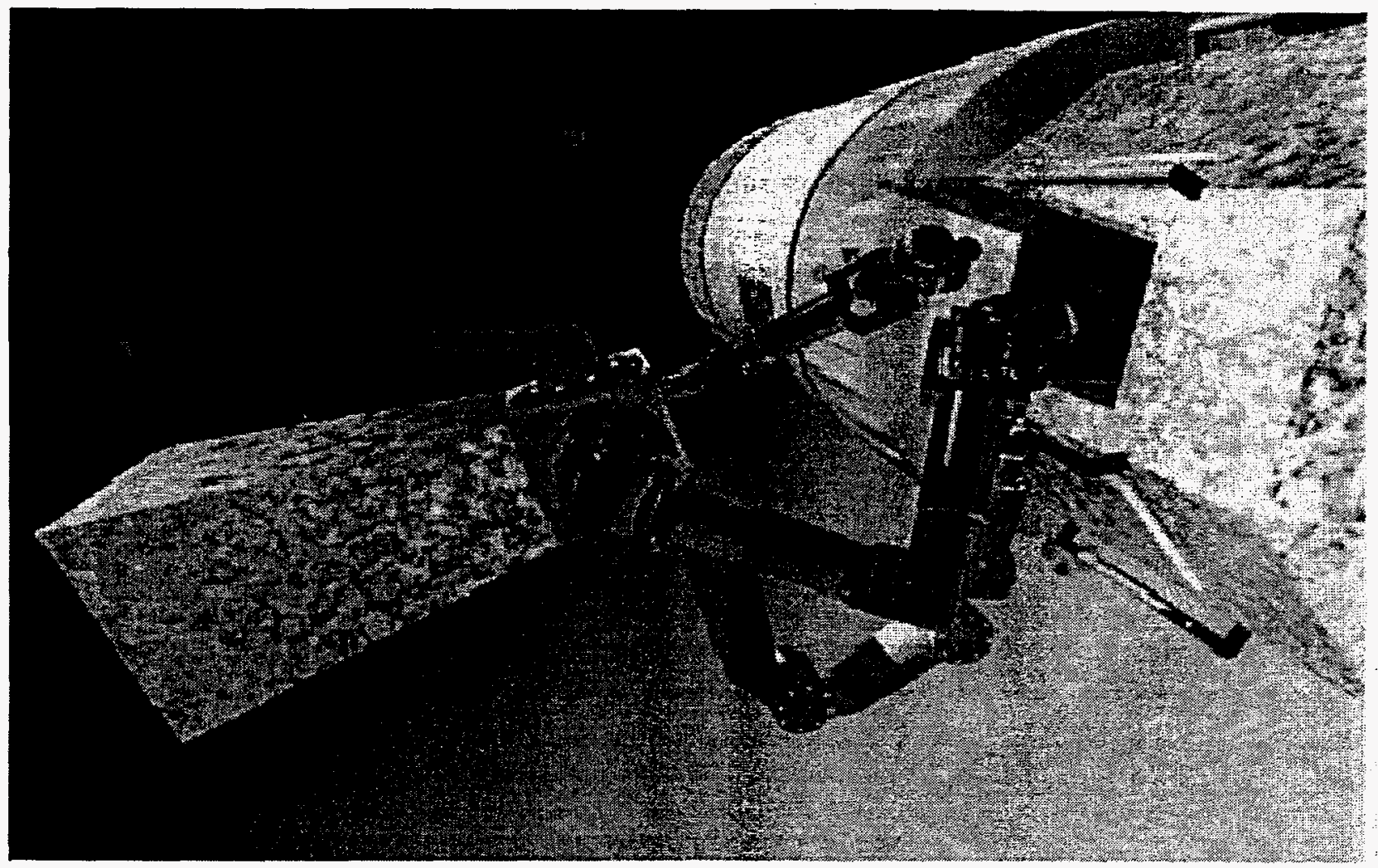

Figure 2-12 Ranger Robot Designed for Space Walk Type Tasks.

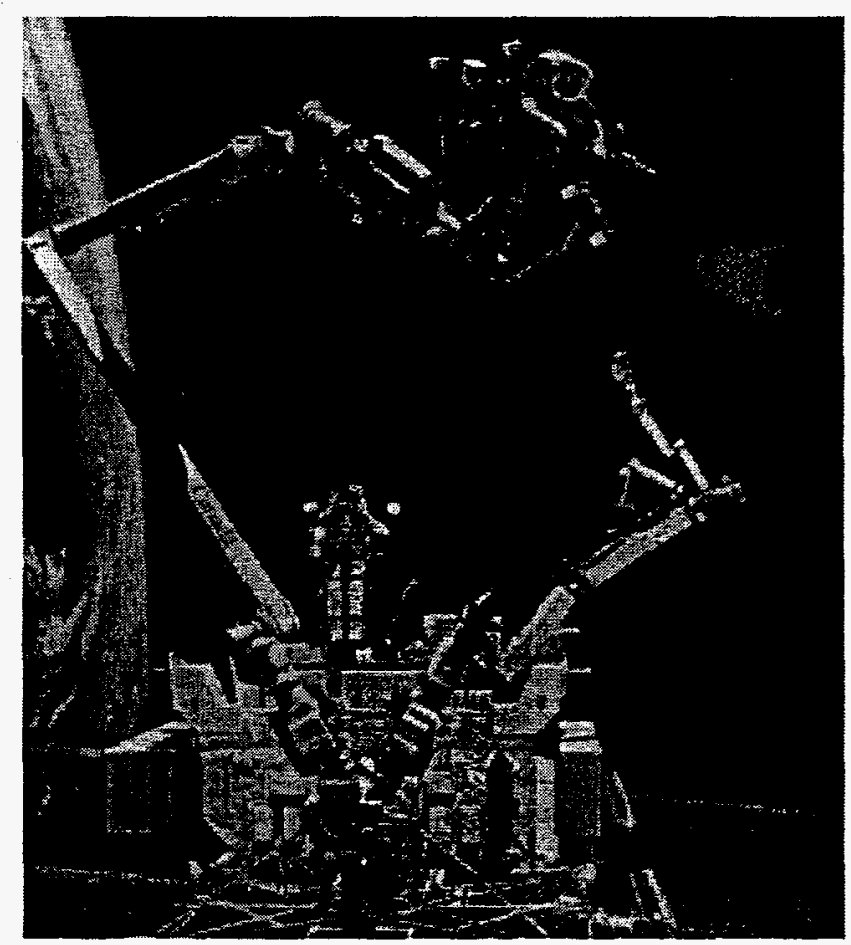

Figure 2-13 Space Shuttle Robot Arm. 


\subsubsection{Fusion Power Systems}

After successful demonstration of remote maintenance on the Tokamak Fusion Test Reactor (TFTR) and the Joint European Torus (JET), the use of robotic systems for remote maintenance (RM) is being planned for the next generation of fusion machines. RM robotic systems have been proposed for the Tokamak Physics Experiment (TPX) ${ }^{11}$ and the International Thermonuclear Experimental Reactor (ITER) $^{12}$. The radiation fields estimated for these $\mathrm{RM}$ activities range from hundreds of $\mathrm{R} / \mathrm{hr}$ to millions of $\mathrm{R} / \mathrm{hr}$ although the latter is based upon fairly optimistic operating conditions for ITER. However, even the former can be stressing for commercial electronic piece parts that are used as a part of an in-vessel robotic assembly. Although not under serious consideration at the present time, a concept has been proposed for a robotic assembly that resides within the blanket region just outside the first wall during plasma-burn operations. In such a case, neutron fluence requirements would be placed on the system also, with the attendant concern about displacement damage and SEE, at least for high-power long-burntime machines.

\subsubsection{Waste Isolation Pilot Plant (WIPP)}

DOE is proposing that the Waste Isolation Pilot Plant (WIPP) be the final disposal site for transuranic waste after a successful demonstration period. The objective is to demonstrate the safe and permanent disposal of transuranic waste in a salt formation more than 2000 feet underground.

At the end of 1990 the inventory of TRU waste was 60,600 cubic meters, 91 percent of which can be contact handled (CH TRU) while the remaining 3 percent must be remotely handled (RH TRU). ${ }^{13}$ It is estimated that another 48,500 cubic meters of $\mathrm{CH}$ TRU will be generated through the year 2013. This latter estimate does not take into account the changing requirements for nuclear weapons or the effect of the weapon dismantlement program.

This transuranic waste, shipped from generating sites to WIPP, must be in a form acceptable for disposal. The RH TRU waste will be contained in canisters, with contact dose rates of from $200 \mathrm{mrem} / \mathrm{hr}$ to 1000 $\mathrm{km} / \mathrm{hr}$. DHLW canisters may range up to $15000 \mathrm{rem} / \mathrm{hr}$. At WIPP the TRU containers (see Figure 2-14) that can be handled directly will be stacked in underground rooms. Containers that must be handled remotely, because of radiation levels, will be inserted into holes bored in the salt walls. A specially designed machine, which emplaces the containers and plugs the hole, can also retrieve this remotehandled waste if required (see Figure 2-15).

Potential "in-cell" robotic applications include such items as swiping, welding of overpacks (off-normal), grappling, shield plug removal, etc., and "out-of-cell" they include adapter installation using bolting procedures impact limiter and dust seal removal, etc. 


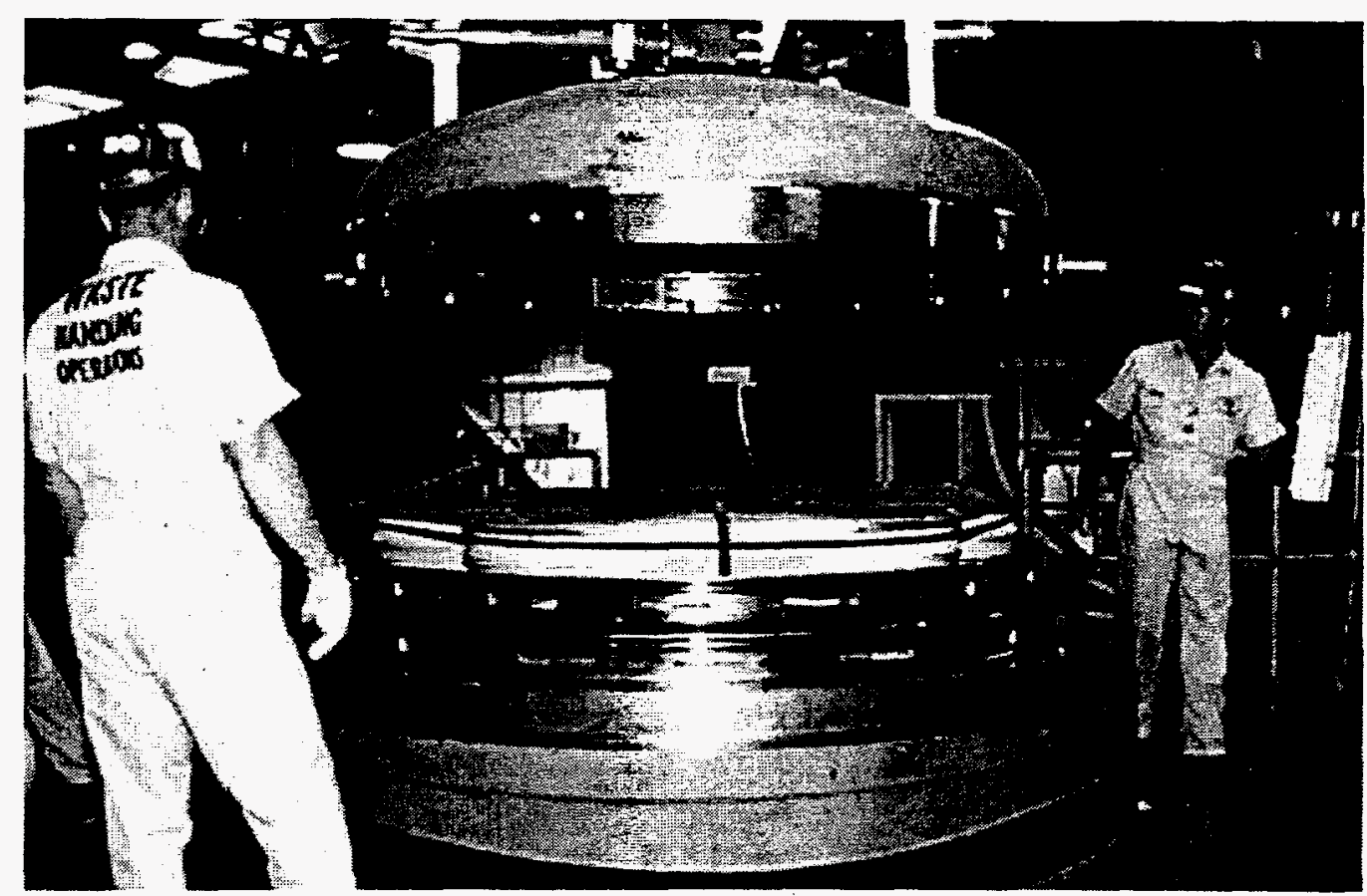

Figure 2-14 Drums of waste are unloaded from a TRUPACT-II transportation cask at the Waste Isolation Pilot Plant for disposal (WTPP).

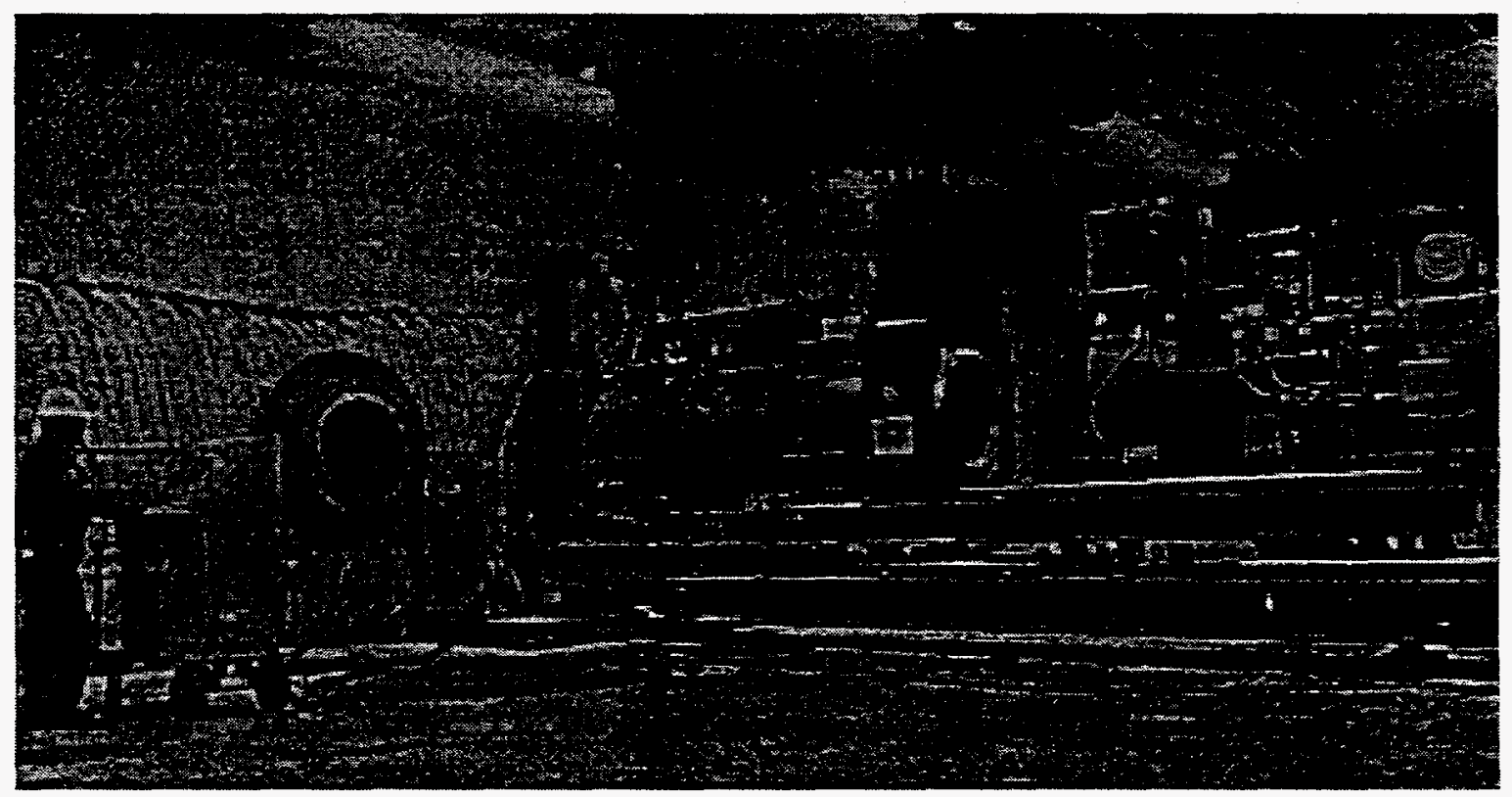

Figure 2-15 Specially designed machine for remote emplacement of containers at WIPP. 


\subsubsection{Fission Power Plants}

The uses of robotic systems at nuclear power plants can include surveillance, visual inspection, ultrasonic examination, and maintenance missions. Extensive remote inspection of steam generator tubing and reactor pressure vessels is currently being performed 14 . They have been used to monitor radiation levels, temperature, humidity and sound level and to take smear samples. There are even cases where robots, the pipe-crawling type, can perform welding tasks. Economic analysis projects that the use of robots in many nuclear plant operations can reduce the associated costs by as much as $50 \%$.

In the USA, Commonwealth Edison has established a robotic unit based at the Byron Station to provide remote inspection and repair services at all Commonwealth Edison nuclear plants. Also, Public Service Electric \& Gas Company's robotics program, which started in 1986 demonstrated a cost-benefit ratio of 1:3 (i.e., \$1.6M spent and \$5.3M saved) during the first five years of using this technology at its Salem-1 and-2 and Hope Creek power units.

One example of the pipe-crawler type of robot is URSULA which was developed by B\&W Nuclear Services and has eliminated the need for divers. URSULA utilizes graphical programming concepts, allowing for review and approval of the robotic operation prior to execution.

A study conducted by the Utility/Manufacturer Robot Users Group (UMRUG) of forty-four nuclear utilities reported 193 robotic applications occurring from 1982 through 1990 and the applications have continued to increase over the last five years.

\subsubsection{Fuel Reprocessing Plants}

Reprocessing is a means of recovering the relatively high percent of fissile uranium and plutonium from reactor-discharged fuels. It can also be used to separate long-lived isotopes from bulk waste, reducing disposal requirements and accompanying costs. One ton of spent light water reactor (LWR) fuel cooled 3 years contains approximately $790,000 \mathrm{Ci}$ of fission products ${ }^{15}$, resulting in substantial potential for radiation exposure. The UK, France, Russia and India have operating fuel reprocessing plants. In the United States, no reprocessing has occurred since 1992.

Several plants were built to reprocess fuel in the US. Civilian facilities were built at West Valley, New York, and Barnwell, South Carolina. West Valley began operation in 1966 and processed 600 tons of fuel prior to 1972, when it was closed for upgrades, and subsequently never re-opened. Spent fuel at West Valley has been in place since 1973, and is being prepared for shipment to another site for storage. In the preparation of the transport casks for shipment, a dose of 150 mrem is expected. With a facility administrative limit of 500 person mrem/year, each crew will be able to prepare only 3 casks. The plant at Barnwell was built by Allied General Nuclear Services, undergoing cold processing with natural uranium. Start-up was scheduled in 1976, but changing regulations and intervenor complaints prevented the plant from going in to operation. The plant remains intact today (except for easily-sold items) with only slight contamination.

The Savannah River Site and Idaho Chemical Plant reprocessed nuclear material for the US Government. Each of these facilities has undergone or will undergo D\&D. Savannah River used the PUREX process to separate plutonium in two 800 -foot-long concrete structures known as canyons. These canyons are currently dormant, holding the process fluids until recovery is desirable. Idaho Chemical Processing plant used a hybrid combination of PUREX, REDOX and denitration for plutonium separation. D\&D work is now being done to characterize waste tanks and to process waste in the tanks. This work is being 
done using telemanipulation in hotcells, where the radiation levels reach $500-1000 \mathrm{R} / \mathrm{hr}$ at $35^{\circ} \mathrm{C}$. Through-the-wall radiation is about $.125 \mathrm{mR} / \mathrm{hr}$, with human exposure about $100 \mathrm{mR} /$ year

In the United Kingdom, British Nuclear Fuels, Limited (BNFL) operates the Sellafield site, reprocessing spent nuclear fuels from around the world. Manipulators have been used to inspect and repair an active dissolver vessel, move obstructions including pipework, materials movement and packaging. Other remote devices include an infrared-controlled remote inspection vehicle, an underwater bottle opening machine, and an underwater inspection unit. Decommissioning has also been carried out with remote manipulators and robots, with a tendency toward more autonomy 16 . Fifty-eight electric and hydraulic remote manipulators and robots ${ }^{17}$ (Personal Communication, Mr. D. Webster, BNFL, Risley, UK, 8/95) are currently in use by BNFL, with the intent to install more in low-dose areas/operations. Robots performing such operations have been shown to be more efficient and less expensive than conducting these operations using other means. The most common radiation environments for robot installation have been approximately $1000 \mathrm{R} / \mathrm{hr}^{18}$, using lower-dose $\mathrm{D} \& \mathrm{D}$ operations as a proving ground.

Other countries operate substantial reprocessing facilities as well. Cogema operates the LaHague plant in France, reprocessing $1500 \mathrm{MTU} / \mathrm{yr}$. Up to May 1994, 15470 MTU have been processed at LaHague 19 . The plant uses remote, semi-automated manipulators to process 9 different types of transport casks, 200 casks/year in a single line. Radiation doses have been significantly reduced as a result of the implementation. Russia currently operates the RT-1 plant, reprocessing $400 \mathrm{MTU} / \mathrm{yr}$., and is building the RT-2 plant, which will reprocess 1500 MTU/yr. using the Purex process 20 . Large remote systems were designed to handle materials throughout the RT plants. 


\section{Robotic System Categories and Components}

\subsection{Categories of Robotic Systems}

Robotic systems range from the presently demonstrated types such as stationary manipulators (possibly of the master/slave type), through the teleoperated mobile types with or without manipulator arms, up to and including the more developmental semi-autonomous and autonomous types. The teleoperated systems can be tethered or, alternatively, communication can be accomplished via an rf-link. For the purposes of further discussion, robotic systems will be further subdivided in the following manner.

\subsubsection{Fixed/Tracked Robotic Systems with or without Manipulator Arms}

Applications of these type of robotic systems are the handling, examination, processing and testing of radioactive objects such as barrels containing waste, fuel rod bundles, fuel rod components, etc. Sites using such systems would be reactor facilities, temporary storage facilities such as the proposed MRS, fuel reprocessing facilities, permanent disposition facilities such as the proposed WIPP, etc. These robotic systems can take on many forms from those with remotely controlled specialized tools to the more versatile situation incorporating the use of manipulator arms. The robotic assemblies can be stationary or attached to platforms that are tracked to move in fixed paths. In the vast majority of cases, these robotic systems are of the tethered type and include teleoperation. Such systems do not generally require the use of sophisticated electronic hardware on the robotic assembly itself. The control electronics, which can be very sophisticated, can be located with the operator out of the radiation field. However, it is almost certain that some radiation-sensitive sensors will be located on the robotic assembly, or at least within the radiation field, such as $\mathrm{CCD}$ video cameras. Examples of sensors used to monitor the functional state of the robotic assembly are joint resolvers (e.g., for position and velocity) as well as torque sensing elements. In systems of this type sensors can also be used for such purposes as collision avoidance, temperature measurement, tactile "touch" force measurement, visual observation, etc.

It is possible, although not highly probable, that these type of robotic systems will not be tethered but rather communicate between robotic assembly and operator via a microwave link. An example of such is the ORNL developed wireless communication system for the West Valley Transfer Cart ${ }^{21}$. This system required that more sophisticated electronic hardware be on the cart. This electronics was designed to operate in radiation fields of $1 \mathrm{E} 4 \mathrm{R} / \mathrm{hr}$ while withstanding a total integrated exposure dose of $1 \mathrm{E} 7 \mathrm{R}$. This system did not use a microprocessor, whereas other applications might require such a device; in which case a lower operational TID limit would be realized.

\subsubsection{Mobile Tethered Robotic Systems with or without Manipulator Arms}

In many robotic applications the robotic assemblies must have greater freedom of movement than those discussed in the previous subsection. These applications could include fission power plant maintenance, radiation emergencies and/or accidents and some aspects of environmental restoration and waste management. In this case the sensor and electronic hardware requirements are very similar to those described in the preceding subsection. An example of type are the ANDROS series of robotic systems manufactured by REMOTEC 22 . The Mark V-A model has a manipulator arm with rotating gripper, CCTV, 2-way audio and can be further equipped with contamination smear fixture, VCR, double pincher end effectors and infrared camera. This is a relatively small and simple version of a mobile system. Many more complex systems have been constructed and operated and some are commercially available. 


\subsubsection{Mobile Semi-Autonomous or Autonomous Robotic Systems}

In general, the robotic systems requiring the most sophisticated electronics and most extensive array of sensors are the semi-autonomous and autonomous types. Although the former could be tethered, it is more likely that communication with the control point will be of a wireless nature. The applications for these types of systems are expected to be very similar to the tethered systems discussed in the previous subsection. However, their electronics will be more complex because they are expected to do more on their own. The potentially higher radiation fields encountered in the emergency or accident situations are sure to stress the electronics required to implement the design of these systems. This is where the tradeoff between commercial and hardened electronic hardware is sure to be an important factor.

One demonstration of a semi-autonomous system was the Robotics Testbed DEMO I held during April/May 1992 at the U.S.Army Aberdeen Proving Ground 23 . The mobile base unit (MBU) used in DEMO I was a six-wheeled skid-steer vehicle. Since this was a control system test the primary sensor on the MBU was a low light-level, color video camera. MBU heading was computed from differential travel of the left versus right wheels (as determined by shaft encoders placed on the axles of the left and right set of wheels). This was augmented with a flux-gate magnetic heading sensor. The onboard computer was a 486 ISA machine running at $33 \mathrm{MHz}$. This computer communicated with an identical computer at the operator control unit (OCU) via an rf data link. The data link consisted of two ARLAN 620 units operating at a frequency of $915 \mathrm{MHz}$. The resulting effective data rate was $300 \mathrm{Kbits}$ per second. This resulted in a video frame rate of $3 \mathrm{~Hz}$ at a picture resolution of $128(\mathrm{H}) \times 120(\mathrm{~V})$ or $512 \times 240$ but at a reduced frame rate of one picture every $3.5 \mathrm{sec}$.

Another example of this type of robotic system is the Remote TeleRobotic Vehicle for Intelligent Retrieval (RETRVIR), ${ }^{24}$ as shown in Figure 3-1, and consists of a Schilling Titan II manipulator arm mounted on a Honda Pilot off-road vehicle modified for remote driving. RETRVIR integrates modelbased, sensor-directed robotic manipulation with the remotely operated vehicle. The Generic Intelligent System Control (GISC) approach, developed by the U.S. Department of Energy's Office of Technology Development (OTD), is used by RETRVIR to provide model-based control of the manipulator and vehicle. Computer assisted operations allow shared operator/computer control to provide semiautomated operation at remote sites. Graphic displays allow the operator to preview all operations prior to execution to allow the operator to ensure safe operation. 


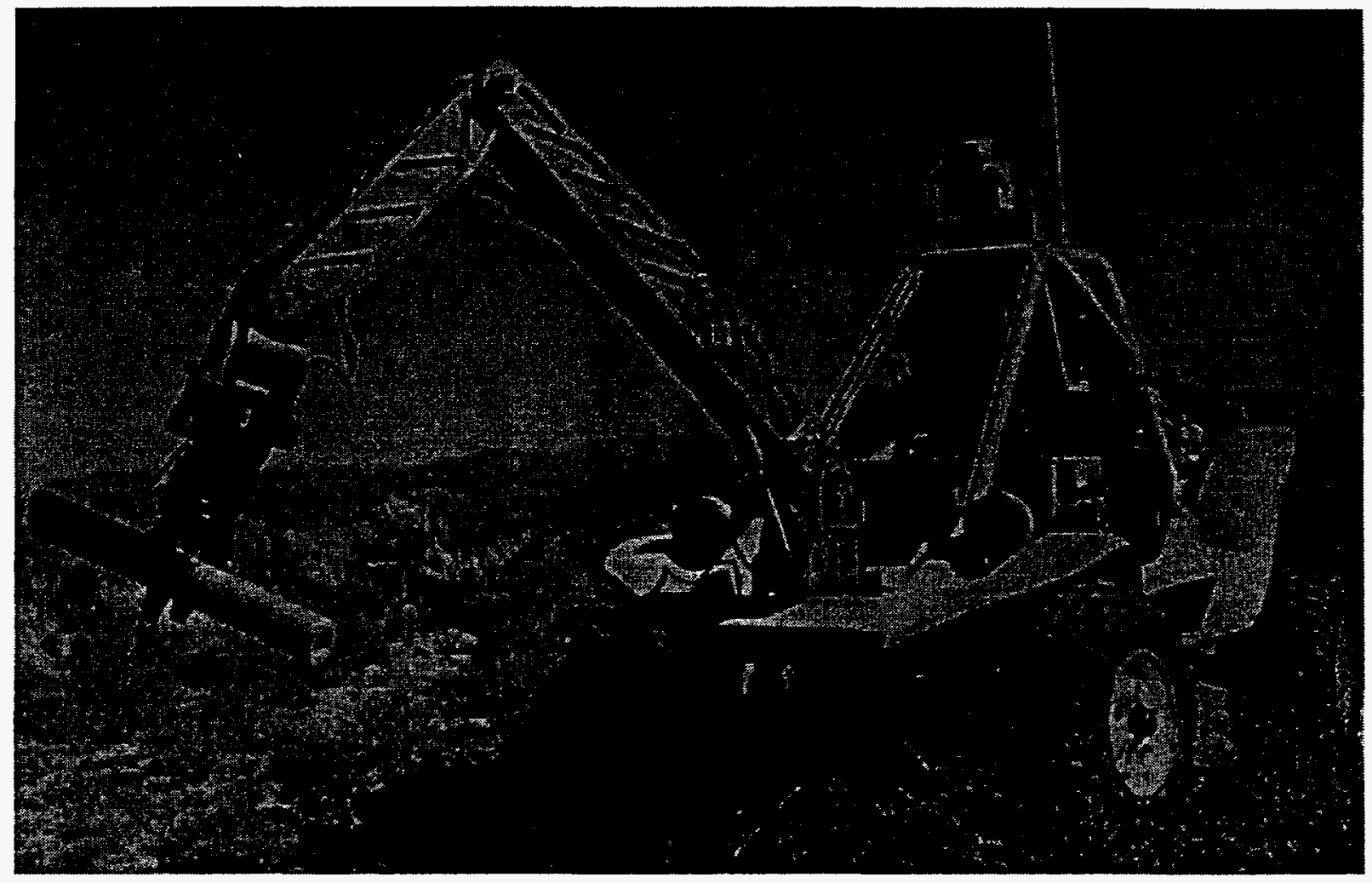

Figure 3-1. The RETVIR robot at Sandia National laboratories integrates on-board intelligence and sensors with commercially available robot and vehicle.. 


\subsection{Robotic System Components}

When considering the composition of robotic systems from a radiation tolerance viewpoint, it is useful to separately consider electronic piece parts (i.e., discrete devices, integrated circuits, hybrid microcircuits, etc.), sensors (most of which are electronic in nature), materials and other components. This breakdown allows for a more logical and tenable discussion of the radiation hardness of the constituents of these categories. These constituents will be detailed in the following paragraphs.

The type of electronic piece parts found in robotic systems varies widely. Stationary manipulator arms have relatively simple electronic parts (with the possible exception of tactile "touch" sensors) while autonomous robotic systems require a large parts inventory of varying degrees of sophistication. In general, the more sophisticated a part, the more sensitive it is to radiation; except for those parts that are specifically designed and fabricated to be radiation hard. These parts can be of various semiconductor technologies. The technology type determines the specific radiation effect to which a part is susceptible (e.g., total ionizing dose, neutron displacement damage or single event effects). Depending upon the specific application, non-hardened or hardened parts will have to be utilized. The latter are always more costly than the former. The following is a list of part types that may be found in robotic systems:

1. microprocessor, $\mu \mathrm{P}$

2. memory, RAM/ROM

3. analog-to-digital converter, $\mathrm{ADC}$

4. digital-to-analog converter, DAC

5. operational amplifier, op amp

6. pulse width modulator, PWM

7. multiplexer

8. CD4000 series in CMOS

9. $54 \mathrm{xxx}$ series

10. $74 \mathrm{xxx}$ series

11. 29xx Series in TTL or CMOS

12. voltage reference

13. transistor

14. diode

15. temperature compensated diode

16. capacitor

17. resistor

18. light emitting diode, LED

19. semiconductor laser

Sensors exhibit a wide range of hardness since some are primarily mechanical in nature while others possess significant electrical elements. The specific nature of the sensors used in a given robotic system is determined by its application. A list of those used to both sense the state of the robot and that of the environment external to the robot is as follows:

1. CCD video camera

2. Vidicon video camera

3. Infrared camera

4. Photoelectric rangefinder

5. Laser rangefinder

6. Infrared thermometer/scanner 

7. Optical pyrometer
8. Ultrasonic rangefinder
9. Gas detection instrument
10. Humidity sensor
11. Raman spectroscopy instrument
12. Tactile "touch" sensor
13. Force/torque sensor
14. joint encoder
15. Pressure transducer
16. Strain gauge
17. Accelerometer
18. Electromagnet induction instrument
19. Ground penetrating radar

Robotic systems also include other electromechanical devices and constituent materials which contribute to the control and operation of the robotic assembly and are therefore subject to the radiation environment. These components and materials are, as a group, generally harder to radiation than are the sensors. Items included in this category are the following:
1. Metals
2. Insulators
3. Glasses
4. Adhesives
5. Camera lenses
6. Infrared window
7. Fiber-optic cable
8. Fiber-optic coupler
9. AC servo-motor
10. DC servo-motor
11. Stepper motor
12. Solenoid
13. Gasket
14. O-ring
15. Electrical wire
16. Electrical cable
17. Lead-acid battery
18. Load Cell

In most cases purely mechanical components have not been included unless they contain a material constituent with a potential susceptibility to radiation. 


\section{Radiation and Radiation Effects}

The purpose of this section is to give the robotic-system designer a basic introduction to radiation physics and radiation effects with particular emphasis on radiation-induced changes in material properties and semiconductor-device parametrics that can be significant to the design of a robotic system that will have to operate in a radiation environment. It will be assumed that the reader has had a basic introduction to atomic, nuclear and particle physics (i.e., the Bohr atom and excited atomic states, simple nuclear models and excited nuclear states and basic particles such as photons, electrons, neutrons, protons and highenergy heavy ions [cosmic rays]). These basic particle types and the way in which they interact with matter will first be discussed and then their detrimental effects upon materials and electronic devices will be considered.

\subsection{Radiation Physics}

A detailed discussion of the entire field of radiation physics is not within the scope or purpose of this tutorial.

The primary ways in which the basic particle types mentioned above interact with matter are (1) through the excitation of atomic electrons in matter which is commonly referred to as atomic or electronic excitation processes, (2) through nuclear interactions such as nuclear excitation, nuclear scattering (i.e., elastic or inelastic) and nuclear reactions, and (3) the breaking of chemical bonds in materials via electronic excitation and/or nuclear reactions. The electronically charged particles (i.e., electrons, protons and high-energy heavy ions) have a much greater probability of interaction with matter than do the neutral particles (i.e., photons [x-rays and $\gamma$-rays] and neutrons). Indeed these latter particles must first create an energetic secondary charged particle (i.e., an electron or a displaced lattice atom with sufficient kinetic energy to be stripped of its outer atomic electrons) in order to ionize the material.

The interaction probability for these processes is usually expressed in terms of an attenuation coefficient, $\mu$, or the so-called "cross section" for a given interaction. In the case where a cross section is used, the interaction ( also called reaction) rate is given by

$$
\text { I.R. }=\text { R.R. }=\left(\rho N_{A} / A\right) \sigma_{I} \Phi
$$

where R.R. is the reaction rate in reactions per $\mathrm{cm}^{3} \cdot \mathrm{sec}, \mathrm{N}_{A}$ is Avagadro's Number, $A$ is the atomic mass of the target atom/nucleus, $\sigma_{\mathrm{I}}$ is the cross section for the given interaction and $\Phi$ is the incident particle flux.

In the case of photons, the attenuation coefficient formalism is used. In this approach, the uncollided (no interaction) flux at a depth of penetration $x$, into a semi-infinite slab, is given by

$$
\Phi=\Phi_{0} \mathrm{e}^{-\mu \mathrm{x}}
$$

where $\mu$ is the attenuation coefficient (sometimes the mass absorption coefficient, $\mu / \rho$, is used in which case the depth of penetration is alternatively called areal density and is $\rho x$ in units of $g r a m / \mathrm{cm}^{2}$ ), $x$ is the depth of penetration and $\Phi_{0}$ is the incident flux in particles per $\mathrm{cm}^{2} . \mathrm{sec}$.

\subsubsection{Photon (x-ray and $\gamma$-ray) Attenuation}

For comparison purposes the mass absorption coefficients for $\mathrm{Pb}$ and $\mathrm{Si}$ are show in Figures 4-1 and 4-2. It is clear from a comparison of these two figures that $\mathrm{Pb}$ attenuates a photon beam much more 
than does $\mathrm{Si}$. There are three primary processes that contribute to the attenuation of a photon beam in any material. These are (1) photoelectric absorption where an atom absorbs a photon which leads to an excited atomic state with subsequent de-excitation via the emission of a photoelectron, (2) compton scattering where the incident photon suffers an inelastic scattering event with an atomic electron and (3) pair production where the incident photon is annihilated and a pair (i.e., an electron and a positron) are produced. In the figures the darker lines correspond to the photoelectric absorption coefficients and the curves which deviate from this at the higher energies are the energy absorption coefficient and total scattering coefficient respectively.

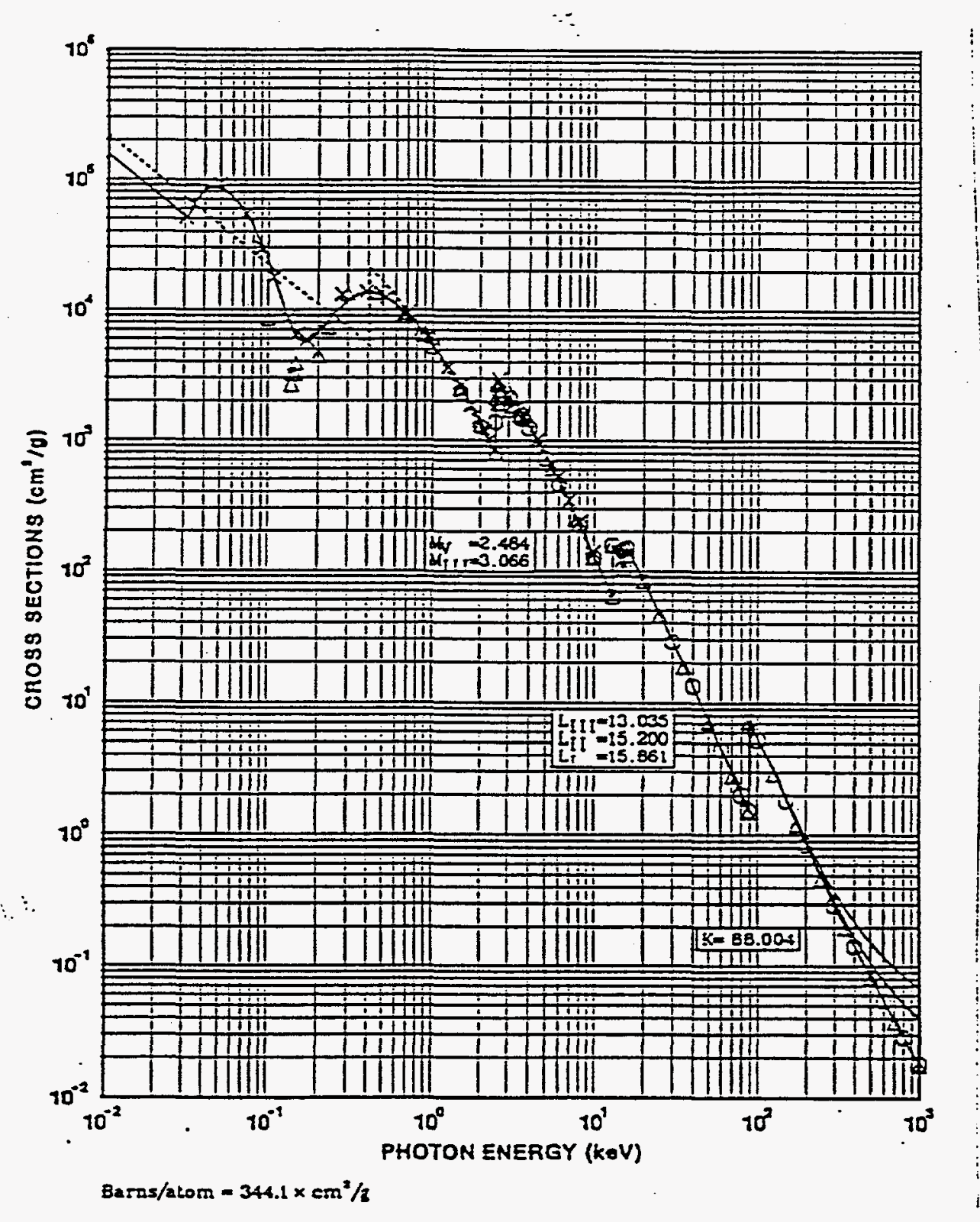

Figure 4-1 Mass Absorption Coefficient for $\mathrm{Pb}$ as a Function of Photon Energy. 


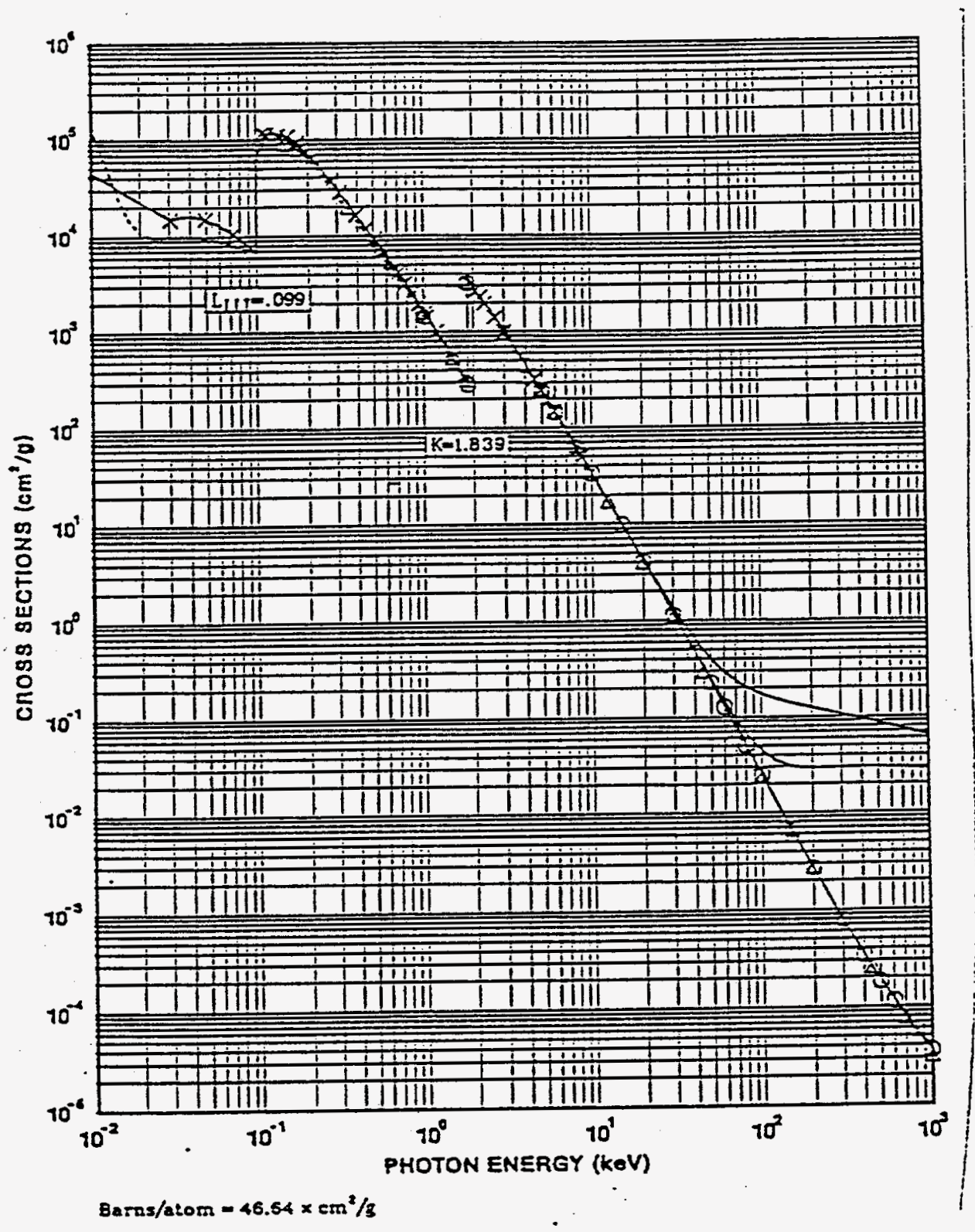

Figure 4-2 Mass Absorption Coefficient for Si as a Function of Photon Energy.

\subsubsection{Electron and Proton Energy Loss}

What can normally be found in tabular form for electrons and protons is the so-called stopping power, $\mathrm{dE} / \mathrm{dx}$, as a function of particle energy. From this type of data it is relatively straight forward, in the case of protons, to obtain the stopping power as a function of depth of penetration. The proton stopping power consists of two contributions; that due to electronic excitations (this contribution is dominate at all but the lowest energies) and that due to nuclear interactions (i.e., nuclear reactions and elastic and inelastic 
scattering) which is dominate only at the lowest energies (i.e., at the end of the proton range). An example of this can be found in Figure 4-3 for aluminum.

The situation for electrons is much more complex as a result of the large-angle scattering that they undergo when they interact with the atoms of a material. The energy deposition as a function of depth of penetration, normally called the depth-dose curve, increases quickly just inside the front surface of the material; peaks at a depth of about a third of the range, and then monotonically decreases until straggling sets in at the so-called extrapolated range. Figure 4-4 presents the depth-dose profiles for 3 Mev electrons normally incident upon $\mathrm{Pb}$ and carbon(graphite). The mean ranges to be used with these curves are 2.384 $\mathrm{g} / \mathrm{cm}^{2}$ for $\mathrm{Pb}$ and $1.703 \mathrm{~g} / \mathrm{cm}^{2}$ for carbon. It can be seen from this figure that the peak in the depth-dose curve occurs much closer to the front surface for the high atomic number material.

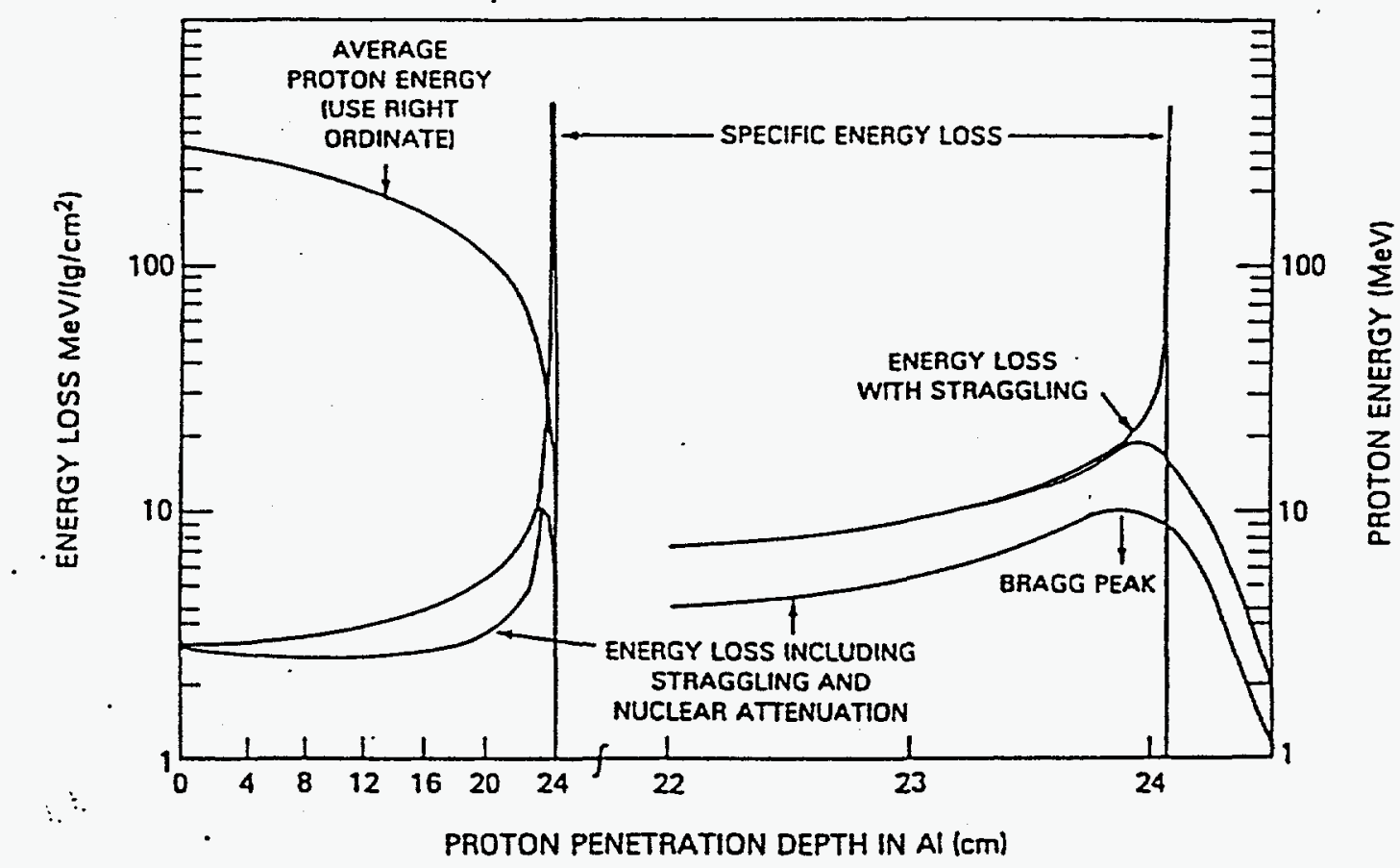

Figure 4-3 Proton Straggling Effects for $300 \mathrm{MeV}$ Protons 


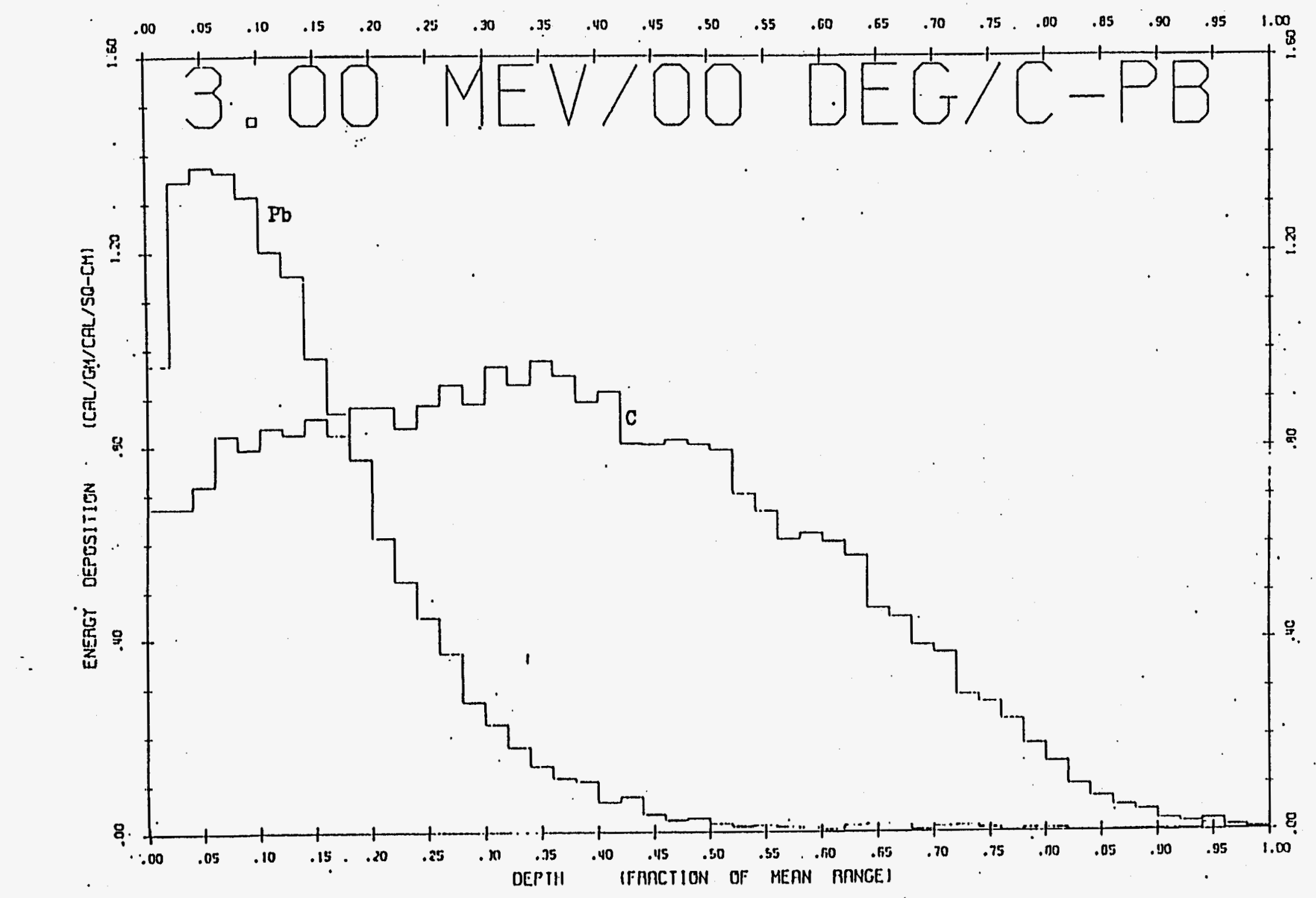

Figure 4-4 Dependence of Electron Energy Deposition Profiles upon the Atomic Number of the Target Material. 


\subsubsection{Heavy Charged Particle Interactions}

Heavy charged particles and protons can undergo nuclear reactions with lattice atoms. In almost all cases of potential robotic applications these reactions are not of practical significance. However, heavy charged particles, and to a lesser degree protons, can produce single event effects (SEE) in silicon ICs. The heavy charged particles produce a very high specific ionization track as they pass through the silicon. In some cases, the charge produced in the track and adjacent regions (i.e., if the minority carrier lifetime is long enough to collect this charge prior to recombination) is sufficient to change the charge state of a node within an IC. This causes an upset of the IC with the possibility of improper functional operation. There is also the possibility of single event induced latchup in an IC (SEL) or single event burnout. These processes would only be important for a space robotic system. Neutrons have also been shown to be capable of producing SEU (i.e., both soft and hard errors) in ICs.

\subsubsection{Neutron and Proton Displacements Damage}

Neutrons, and protons near the end of their range, have a moderate-to-high probability of interacting with lattice atoms of a material and displacing them from their equilibrium position in the lattice structure to an interstitial location. In general, this creates an electrically active defect site; whether it be the interstitial site or the vacant lattice site left behind. These electrically active sites, often called defect sites, can produce changes in the electrical properties of metals, semiconductors, and insulators. We are most interested in semiconductor response since modern ICs and piece parts are based on semiconductor materials.

Early in the characterization and understanding of neutron-induced displacement damage in discrete silicon devices, a methodology was developed to correlate the displacement damage produced by different neutron environments (i.e., various reactor types, neutron generators, neutron-emitting radiosope sources, etc). This methodology, also referred to by some as a protocol, invokes the use of the 1-Mev equivalent neutron-induced displacement damage when describing the damage produced by a neutron environment with known number and/or energy spectrum (i.e., $\Phi(E)$ and $E \Phi(E)$ respectively where $\Phi(E)$ is the neutron fluence, $\Phi(E)=\int \Phi(E, t) d t=\int N(E, t) v(E, t) d t$ and $E \Phi(E)=\int E(t) \Phi(E, t) d t=\int E(t) N(E, t) v(E, t) d t$ where $\Phi(E, t)$ is the neutron flux, $N(E, t)$ is the neutron density, and $n(E, t)$ is the neutron velocity. $\Phi(E)$ has the units of neutrons $/ \mathrm{cm}^{2}$ and $\Phi(E, t)$ has units of neutrons $/ \mathrm{cm}^{2} \bullet \mathrm{sec}$ ) Figure 4-5 presents the damage constant for $\mathrm{Si}$ as a function of neutron energy. Using this functional dependence, and the spectrum for a given neutron environment, it is then possible to calculate the integral displacement damage produced by this environment and to equate it to that produced by 1-Mev neutrons alone; thus the terminology of 1Mev equivalent damage. This methodology, or protocol, has been used extensively in the experimental investigation of neutron-induced effects in Si devices.

It has been demonstrated experimentally, using discrete transistors, that the damage produced in Si by a 1-Mev equivalent neutrons is essentially the same as that produced by $200 \mathrm{Mev}$ protons (see Fig. 5-2 in Section 5).

The ways in which these defects can affect the parametric properties of ICs and discrete devices will be discussed below. 


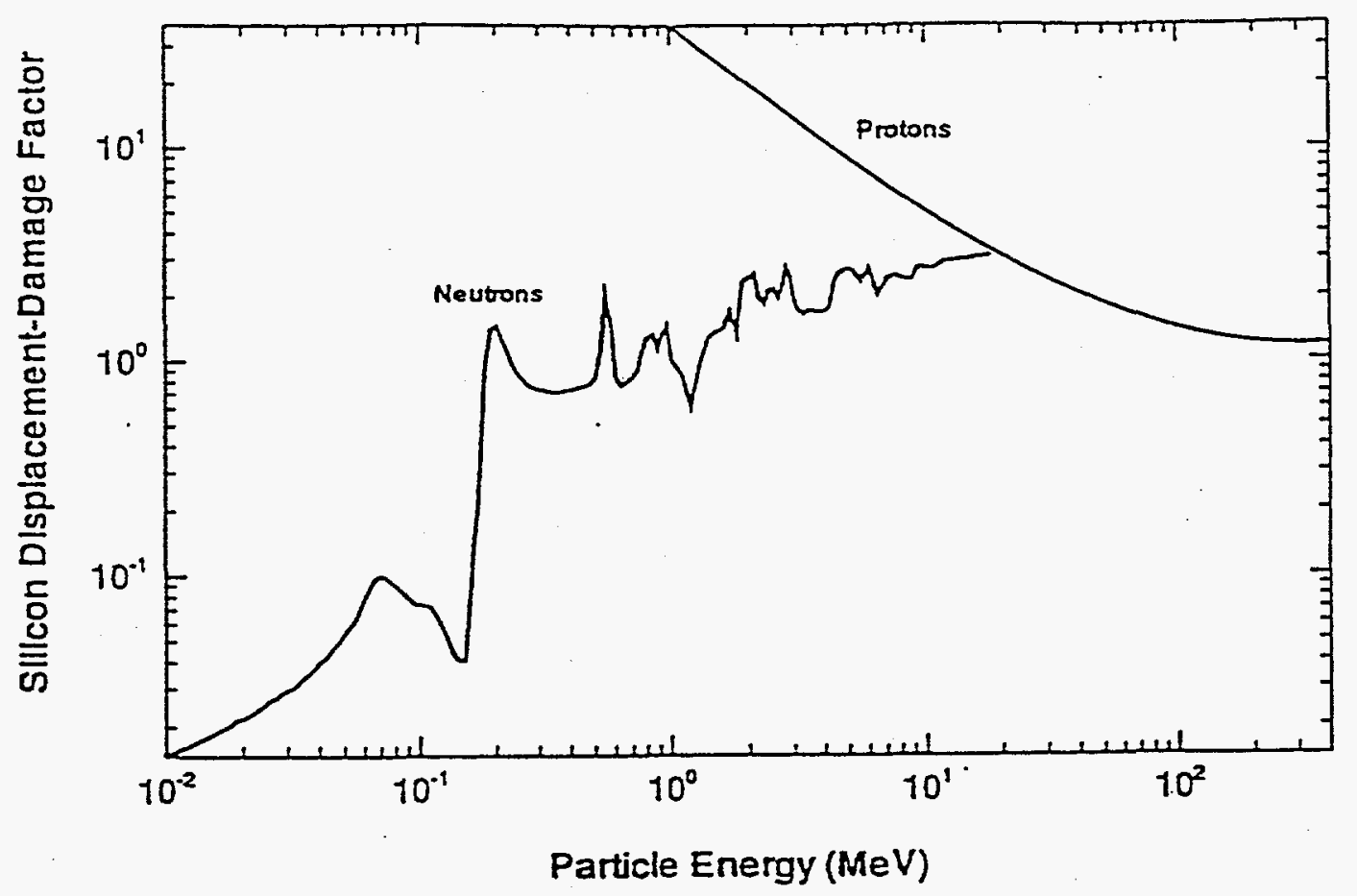

Figure 4-5 Silicon Displacement Damage Factors for Neutrons and Protons

\subsection{Radiation Effects}

For the vast majority of robotic systems, the primary radiation driver is that of total ionizing dose (TID). This is especially true for systems based upon MOS-technology devices, although some bipolar ICs are sensitive to TID, especially for low dose rate (i.e., $<1 \mathrm{rad}[\mathrm{Si}] / \mathrm{s}$ ) situations. Space robotic systems are an example of alternative applications where displacement damage in bipolar devices and SEE in MOS-type devices may also be of practical importance.

\subsubsection{Total Dose Effects}

The energy deposition giving rise to total-dose (TID) effects can be produced by photons, neutrons, electrons, protons, and high-energy heavy ions, although the most important of these for robotic applications are the photons. In most cases these are the gamma-rays that are emitted by radionuclides such as the fission products present in spent reactor fuel.

These TID effects can be time dependent due to the competing kinetics of the damage produced by the dose and the competing annealing of this damage. These time dependent effects can make for a very complex response for many modern ICs. An example of this for MOS-type ICs can be found in Figure 4-6 where the failure dose is presented as a function of dose rate. Figure 4-7 presents the threshold voltage shift as a function of dose for four different dose rates. These two figures give the reader an indication of the complexity for such device types. A thorough discussion of this area is beyond the scope of this work. The interested reader is directed to Dan Fleetwood of Department 1332 at SNLNM.

In the case of some bipolar ICs, a continued decrease in radiation resistance as the exposure dose rate is decreased has recently been observed (see Fig. 4-8). 


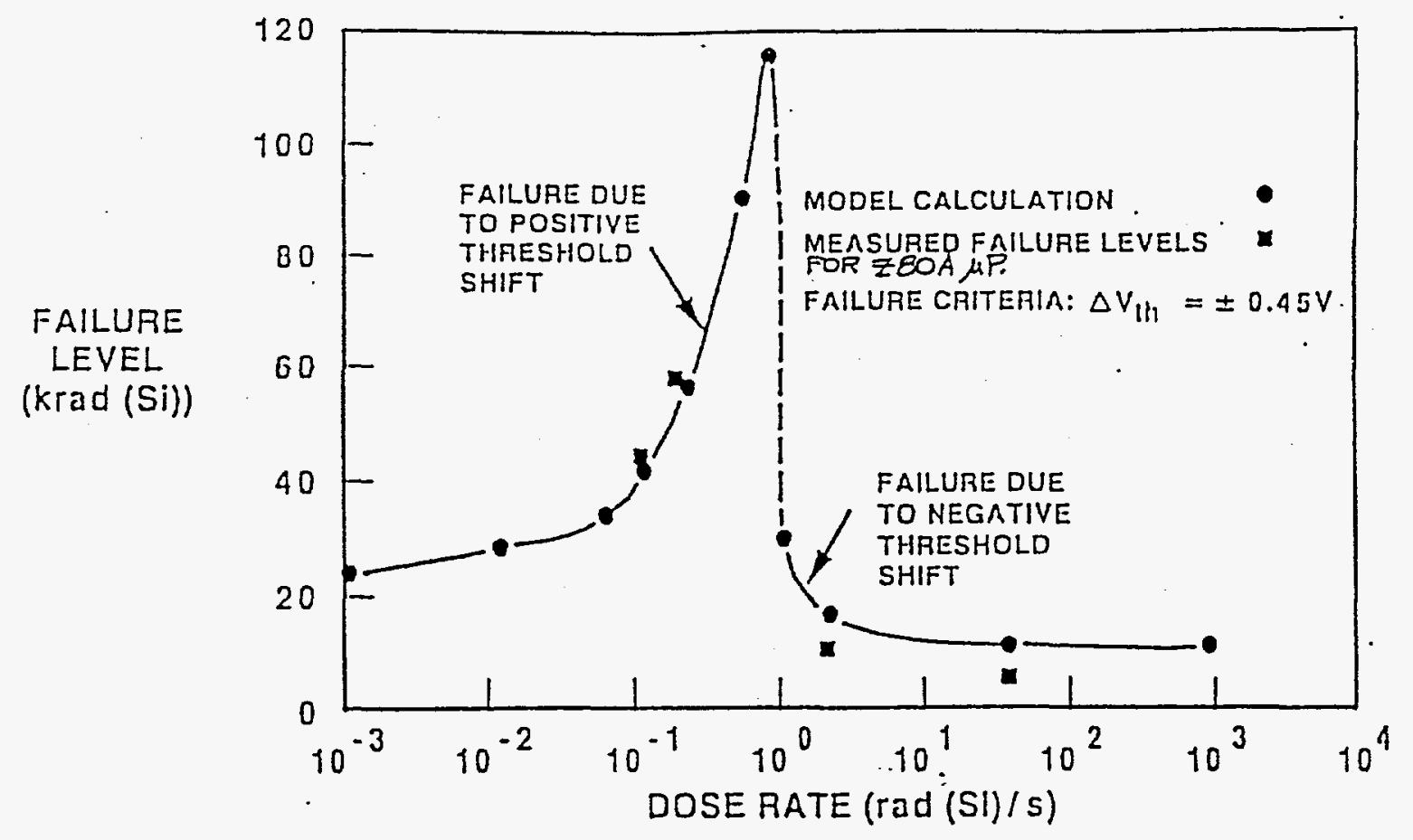

Figure 4-6 IC Failure Level Dependentcy on Dose Rate (A.H. Johnston et, IEEE Trans. on Nucl. Sci., NS-31, p. 1427, 1984)

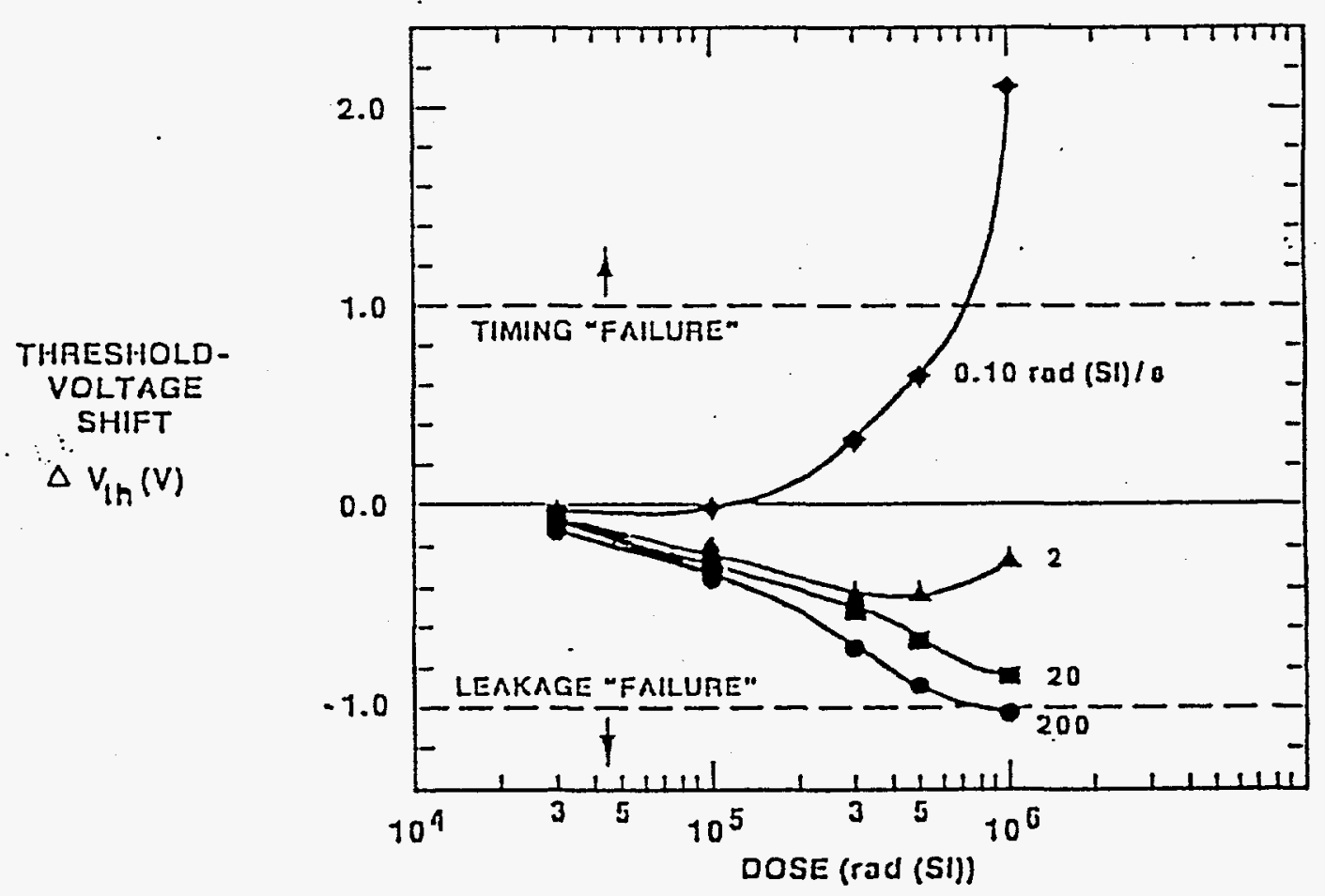

Figure 4-7 Threshold-Voltage Shift vs. Dose at Varying Dose Rates (P.S. Winokur et. al., IEEE Trans on Nucl. Sci., NS-33, p. 1343, 1986) 


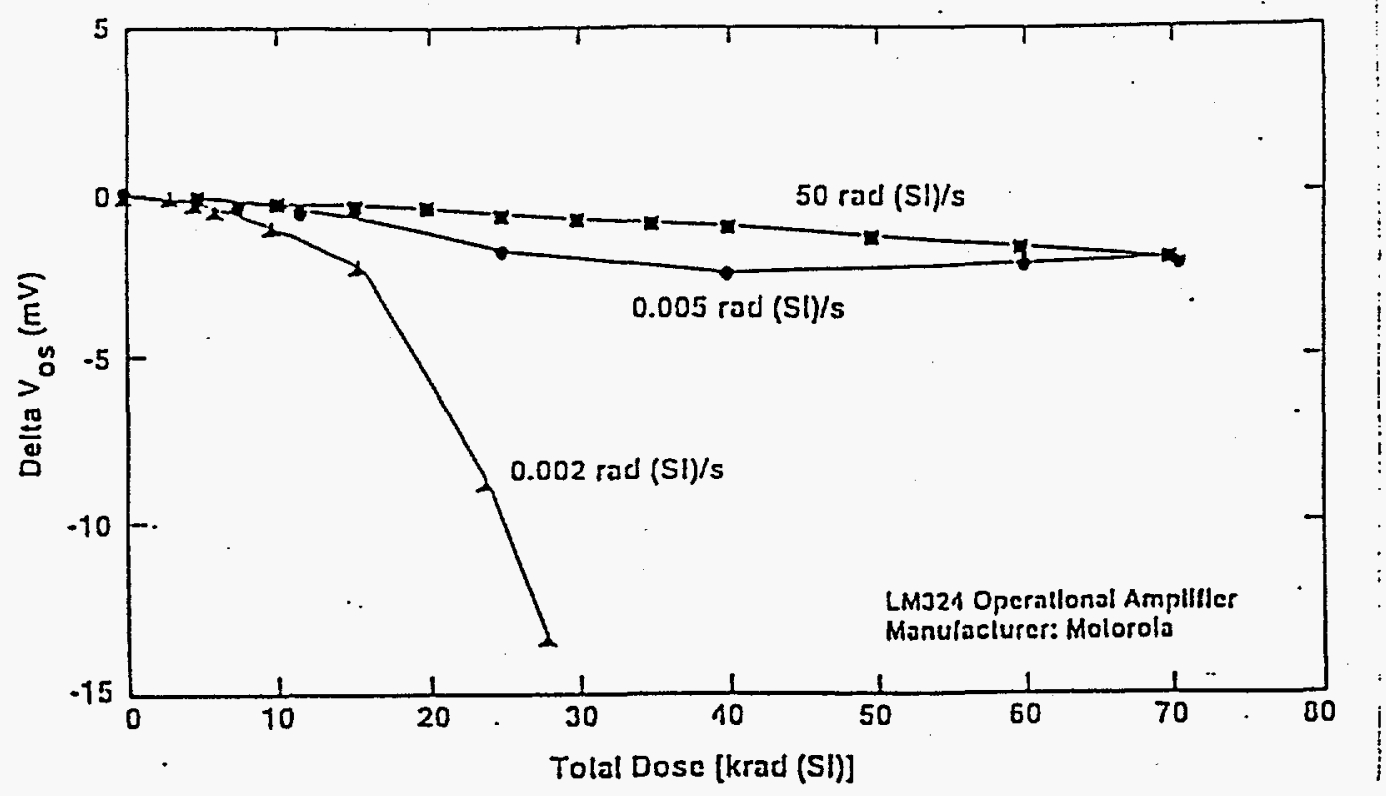

Figure 4-8 Input Offset Voltage vs. Total Dose for the LM324 Op-amp at Various Dose Rates (A. H. Johnston et. al., IEEE Trans. on Nucl. Sci., NS-42, p. 1650, 1995.

\subsubsection{Dose Rate Effects}

At low dose rate (i.e., much less than IE3 rad[Si]/s) the kinetics of the damage, and subsequent annealing, processes can lead to a very complex response as described above. At higher dose rate (well above lE6 $\mathrm{rad}[\mathrm{Si} / \mathrm{s}$ ) the primary response of interest is the upset of ICs with the possibility of device burnout at very high dose rates (i.e., greater than $1 E 11 \mathrm{rad}[\mathrm{Si}] / \mathrm{s}$ ). In Section 1 of this report it was stated that consideration would be limited to a dose rate of about $30,000 \mathrm{rad}[\mathrm{Si}] / \mathrm{hr}$ or about $10 \mathrm{rad}[\mathrm{Si}] / \mathrm{s}$. Therefore, these more traditional dose-rate response modes are of no consequence, but have only been mentioned for completeness.

\subsubsection{Neutron Fluence Effects}

For the following discussion, it is assumed that the reader is familiar with the concept of minority and majority as applied to semiconductor materials. Without such a background, the reader is referred to such texts as "Physics of Semiconductor Devices" by S.M. Sze".

The properties of semiconductors that are the most sensitive to displacement damage are (a) the minority carrier lifetime of the material and (b) the mobility of the majority carriers. This latter property is also important for metals. Displacement damage, produced by any of the particle types discussed above, leads to a decrease in the minority carrier lifetime and to a decrease mobility of both majority and minority carriers. Significantly more damage is required to produce the mobility changes. Permanent radiation damage makes $\mathrm{n}$-type material tend towards p-type and makes p-type material become higher resistivity ptype. 
In addition to the 1-Mev neutron equivalency methodology described above, the time dependence of the annealing of neutron-induced displacement damage in Si discrete devices has been characterized in terms of a universal decay curve and a nomograph has been developed (see Figure 4-9) in order to determine the effects of such damage as a function of time after irradiation. The applicability of this approach has not yet been confirmed for bipolar ICs.

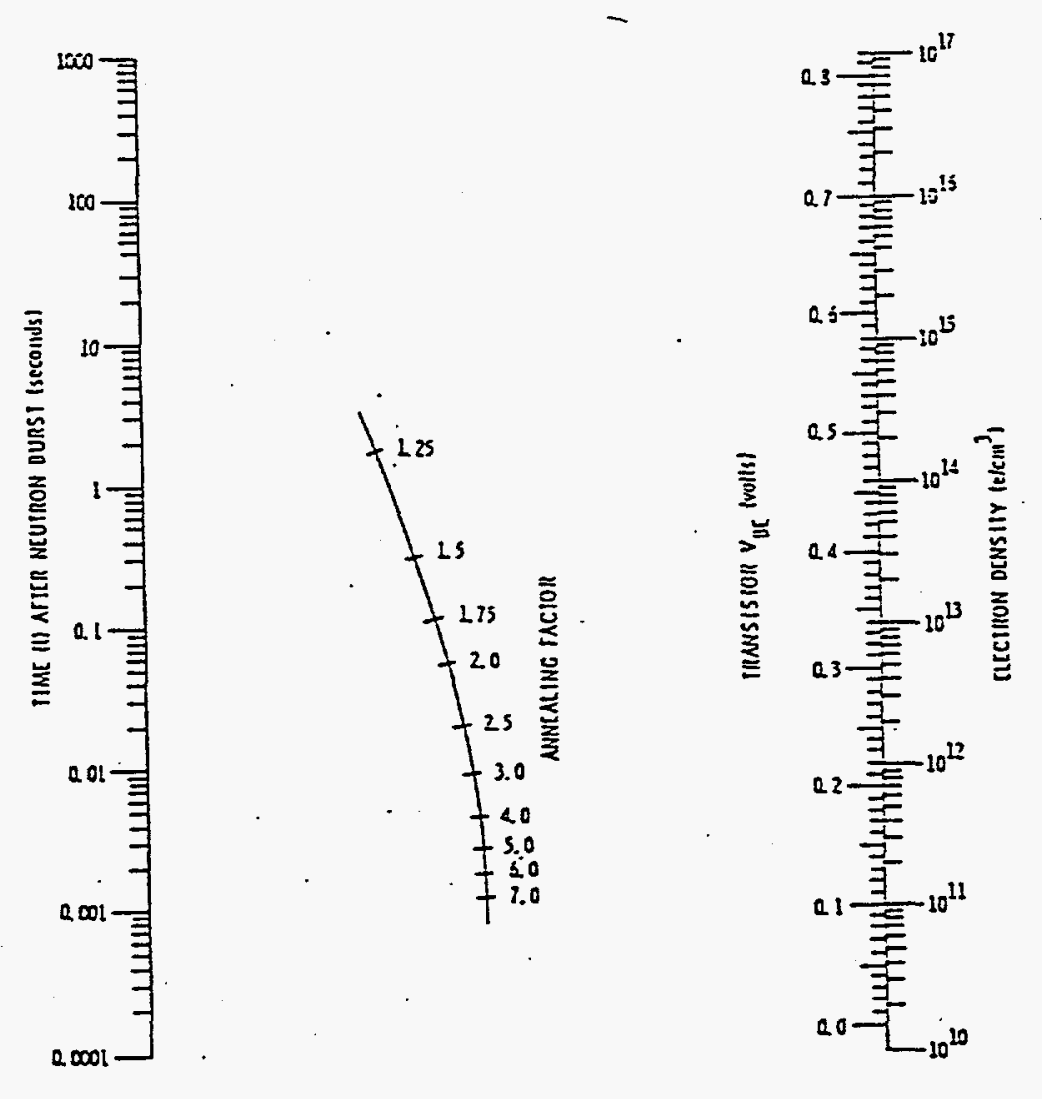

The appropriate Ameali=g Fasto: for. 2 trasistor is grved by the inter-

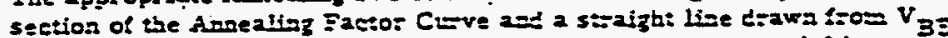
(zeasured at the appropiate collectso etront) and the Ti=n (o! ireasi) After Netron Burst.

Figure 4-9 Nomograph for Prediction of Annealing Factors, at Room Temperature.

\subsubsection{SEE Effects}

Except for the applications of robotics in space, SEE are of only minor importance for the vast majority of robotic applications. In the absence of protons and high-energy heavy ions, effects of this type can only be produced by neutrons. Although it was thought that high energy neutrons were required, recent experimental data has shown that epi-thermal neutrons can also be reasonably effective in producing $S E E^{26}$. This has been attributed to the certain types of impurities used to obtain n-and p-type doping. However, relatively high neutron fluences are required so that it should not be of practical concern for most robotic systems and applications. In spite of this low probability, the possibility of the existence of neutroninduced SEE should be addressed for radiation environments with a neutron component. 


\section{Radiation Sensitivity Of Robotic Components}

In order to address the radiation sensitivity of robotic systems it is expedient to consider separately those constituents falling into the categories of (A) electronic components, (B) sensors and (C) materials and miscellaneous components.

The radiation vulnerability of electronic components (i.e., electronic subsystems, individual circuits, etc.) can be quantitatively assessed by considering the response of the constituent piece parts to the primary radiation effects. The incident radiation produces an effect in the materials comprising an electronic piece part. These effects are (1) total ionizing dose (TID) produced by all the ionizing particle types, (2) neutron and/or proton induced displacement damage (gamma's and electrons can also produce displacement damage but not to the extent of the heavier particles and this damage more readily anneals out) which can be important for space and possibly fusion applications and (3) single event effects (SEE) which can be produced by high-energy neutrons and space radiation.

The electronic piece parts that are the most susceptible to radiation effects are the semiconductors, the semi-insulators and, in some cases, the insulators. Of course, the most important of these are the silicon family of piece parts. In order to facilitate further discussion, this very large family of part types will be further sub-divided into commercial (non-hardened) and hardened categories.

In many cases sensors are the part of the system most sensitive to radiation effects. In general this results from the fact that optical parts are designed to exhibit a reasonable response to low levels of incident radiation (i.e., infrared through visible into the ultraviolet and very low-energy X-ray regions). This category has a great deal of overlap with the category of electronic components since many sensors include electronic piece parts; indeed some contain silicon sensing elements such as the CCD chips of video cameras. On the other hand there are some very radiation resistant sensors such as the electrostatic version of an ultrasonic rangefinder which does not contain any semiconducting materials.

The final category contains materials from metals to insulators (e.g., kapton, polyethylene, etc.) and other non-semiconductor based electronic and electromechanical components such as servo-motors (AC and DC), batteries and many others. Items included in this category are generally much harder than those in the previous two categories with the possible exception of fiber-optic materials/components although, even here, the hardened version of these exhibit a greater radiation resistance than most of the radiation hardened semiconductor piece parts and/or sensors.

\subsection{Electronic Components}

Potentially, the most radiation sensitive parts of a robotic system are the electronic components. Robotic systems can require a significant amount of data processing and control electronics at the operator interface and, in many cases, onboard the robotic assembly. It is the latter electronics, residing within the radiation field, that is of concern. For the applications presented in Section II.A., the primary radiation effects of concern are total ionizing dose (TID), the neutron-induced displacement damage (possibly for the fusion application) and single event effects (SEE) produced by high energy neutrons in the upper atmosphere and by trapped protons and/or cosmic rays in the space application. For these types of radiation effects, the behavior of electronic circuits/subsystems is controlled by piece part response (i.e., synergism among the responses of a number of piece parts that reduces radiation resistance is not of primary importance). To first order, the radiation response of circuits is determined by the most radiationsensitive parts in the circuit. The same thing can be said for the dependence of electronic subsystems upon the radiation response of their constituent subsystems. Therefore, the radiation resistance (hardness) 
of the piece parts used in a robotic system is of primary importance in determining its utility for specific applications.

Electronic piece parts can be more easily procured in their commercial (unhardened) form. Nothing special is done in the fabrication process of these part types to assure hardness. This is not to say that the final product will not exhibit a moderate degree of hardness. Many commercial piece parts are found to be reasonably hard to one or more of the radiation effects described above. In contrast, special fabrication procedures are employed in order to produce hardened piece parts and varying levels of hardness have been achieved in this way. Commercial and hardened parts will be treated separately in the following subsections.

The complexity of electronic piece parts, whether commercial or hardened, covers a very broad range (i.e., from simple diodes to very complex ICs such as microprocessors). The complexity of the part types that are used in a given robotic application depends upon the specific performance characteristics of the robotic system. Autonomous robotic systems must use the more sophisticated piece parts in order to satisfy their functional requirements, whereas manually controlled manipulator arms can get by using less sophisticated part types.

\subsubsection{Commercial Parts}

As implied above, commercial part types vary dramatically in terms of their radiation hardness; i.e., from less than $10 \mathrm{krad}[\mathrm{Si}]$ to possibly $100 \mathrm{krad}[\mathrm{Si}]$ or more (i.e., for MOS type parts) or even up to 10 Mrad[Si] or so (i.e., for bipolar-type discrete devices or even small-scale ICs). A similar pattern is observed for the case of neutron exposures except that the roles are reversed with bipolar-type parts being less resistant to neutron fluence than MOS-type parts. Bipolar parts are usually hard to neutron fluences in excess of $1 \mathrm{E} 12 \mathrm{n}[1-\mathrm{Mev}] / \mathrm{cm} 2$ and some may possess a hardness of about $1 \mathrm{E} 14 \mathrm{n} / \mathrm{cm} 2$. In contrast, the hardness of commercial MOS-type parts can be an order of magnitude higher. A useful way of presenting this hardness information is shown in Figure 5-1 which was first formulated by E.L. Peterson 27 . The lower end of these limit boxes correspond to the capabilities of commercial piece parts. See Appendix B for more information concerning the different part types and/or technologies and the available radiation response data.

For the space application, protons degrade bipolar-type parts much the same as neutrons. In particular, the degradation in transistor gain is essentially identical for equal fluences of 1-Mev equivalent neutrons and $200 \mathrm{Mev}$ protons. However, the damage produced by lower energy protons increases relative to 1Mev neutrons with decreasing proton energy. Measured data are presented in Figure 5-2 which was taken from the work of G. P. Summers, et. al. 28. Protons also produce ionization and therefore can contribute to TID. Figure 5-1 includes lines showing the relation between displacement damage (1-Mev neutron equivalent) and ionization dose for three different proton energies. As an example, this shows that although commercial CMOS parts can easily survive a neutron fluence of $1 \mathrm{E} 14 \mathrm{n}[1-\mathrm{Mev}] / \mathrm{cm} 2$, they are not capable of surviving the corresponding dose of 4 to $10 \mathrm{Mrad}[\mathrm{Si}]$.

Commercial piece parts can be very sensitive to SEE whether caused by high energy neutrons, high energy protons or cosmic rays. This type of response to radiation includes both single-event upset (SEU) and single-event latchup (SEL). The former is of primary importance for RAM/ROM chips and microprocessors while the latter can be important for nearly all part types; especially if the latch is of the destructive type. 

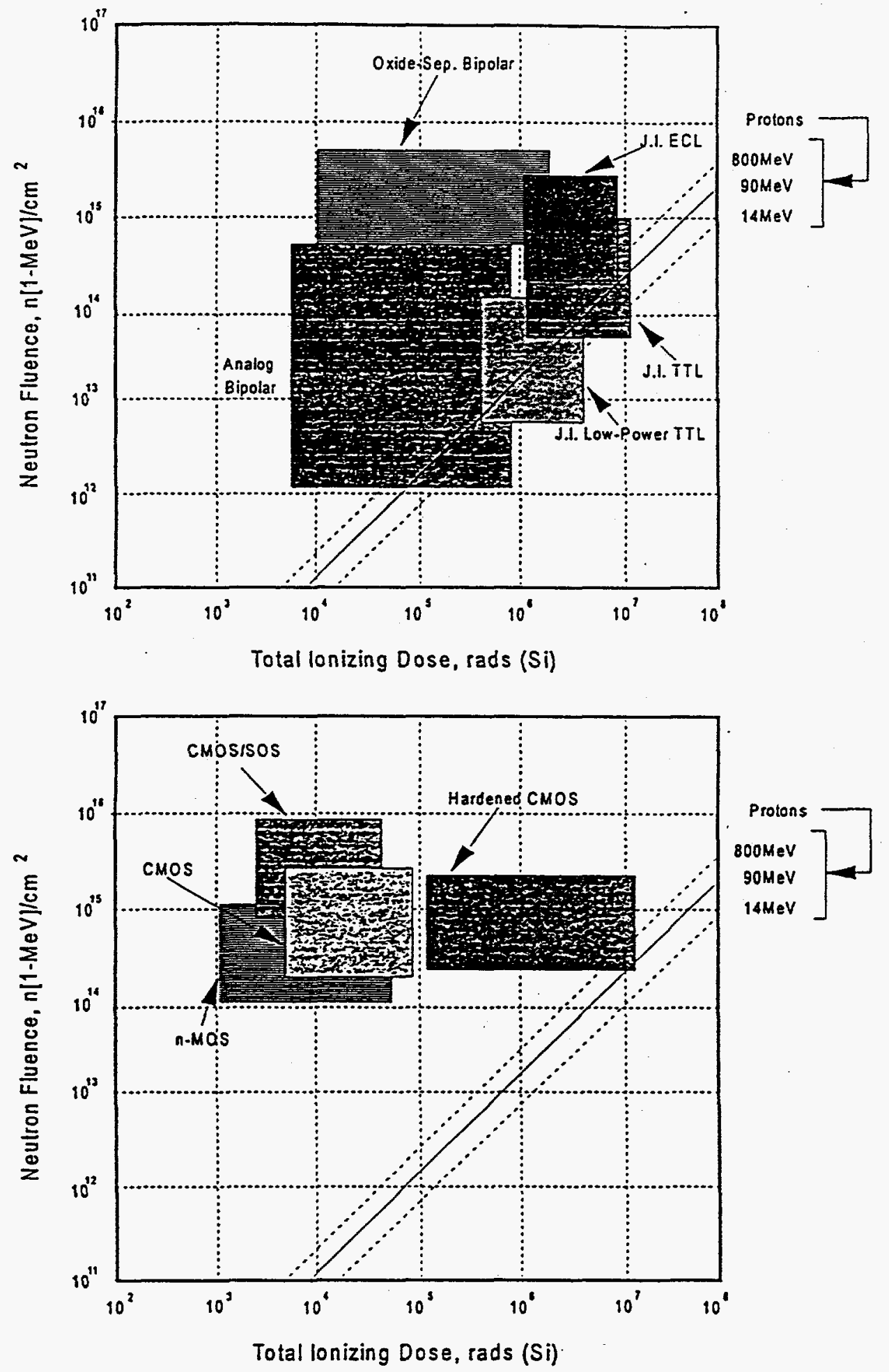

Figure 5-1a and b TID and Neutron/Proton Fluence Hardness for Various Electron Piece-Part Type 


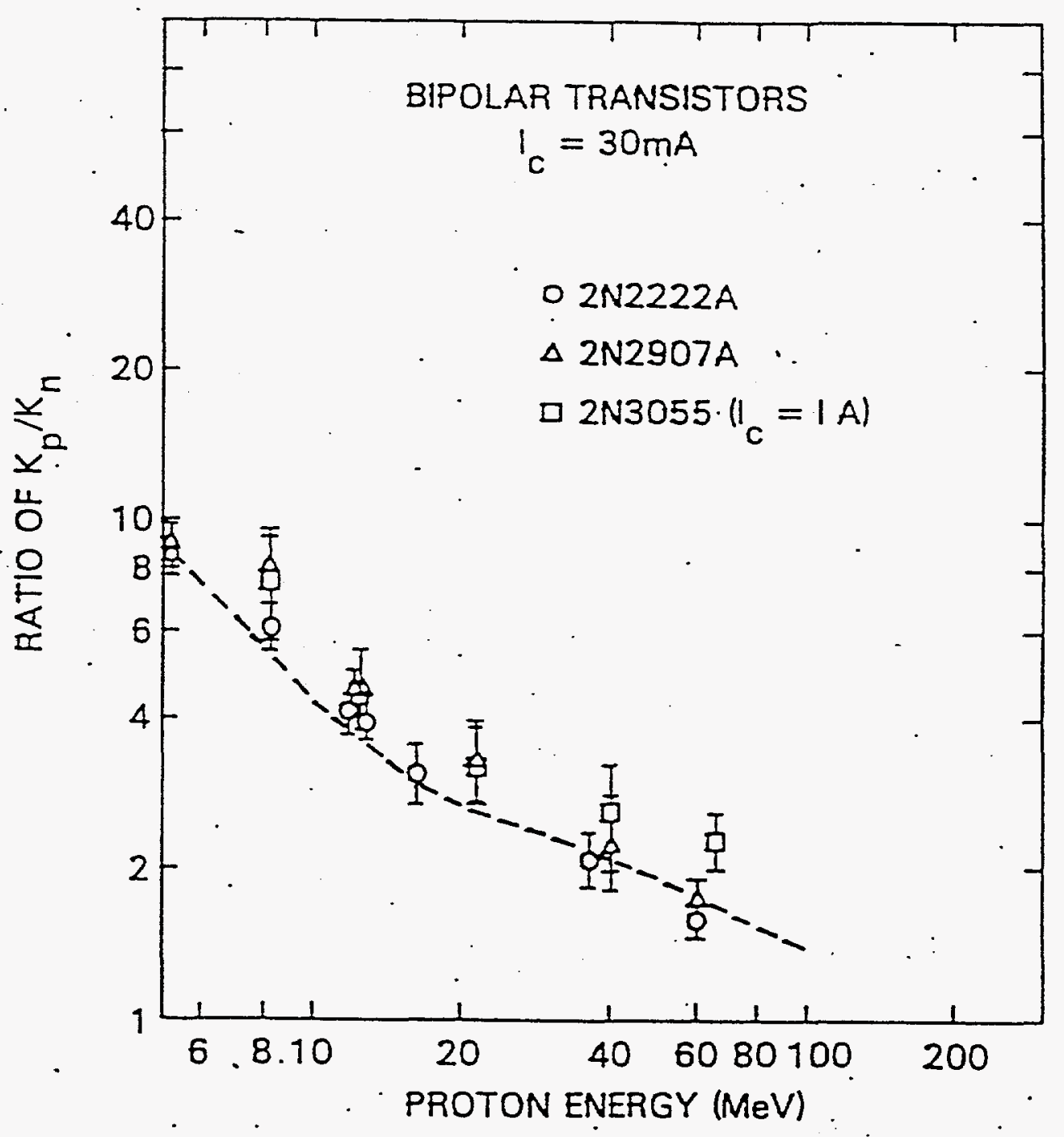

Figure 5-2 Energy Dependence of the ratio of Proton-to-Neutron Damage Constants for Selected Transistors a function of Proton Energy. 


\subsubsection{Hardened Parts}

As mentioned above, the production of hardened piece parts requires that special procedures be used in the fabrication process. In practice this leads to a significant increase in the part cost. Many manufacturers are capable of producing hardened parts but do not produce a supply to have "on the shelf" because of limited demand. As a result, the use of hardened parts can be a very expensive endeavor. Unless it is possible to "ride along" with another sizable order for the same part type, suppliers require an order for 1000 parts at about $\$ 1500.00$ per part (i.e., a total of $1.5 \mathrm{M} \$$ ) before commencing a production run to achieve a $1 \mathrm{Mrad}[\mathrm{Si}]$ hardness level. Appendix B contains more detailed information concerning manufacturers and "nominally available" hardened part types. This appendix also has some data references on the testing of hardened parts. The "off the shelf" availability of hardened piece parts with associated test data is certainly significantly less than their commercial alternates.

It should be possible to obtain modern high-performance piece parts (in either MOS or bipolar technologies) that are hard to $1 \mathrm{Mrad}[\mathrm{Si}]$, but only at a very high price. At present it appears that achieving a 10Mrad[Si] hardness level is not possible using modern, sophisticated MOS-technology parts (although they have been produced on a very limited basis), but can only be accomplished using older, less sophisticated, bipolar technology parts. This may indeed be quite acceptable for some robotic system applications 29 .

\subsection{Sensors}

An extensive variety of sensors have been used in, and/or have been considered for, numerous robotic applications. For the purpose of the present valuation, sensors have been categorized as optical, thermal, acoustic, chemical, mechanical and electrical in order to make the process more tractable. In reality, there is a good deal of overlap among these categories over the range of sensors considered.

\subsubsection{Optical}

\subsubsection{Video Systems}

The use of video equipment in robotic systems is commonplace. TV cameras are generally a part of robotic systems whether they be onboard the robotic assembly or separate from the assembly, but an integral part of the overall system. In most cases, cameras are tethered to control electronics (possibly including video recording and playback equipment) including monitor techniques whether analog or digital. The vast majority of this type of hardware in use today employs non-hardened commercial electronic components and/or discrete devices. The part of the system that is the most likely to be in a radiation field is the camera. Basically, cameras come in the unhardened chip (CCD) type and in the intrinsically harder vidicon (tube) type.

\section{CCD Camera}

CCD, chip, cameras are the most susceptible to radiation damage but are significantly less expensive than the harder vidicon cameras. Therefore, this type of camera have an important place in robotic systems that have relatively modest radiation requirements (i.e., tens of krads[Si] or less). The use of chip cameras can be cost effective in such applications, especially if replacement is possible during the life of the robotic system. 
Radiation hardness testing of chip cameras, or the more common approach of evaluating the chip alone, has led, in most cases, to little information concerning the visual performance of these units. One of the newer moderate-hardness chip cameras is the Sony Model XC-999. However, quantitative hardness data was not available on this camera. In light of the practical importance of chip cameras in robotic system applications and the fact that this camera was purported to be the hardest in this category, the decision was made to quantify it's hardness early in this work. This was accomplished using the Gamma Irradiation Facility (GIF). Details of this test can be found in Appendix D. In this test, performance of the camera was based upon line-resolution capability (i.e., visual performance) and not upon device parametric changes (i.e., electrical performance). The camera was found to exhibit acceptable resolution and color reproduction up to a cumulative dose of $25 \mathrm{krad}$ [Si]. This test was carried out at a dose rate of $520 \mathrm{rads} / \mathrm{min}$. This rate is higher than that corresponding to some of the possible applications. Based upon this fact it is possible that this camera could exhibit a higher cumulative-dose damage threshold for applications where the operational dose rate is significantly less than this test condition.

\section{$\underline{\text { Vidicon Camera }}$}

Vidicon camera systems are available with a hardness capability of $1 \mathrm{E} 8 \mathrm{rad}[\mathrm{Si}]$. A variety of lenses are available for these cameras which have an equivalent hardness capability. The cost of these systems can be an order of magnitude or more of the cost of the CCD cameras.

Test data on the neutron hardness of this type of camera could not be found. However, they should also be harder to neutrons than are the CCD cameras (i.e., neutron fluences of less than $1 \mathrm{E} 15 \mathrm{n} / \mathrm{cm} 2 \mathrm{should}$ not affect them). Lenses are not expected to be as insensitive to neutrons as are the vidicon cameras. The lenses are expected to start exhibiting transmission degradation at fluence levels of $1 \mathrm{E} 13$ to $1 \mathrm{E} 14 \mathrm{n} / \mathrm{cm} 2$.

The entire camera system, including the lenses, should be insensitive to SEE.

\subsubsection{IR Camera}

Infrared cameras can be used to measure the spatial distribution of the temperature of bodies. Infrared imaging with cameras of this type has been proposed as a technique to look for hot spots in the 24 radioactive storage tanks at Hanford which contain ferrocyanide 30 . One such camera is the FLIR Systems Inc. Model 7300 which consists of a scanner assembly, image processor and color display. In this camera the IR detectors are cooled to $-73^{\circ} \mathrm{C}$ with a Peltier cooler. Each detector has its own multistage complimentary metal oxide semiconductor (CMOS) multistage amplifier. The detectors and their amplifiers are sensitive to TID (the only radiation response of interest in this application unless a criticality accident were to occur in which case the camera would likely be destroyed in other ways anyway). The lense is calibrated with the camera at the factory. This calibration will certainly be sensitive to TID. The amplifiers have been estimated to be the most radiation sensitive part of the camera head (see Reference 29) with a hardness level of $1000 \mathrm{R}$. This seems somewhat low even at the reduced operating temperature. A hardness level of 3 to $5 \mathrm{krad}[\mathrm{Si}]$ would be more in line with the information contained in Figure 5-1(A). Even if the lower estimate is correct, with the proposed $\mathrm{Pb}$ shielding one camera system is projected to be sufficient to image all 24 tanks prior to being rendered inoperative from radiation damage.

\subsubsection{Photoelectric Rangefinder}

This sensor uses a light emitting diode (LED) as a light source with a photodiode being used to detect the light reflected from an object. On the one hand, photodiodes, of discrete bipolar technology, can exhibit a TID hardness of better than $1 \mathrm{E} 8 \mathrm{rad}[\mathrm{Si}]$ and a neutron hardness of better than $1 \mathrm{E} 14 \mathrm{n}[1-\mathrm{Mev}] / \mathrm{cm} 2$. On 
the other hand, the situation for LEDs can be quite different. Some LEDs are neutron hard to no better than 2 to $3 \mathrm{E} 12 \mathrm{n}[1-\mathrm{Mev}] / \mathrm{cm} 2$ and to be TID hard to less than or about $1 \mathrm{Mrad}[\mathrm{Si}]$. However, with careful selection of the LED and photodiode, it should be possible to achieve a relatively hard sensor of this type.

\subsubsection{Laser Rangefinder}

In this type of sensor, a moderate-power laser is used to illuminate the subject area with a collimated beam (see Reference 1). The backscattered light is measured by a detector of appropriate sensitivity (e.g., a photomultiplier detector). Intensity variations of the backscattered light yields information on the reflectance of the object in the path of the collimated beam. A range map of the subject area is produced by scanning the laser beam over the area of interest. Although the range of an object in the collimated beam can be obtained from the round-trip transit time, a more often used approach is to modulate a burst of laser power in which case the phase difference between these modulations on the transmitted and backscattered light beams yields the time delays of interest. The primary drawback of this kind of sensor is the amount of time that it takes to accumulate a range map.

The components of a sensor of this type can be radiation hard if properly selected. A gas laser such as the HeNe type should be TID-hard to greater than $1 E 7 \mathrm{rad}[\mathrm{Si}]$. Since it is a gas system it should also be hard to neutrons. The optical detectors used to measure the backscattered light and the sampled light in the feedback gain control circuit may control the hardness of the sensor although proper selection should yield a TID-hardness somewhat in excess of $1 E 7 \mathrm{rad}[\mathrm{Si}]$ and a neutron-hardness of between $1 \mathrm{E} 14$ and $1 \mathrm{E} 15 \mathrm{n}[1-\mathrm{Mev}] / \mathrm{cm} 2$.

\subsubsection{Structured Lighting 31}

Although, strictly speaking, this is a diagnostic technique and not a sensor, it is included in this subsection because of its significance (see Figure 5-3 for an example of its performance). The sensors that are an integral part of the system are video cameras (either the vidicon or CCD type). These components of the system therefore control the hardness achievable for this diagnostic technique (at least for the CCD type). Therefore, hardness capabilities are the same as those presented in Section 5.2.1.1 above. 

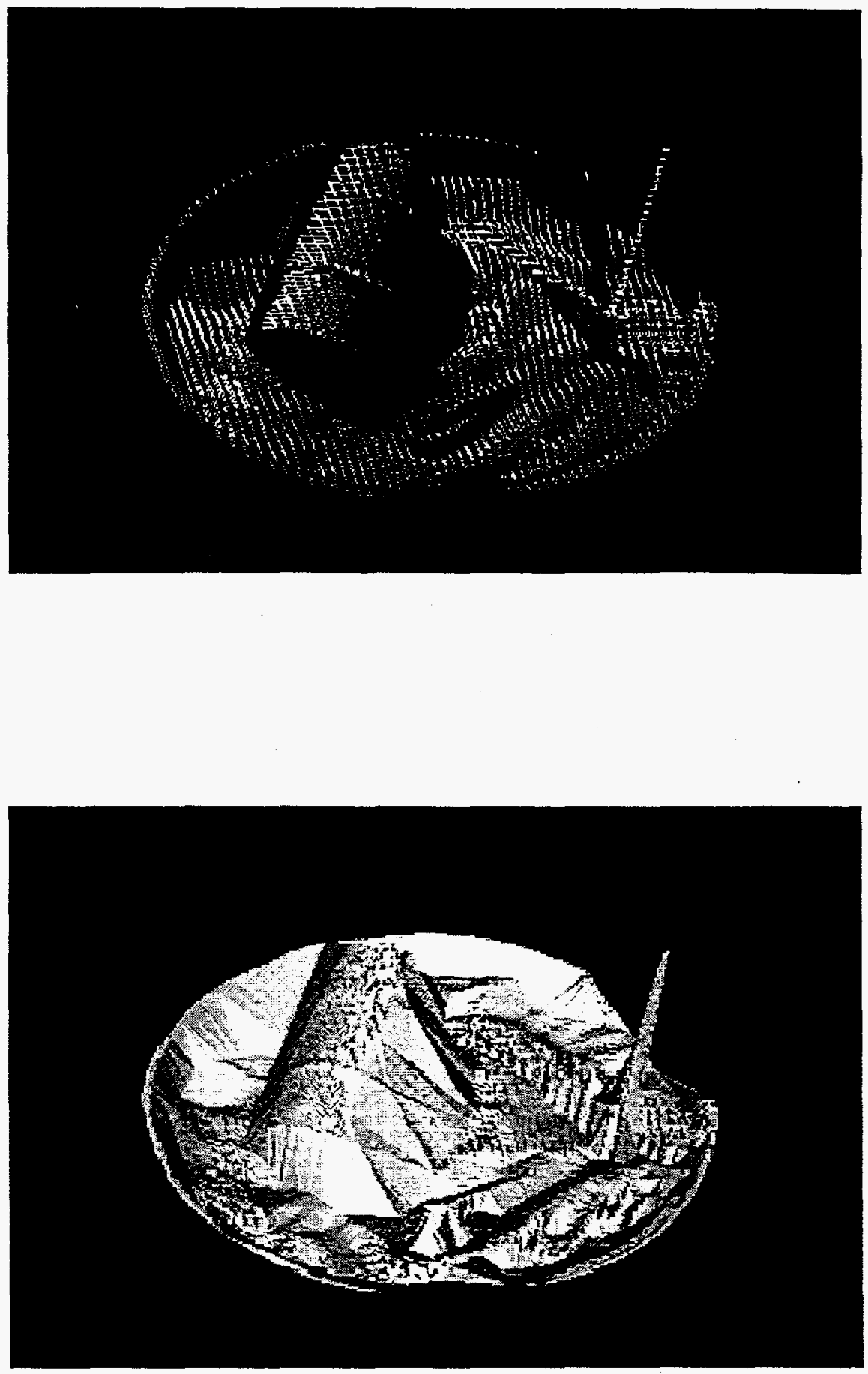

Figure 5-3. Structured Lighting has been Demonstrated as a Tool to Scan Surfaces and Rapidly Build a Simulation Model for Robot Programming and Control. 


\subsubsection{Thermal}

\subsubsection{Infrared Thermocouple/Scanner}

Infrared scanners can be used to measure the temperature of a body. It has been proposed that an infrared scanning device be used to measure the spatial distribution of the surface temperature of the waste in the ferrocyanide tanks at Hanford 32 . In this system the scanner output is computer analyzed and the results presented in color displays. An example of these instruments are the Exergen line of infrared scanners. Exergen calls the sensing element an infrared thermocouple (IR t/c) and it uses the thermoelectric effect to provide the output which is on conventional thermocouple wire.

A temperature sensor of this type could be used on a robotic assembly to measure the temperature of objects in reasonably close proximity without the need to make direct contact. The exact fabrication details of these Exergen sensors are proprietary, but aside from limitations of any adhesives or potting materials these devices should be hard to a TID of 1E8 to 1E9 rad[Si] which is the radiation effect of interest for the application mentioned above. These devices should be hard to neutrons also (i.e., well in excess of $1 E 15 \mathrm{n} / \mathrm{cm} 2$ ) and insensitive to SEE.

\subsubsection{Thermocouple}

In those cases where the robotic assembly end effector can make direct contact with the objects of interest, conventional thermocouples can be employed for surface temperature measurements. However, thermocouples do not offer much advantage over the IR scanners mentioned above except for their small size and superior sensitivity. The sheathing and insulation in commercial thermocouple elements would likely limit useful performance in a radiation field to a TID of 100 to $1000 \mathrm{Mrad}$ [Si]. These devices should be very hard to neutrons also and completely insensitive to SEE.

\subsubsection{Acoustic}

\subsubsection{Ultrasonic Rangefinder}

Object detection and associated distance measurements can be performed using ultrasonic rangefinder devices. Examples of this type of device are the CONTAQ PRX proximity switches and the CONTAQ ISU series of stand alone transducers. These devices are usually of the electrostatic type but can also be obtained with a piezoceramic transducer (i.e., for use in hostile environments). The ISU series includes an onboard microprocessor, the COPS400, to make it a stand alone unit. The central element of the electrostatic type is a gold plated kapton film which forms a capacitor with an aluminum housing. The hardness is therefore limited by the mechanical and electrical properties of the gold-plated kapton film or the dielectric used in the signal cable(s). The radiation limit for kapton is $>100 \mathrm{Mrad}$. However, the dynamic stresses placed on the film plating may result in a lowering of the damage threshold although this may be compensated to some degree by the gold plating. Without test data available, the hardness of the PRX series is conservatively estimated at $10 \mathrm{Mrad}[\mathrm{Si}]$. The uncertainty about the film properties indicates that testing is in order for these devices.

The microprocessor present in the ISU series reduces the hardness of this type to a level corresponding to that of the IC. The operational limit is therefore determined by that of the COPS400 which is available in nMOS and CMOS versions. Therefore, the TID hardness could be as low as $1 \mathrm{krad}[\mathrm{Si}]$ and the neutron hardness should be greater than $1 \mathrm{E} 14 \mathrm{n}[1-\mathrm{Mev}] / \mathrm{cm} 2$. 


\subsubsection{Chemical}

\subsubsection{Gas Detection Instruments}

Sensors available for the detection of gas species are applicable to such gases as oxygen and nitrogen, the organic gases like methane and propane, toxic gases like carbon dioxide and ammonia, etc. One manufacturer of these type of sensors is Figaro 33 . They produce a line of sensor designs which possess different gas-species sensitivities by selecting the most suitable combination of sensor material, temperature and activity.

A specific example of Figaro Gas Sensors are the GS Oxygen Sensor Model KE-Series. This type of sensor incorporates a lead-oxygen cell with a lead anode and a gold cathode. Oxygen molecules diffuse through a non-porous teflon membrane into the electrochemical cell and are reduced at the gold-film electrode. The current flowing between the electrodes is proportional to the oxygen concentration in the gas mixture. The output signal is the voltage developed across a load resistance which is temperature compensated by a thermistor. Sensor components that can control the radiation hardness are the teflon membrane, o-ring material, acid electrolyte and /or plastic housing. Based upon its bulk properties, teflon appears to be the limiting material for TID with the result that the estimated TID hardness limit is $>$ $1 \mathrm{Mrad}[\mathrm{Si}]$ while the estimated neutron hardness of $1 \mathrm{E} 16 \mathrm{n} / \mathrm{cm} 2$ might be controlled by any of these components. Although all the different gas-specific sensors are of differing physical design, their hardness levels are expected to be as good as, if not better than, those estimated for the GS Oxygen Sensor.

\subsubsection{Humidity Sensors}

Relative humidity measurements are a part of the environmental diagnostics required for some of the robotic applications. An example of devices available to make such measurements are the Figaro $\mathrm{NH}$ Series. These sensors consist of a humidity sensitive element and a printed thermistor mounted on an alumina substrate. A $5.0 \mathrm{~V} \mathrm{AC}$ signal $(50 \mathrm{~Hz}$ to $1 \mathrm{kHz})$ is applied across a series arrangement of the two elements. The $\mathrm{AC}$ resistance of the humidity-sensitive element changes exponentially with the change in relative humidity. From the voltage ratio and a calibration curve for the sensor, the relative humidity can be determined.

All of the elements of this sensor are relatively insensitive to radiation. Possibly the most sensitive is the high polymer electrolyte with which the water vapor interacts. It is estimated that this sensor should survive $10 \mathrm{Mrad}[\mathrm{Si}]$ and can likely continue to function at doses in excess $100 \mathrm{Mrad}[\mathrm{Si}]$ although the calibration curve will likely change. In addition, neutron fluences in the range of $1 E 16 \mathrm{n} / \mathrm{cm} 2$ should be survivable.

\subsubsection{Raman Spectroscopy}

One specific example of a potential use of this technique was an evaluation of remote Raman screening applied to the processing of mixed waste in drums ${ }^{34}$. An analysis of samples was performed by the Nicolet Corp. to evaluate the viability of library searching in reasonably large spectral libraries (i.e., in excess of 300 components). Both direct surface sampling and remote sampling with a six-around-one silica fiber-optic probe 35 were performed. A Nicolet Raman 910 Fourier Transform Raman Spectrometer was used for sample excitation, data acquisition and analysis. The remote approach is the most probable for waste processing. In this case, the instrument can be located out of the radiation environment, or at least shielded in order to significantly reduce the radiation levels. Then only the fiber 
optics will be exposed to the radiation field. Therefore the radiation hardness would be controlled by the type of fibers used. See Section C.2.

\subsubsection{Mechanical}

A variety of mechanical sensors are required for the design and fabrication of robotic assemblies. For the purpose of discussing these sensors, they will be subdivided into the categories of tactile sensor, force sensor, joint encoder, pressure gauge, strain gauge and electromagnetic types.

\subsubsection{Tactile "Touch" Sensor}

Tactile sensors, which are meant to reproduce the phenomenon of human touch, can be very complex. Examples of some past development efforts are the use of (1) four pressure-sensitive rubber sensors on the inner side of each of two gripper fingers (see Reference 1) and (2) 100 pneumatic snap-action touch sensors built into a gripper on a grid with $0.1 \times 0.1$ in. centers (see Reference 1). However, these were only binary touch sensors and analog sensors are required in order to measure gripping forces.

One of the more recent tactile sensors was a monolithic array of 256 individual elements of $1 \mathrm{~mm} 2$ effective area and possessing a useful range of 1 to $100 \mathrm{~g}$. More detail on this sensor configuration can be found in Reference 1. It is obvious that a system of this type requires either 256 long electrical lines bringing the transducer signals to the control computer or, signal multiplexing and conditioning electronics must exist at or very near the sensor in order to reduce the number of long signal runs required. Therefore, the use of electronic piece parts, especially linear devices such as ADCs, in this type of sensor system can result in a low-to-moderate radiation resistance.

Another recent approach used a VLSI circuit as the central element of a sensor unit (see Reference 1). The VLSI was nMOS technology in this prototype unit. This is the least radiation resistant of the MOStype technologies (see Figure 5-1(A)). Although it should be possible to use a more radiation resistant type of MOS technology, very high spatial-resolution sensors will almost certainly require multiplexing and the use of linear ADCs. In light of these considerations, the present state-of-the-art in the hardening of electronic piece parts implies an upper TID hardening-limit of about $1 \mathrm{Mrad}[\mathrm{Si}]$ for these type of sensors.

\subsubsection{Force/Torque Sensor}

These sensors are primarily mechanical in nature but do require some component to measure the stress and/or strain of a reference metallic body. Strain gauges have been used in one design of this type built at SRI (see Reference 1). In this case, the radiation hardness of the device would be determined by the capabilities of the strain gauges used (see Section 5.2.5.5 below) and/or the adhesives used for bonding (see Section 5.3.1 below). Other possible transducer types include piezoelectric, magnetorestrictive, magnetic, etc. 


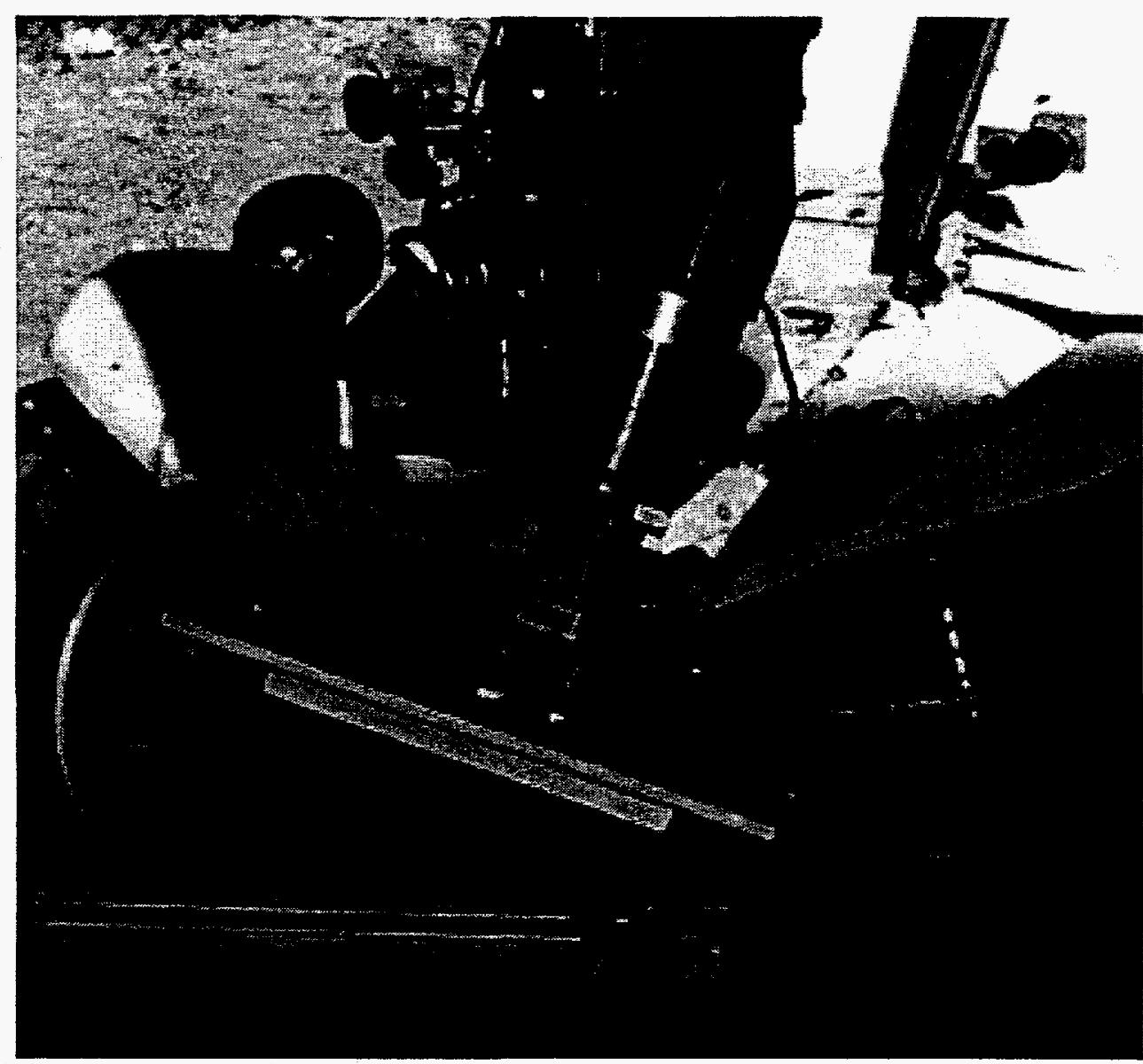

Figure 5. 4 Force/Torque sensors are used extensively in robotic systems throughout the U.S. DOE complex.

\subsubsection{Joint Encoder}

Joint encoders are required in order to send back to the control equipment information on the physical state of the robot assembly. This is more easily accomplished if the electronic parts are located close to the robot-assembly components that are being monitored. In such a case, the resulting hardness of the assembly is controlled by the type of electronic piece parts used. Although some electronic technologies are hard to 1 to $10 \mathrm{Mrad}$ [Si] (see Figure IV.A.1), linear-bipolar piece parts (i.e., ADCs, op amps, etc.) can be much softer and these part types are particularly suited to this application. This is not to say that design techniques yielding harder circuits are not feasible.

\subsubsection{Pressure Gauges}

There are a number of different manufacturers of pressure gauges using their own proprietary fabrication techniques. In the process, different transducers are used in these various designs. However all of them are reasonably hard to radiation. As an example, the Barksdale Series 400 Pressure Transducers use diffused semiconductor sensor technology for the transducer element. The composition of these transducers includes the semiconductor element and associated insulating materials and adhesives. Therefore, careful selection of these materials should a TID hardness well in excess of $10 \mathrm{Mrad}$ [Si]. A neutron hardness of $1 \mathrm{E} 14 \mathrm{n}[1-\mathrm{Mev}]$ should also be easily achievable.

\subsubsection{Strain Gauges}


Strain gauges can be used in a number of different ways in robotic systems. One such application was mentioned above in Subsection IV.B.5.b. In some cases it is not the strain gauge itself that controls its "in-use" radiation hardness. Rather, the hardness may be determined by either the adhesive used to bond the gauge or the or the insulating materials used for electrical isolation. Strain gauges have been found to have an inherent hardness of 200 to $400 \mathrm{M} \mathrm{rad}[\mathrm{Si}]^{36}$. In contrast, some insulators and adhesives are only hard to $10 \mathrm{Mrad}[\mathrm{Si}]$ (i.e., Teflon).

\subsubsection{Electrical}

\subsubsection{Electromagnetic}

Sensing devices based on electromagnetic effects include such types as capacitance, eddy current and Hall effect. The electromechanical nature of the first two makes these type of devices inherently insensitive to radiation effects (i.e., from TID or neutron fluence) while those based upon the Hall effect can be more sensitive depending upon material choice. However, a capacitive device such as WHAP37 contains interface electronics at or near the sensor which leads to a significant reduction in the hardness actually realized. On the other hand, eddy current devices will certainly contain insulating materials. As long as no electronic piece parts are present at the sensor, the radiation hardness will be controlled by the insulator hardness (see Table C.2 in Appendix C). Hall effect sensors are almost certain to be more sensitive to radiation than the other two unless they were to include very sensitive electronic devices. Indeed, there are many potentially radiation-sensitive linear devices such as ADCs (see Figure 5-1).

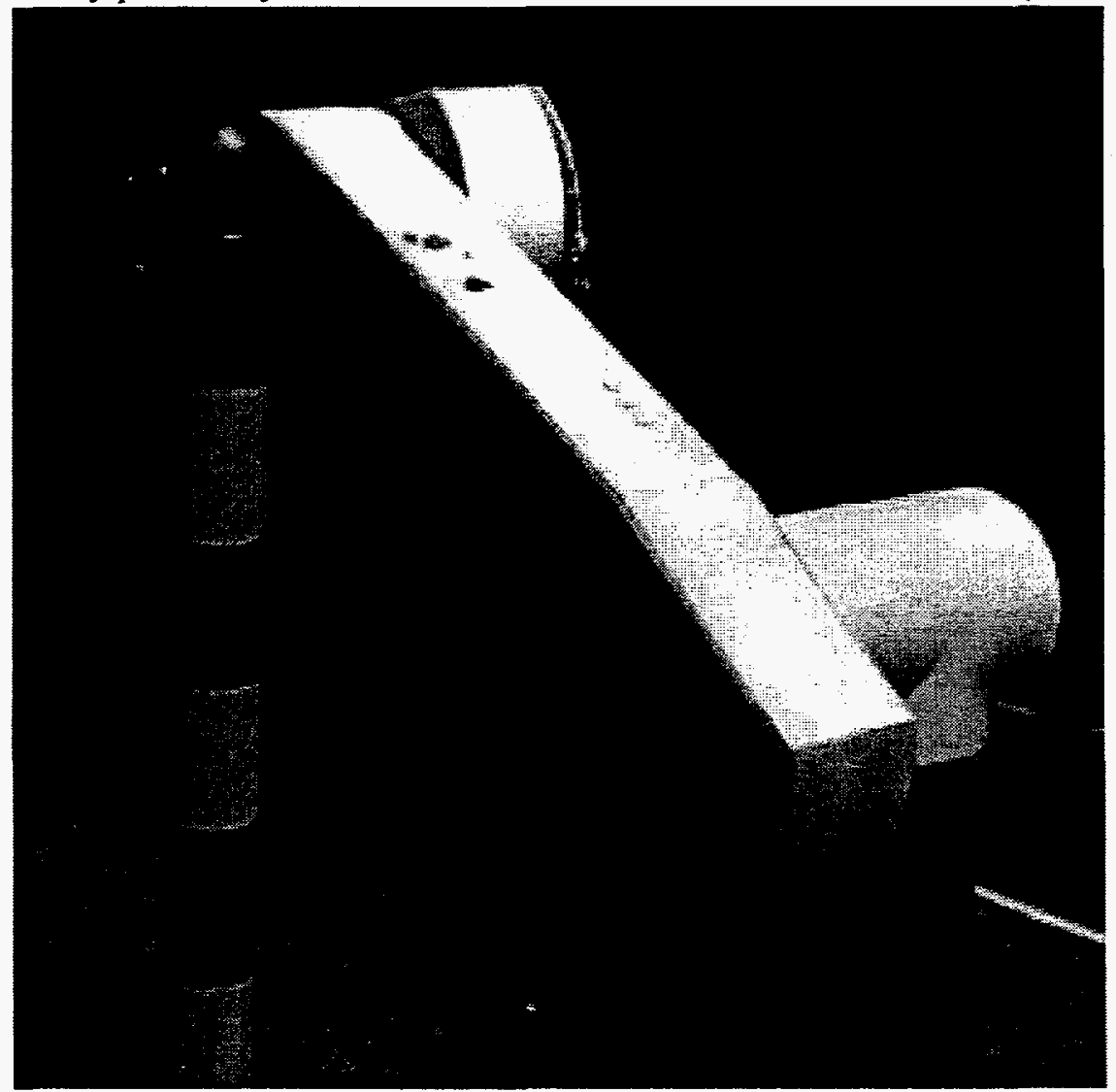

Figure 5. 5. Whole Arm Protection (WHAP) sensors are capacitive based, and have been envisioned as part of a collision avoidance system on robots in unstructured environments. 


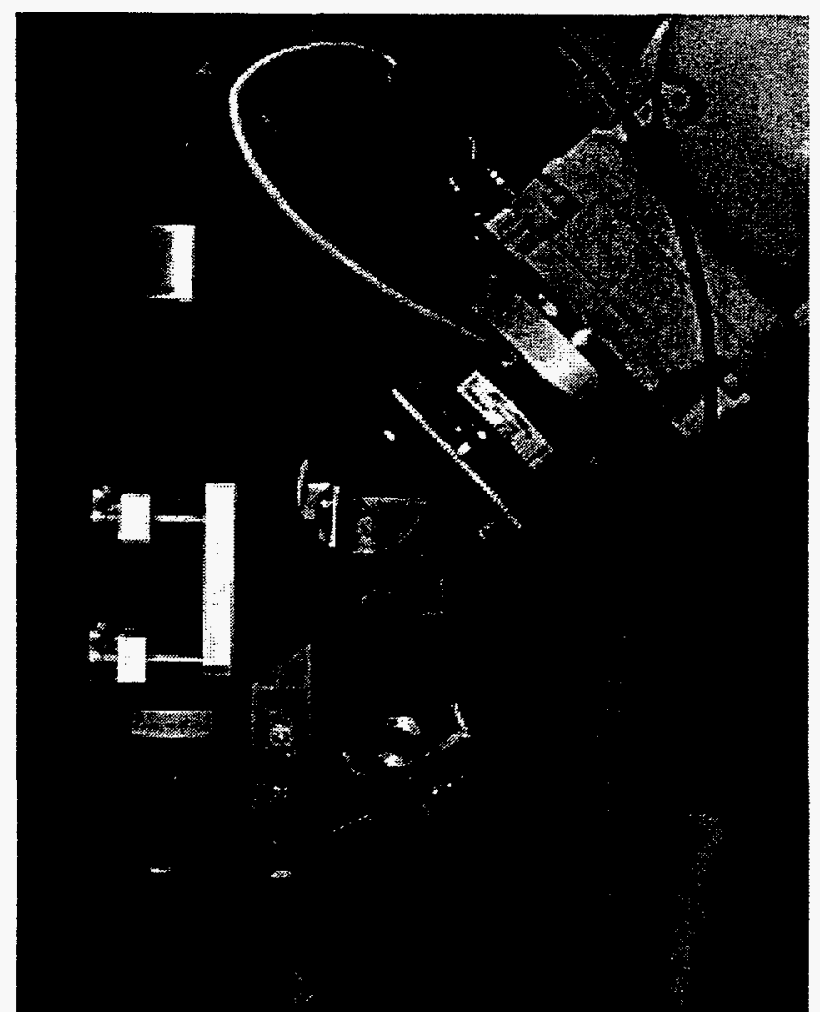

Figure 5. 6. The MAST sensor, also capacitive based, has been demonstrated to be useful in seam tracking, and is being examined as a stand-off sensor for plasma arc cutting.

\subsubsection{Ground Penetrating Radar}

It has been proposed that ground-penetrating radar be used to locate buried metallic waste. This type of monitoring technique is similar to the eddy current method of nondestructive testing. It has been suggested that a time-domain sensor might be more appropriate for this application than the common frequency-domain sensor of metal detectors, etc. Since these devices are primarily electromechanical in nature, it is expected that as long as they do not contain electronic piece parts their TID hardness should be controlled by the insulators and plastics used in the fabrication process. This hardness should therefore be in the range of 10 to $100 \mathrm{Mrad}[\mathrm{Si}]$. The neutron hardness should be greater than $1 \mathrm{E} 15 \mathrm{n}$ [1$\mathrm{Mev}] / \mathrm{cm} 2$ and the only SEE sensitivity would come through the use of electronic piece parts.

\subsection{Materials and Miscellaneous Components}

As stated above, robotic-system materials, other than semiconductors, include a wide variety of metals and insulators and, in some instances, may include liquids such as hydraulic system oil. Most of these materials and the components comprised of them are not as sensitive to radiation as are semiconductorbased electronics or the optical and thermal sensors.

\subsubsection{Materials}

Once again, for ease of discussion, materials are subdivided into the categories of metals, insulators, glasses and adhesives. Each is dealt with separately in the paragraphs below.

\section{METALS}


Metals are the most radiation resistant of the materials used in robotic systems. Neutron fluences in excess of $1 \mathrm{E} 20 \mathrm{n}[1-\mathrm{Mev}] / \mathrm{cm} 2$ are required in order to affect the mechanical properties of metals (e.g., room temperature irradiation of aluminum alloy $52 \mathrm{SH} 34$ to $1 \mathrm{E} 20 \mathrm{n}[1-\mathrm{Mev}] / \mathrm{cm} 2 \mathrm{can}$

produce a $24 \%$ increase in both yield strength and tensile strength 38 . At these neutron fluence levels, the electrical properties of metals are not strongly affected due to the high density of conduction electrons present. Carrier removal is an insignificant effect although mobility changes can be sizable (e.g., irradiation of iron at $80{ }^{\prime} \mathrm{C}$ to $6 \mathrm{E} 20 \mathrm{n}[1-\mathrm{Mev}] / \mathrm{cm} 2$ produced a $9.2 \%$ increase in resistivity 39 but are of no practical consequence. TID is even less important. Metals are unaffected up to TID levels far in excess of the levels projected for the applications listed above.

\section{INSULATORS}

Insulators, on the other hand, can be sensitive to radiation induced dose and displacement damage at levels anticipated for some of the applications listed above. Under irradiation, organic insulators suffer bond breakage and subsequent configuration changes, which can affect both mechanical and electrical properties (e.g., teflon has a useful upper limit of $1 \mathrm{E} 7 \mathrm{rad}[\mathrm{Si}]$ ). Inorganic insulators are less susceptible both electrically and mechanically as a result of the fact that they are relatively impure in the form they are normally utilized. The small concentrations of radiation induced defects are insignificant in comparison to the amount present in normally processed material (e.g., Teflon has a useful upper limit of $10 \mathrm{M} \operatorname{rad}[\mathrm{Si}]$ ).

\section{GLASSES}

As for the inorganic insulators, the mechanical and electrical properties of glasses, for the most part, are insensitive to radiation induced dose and displacement damage, at least to the levels associated with the applications given above. However, in the case of optical properties of glasses the situation can be just the opposite. In those instances where good optical transmission is required, radiation effects may produce a significant reduction in performance.

\section{ADHESIVES}

The hardness characteristics of the electrical and mechanical properties of adhesives are similar to those. encountered for insulators. A hardness level in excess of $10 \mathrm{Mrad}[\mathrm{Si}]$ is almost always assured and, in many cases, a hardness of $100 \mathrm{Mrad}[\mathrm{Si}]$ can be achieved (e.g., epoxy has a TID hardness limit of 400 Mrad[Si]) Neutron hardness test data is not as readily available as it is for TID, but it is believed that neutron hardness levels for almost all adhesives should be greater than $1 \mathrm{E} 15 \mathrm{n}[1-\mathrm{Mev}] / \mathrm{cm} 2$ and for a majority of these materials it should approach $1 \mathrm{E} 16 \mathrm{n}[1-\mathrm{Mev}] / \mathrm{cm} 2$.

\subsubsection{Other Components}

\section{OTHER OPTICAL PARTS}

Other optical parts such as camera lenses, infrared windows and fiber-optic cables and couplers can be susceptible to radiation effects even at moderate levels for the applications given above. The comments found under glasses apply to camera lenses. Indeed, the results presented in Appendix D show that the decrease in transmission for the lense tested with the Sony XC-999 camera was more severe than the degradation in camera performance. 
Fiber-optic components are known to be sensitive to radiation effects 40 . In particular, moderate reductions in transmission of unhardened fiber-optic cables can occur, even for relatively short runs at the higher levels associated with the anticipated applications (e.g., a $2 \mathrm{E} 4 \mathrm{~dB} / \mathrm{km}$ loss in transmission @ 0.82 micron wavelength for $1 \mathrm{Mrad}[\mathrm{Si}])$. Hardened versions of these cables exhibit little change in transmission even at the highest radiation levels of potential use unless the cable length becomes significant (e.g., a $25 \mathrm{~dB} / \mathrm{km}$ loss in transmission @ 0.82 micron wavelength for $1 \mathrm{Mrad}$ [Si]).

\section{ELECTRO-MECHANICAL COMPONENTS}

Electro-mechanical components such as solenoids, AC and DC servo-motors, stepper motors, etc. should be unaffected at even the highest radiation levels of interest unless a poor selection of insulators, adhesives and/or internal wiring is made.

\section{MISCELLANEOUS COMPONENTS}

Miscellaneous items such as gaskets, o-rings, electrical wire and cable, coaxial cable, etc. can be insensitive to radiation effects, even at the highest levels of interest, providing care is taken in the selection of materials used (e.g., metal gaskets are superior to rubber gaskets and polystyrene coaxial cable is superior to polyethylene). 


\section{Robotic System Survivability In Radiation Fields: Two Examples}

The two robotic systems that were evaluated in detail as a part of this work are the SNL Gantry Robot and the SNL RETRVIR Mobile Robot. In order to ascertain the hardness limit for these two robotic systems, it was necessary to carry out TID testing on a limited number of piece-part types. Within the budget for this project, limited resources were available for this testing and, as a result, only the potentially most radiation sensitive part types could be chosen for testing.

\subsection{Gantry Robotic System}

The possible applications for a Gantry Robotic System that have been analyzed in detail as a part of this work are those of the MRS and D\&D (see Section 2.1 for more detail). The radiation produced driver of primary concern for these applications is TID. The results of the modeling and simulation detailed in Appendix I are that (1) in the MRS application a dose of about $8 \mathrm{krad}[\mathrm{Si}$ ] per loading would be experienced with the probability of at least 200 loadings per year (i.e., a potential yearly cumulative dose of 1 to $2 \mathrm{Mrad}[\mathrm{Si}]$ ) and (2) in the D\&D application the cumulative dose for 10 hours of operation was estimated at $350 \mathrm{rad}[\mathrm{Si}] \mathrm{s}$, i.e., potential 200 hour dose of $70 \mathrm{krad}[\mathrm{Si}]$.

One present version of a gantry robot, as implemented at SNL, is described in Reference ${ }^{41}$. Table 6-1 details the subsystems and sensors used in this robotic system. Some of the components of the subsystems

Table 6. 1 Gantry Robot Subsystems/Sensors

\begin{tabular}{|l|l|l|}
\hline Subsystem/Sensor & Component & Function \\
\hline OPTO 22 Mystic Controller & G4D16R B1 Brain Board-Digital & control electronics \\
& G40AC5A Dig. AC Output Module & \\
& G41DC5D Dig. DC Input Module & \\
& G40DC5 Dig. DC Output Module & \\
\hline JR3 Intelligent Force Sensor & $\begin{array}{l}\text { USF Processor Board } \\
\text { USF AD Board } \\
\text { USF Amplifier Board } \\
\text { USF Power Supplies }\end{array}$ & arm force sensor \\
\hline Capacitive Proximity Sensor & charge amplifier & \\
\hline Toshiba IK-C40A & Video Camera & proximity sensor \\
\hline Riegl LD 90-3 Laser Rangefinder & - & vision sensor \\
\hline Ultrasonic Sensor & - & distance, level \& speed sensor \\
\hline Minilab Sensor & - & distance mapping sensor \\
\hline Bar-code Reader & - & end effector \\
\hline Pneumatic Air Hammer & - & item identification \\
\hline Pipecutter & photodiode & mechanical end effector \\
\hline
\end{tabular}

and/or sensors that are potentially sensitive to TID are also called out. A variety of end effectors and sensors can be used with this system as the table shows.

In this subsection the TID hardness of the constituents of the SNL Gantry Robot are addressed on a component-by-component basis, and in many instances on a semiconductor device-by-device basis. The composition and design layout of the components of the robot were identified where possible (some of the information was proprietary). A detailed listing of the more radiation-sensitive constituents are presented in Tables 6-2 through 6-6. These tables contain the radiation hardness of each constituent part, whether obtained from existing data bases, estimated from data for similar part types (i.e., functional type 
and process technology) or for parts of the same family type, or obtained from new testing performed as a part of this work. The OPTO22 Mystic Controller is one of the components for which proprietary considerations limited the amount of available information. In light of the large number of parts for which the hardness had to be estimated (i.e., there was no available part-specific data for about $90 \%$ of the parts), conservatism was used in arriving at the estimates. The actual hardness of a given part type may, in reality, exceed these conservative estimates.

The B1 Brain Board is the most sophisticated part of this subsystem and the device-level information is presented in Table 6-2. There was little available hardness data for these piece parts. From this list, it is anticipated that the MAX1232, CAT24COP and N80C196KB12 are the most radiation

Table 6. 2 Brain Board Piece-Part/Device Hardness

\begin{tabular}{|l|l|l|l|l|l|}
\hline Part Type & \# Used & Manufacturer & Function & Hardness & Data Source \\
\hline MAX 1232 & 1 & MAXIM & uP Supervisory Circuit. & {$[>20 \mathrm{krad}]$} & Estimated \\
\hline CAT 24COP & 1 & CSI & EEPROM & $3 \mathrm{krad}$ & Tested \\
\hline GAL 20XV10B & 1 & & Gate Array Logic & {$[\sim 20 \mathrm{krad}]$} & Similar Type \\
\hline VGT-8005-6173 & 1 & VLSI & & {$[>10 \mathrm{krad}]$} & Estimated \\
\hline N80C196KB12 & 1 & Intel & Micro-Controller & {$[>10 \mathrm{krad}]$} & Family Data \\
\hline VM6@11.0592MHz & 1 & & Crystal & {$[>50 \mathrm{krad}]$} & Estimated \\
\hline SRM49@20MHz & 1 & PLE & Crystal & {$[>50 \mathrm{krad}]$} & Estimated \\
\hline CD74HCT373E & 1 & Harris & Octal Transp. Latch & {$[>100 \mathrm{krad}]$} & Family Data \\
\hline HY6264ALP-10 & 1 & Hyundai & RAM & {$[>10 \mathrm{krad}]$} & Estimated \\
\hline M27C256B-20FI & 1 & ST & RAM & {$[>10 \mathrm{krad}]$} & Estimated \\
\hline TI75176AP & 2 & TI & Diff. Bus Trans. & {$[>200 \mathrm{krad}]$} & Family Data \\
\hline P6KE6 G13 & 3 & & Diode & {$[>500 \mathrm{krad}]$} & Estimated \\
\hline *C4 G29 & 1 & & Diode & {$[>500 \mathrm{krad}]$} & Estimated \\
\hline
\end{tabular}

sensitive. Of these, the CAT24COP EEPROM is available in NMOS and CMOS versions. The use of NMOS parts could result in a hardness limit of less than $10 \mathrm{krad}[\mathrm{Si}]$. All the rest of the piece parts have, or are estimated to have, a hardness limit of $20 \mathrm{krad}[\mathrm{Si}]$ or greater. Therefore the CAT24COP should control the hardness of this subsystem. Based upon this supposition, TID hardness testing was performed for this device as a part of this work and the test results can be found in Appendix F. These results show the hardness to be $3 \mathrm{krad}[\mathrm{Si}]$ which should indeed control the hardness of the B1 Brain Board.

The device-level information for the $\mathrm{AC}$ and $\mathrm{DC}$ modules is presented in Table 6-3. This information was obtained from generic circuit diagrams for these components. There was no device-specific data available from these diagrams. These are potted units and attempts to dissect them in order to obtain partspecific information were unsuccessful. However, they are mainly linear devices and, as such, should

Table 6. 3 AC \& DC Module Piece-Part/Device Hardness

\begin{tabular}{|l|l|l|l|l|l|}
\hline Part Type & \#Used & Manufacturer & Function & Hardness & Data Source \\
\hline- & - & - & Diode & {$[>500 \mathrm{krad}]$} & Type Data \\
\hline- & - & - & Optical Isolator & {$[>25 \mathrm{krad}]$} & Estimated \\
\hline- & - & - & LED & {$[>20 \mathrm{krad}]$} & Type Data \\
\hline- & - & - & Transistor & {$[>500 \mathrm{krad}]$} & Type Data \\
\hline- & - & - & Amplifier & {$[>100 \mathrm{krad}]$} & Estimated \\
\hline
\end{tabular}

possess a radiation-hardness limit well above that estimated for the B1 Brain Board. Therefore, none of these part types were selected for TID testing. 
As a result of the preceding considerations, the hardness limit of the OPTO22 Mystic Controller should be determined by that of the CAT24COP (i.e., $3 \mathrm{krad}[\mathrm{Si}]$ ).

The constituent piece parts of the boards comprising the JR3 Intelligent Force Sensor are listed in Tables 6-4 through 6-6. For the USF Processor Board, the available and/or estimated device-level hardness data is found in Table 6-4. Once again, there was hardly any experimental hardness data available on these specific piece parts. The most radiation-sensitive piece parts on this board are expected to be the 27C256 and $28 \mathrm{C} 64$ based upon the available ERRIC data. Their radiation sensitivity is superior to that of the CAT24COP.

Table 6. 4 USF Processor Board Piece-Part/Device Hardness.

\begin{tabular}{|l|l|l|l|l|l|}
\hline Part Type & \# Used & Manufacturer & Function & Hardness & Data Source \\
\hline 27C256 & 1 & AMD/ITL/TI & EPROM & $10 \mathrm{krad}$ & ERRIC \\
\hline 28C64 & 1 & GIC/STU/AD & EEPROM & $10 \mathrm{krad}$ & ERRIC \\
\hline 80188 & 1 & Intel & Hi Integ uProcessor & {$[>30 \mathrm{krad}]$} & Family Data \\
\hline 74LS32 & 1 & & Quad or Gate & {$[>200 \mathrm{krad}]$} & Family Data \\
\hline 74LS86 & 1 & & Quad Xor Gate & {$[>200 \mathrm{krad}]$} & Family Data \\
\hline 74LS161 & 1 & & 4-bit Counter & {$[>200 \mathrm{krad}]$} & Family Data \\
\hline 74LS373 & 1 & & Octal Latch & {$[>200 \mathrm{krad}]$} & Family Data \\
\hline 74LS374 & 1 & & Octal d-ff & {$[>200 \mathrm{krad}]$} & Family Data \\
\hline P8256AH & 1 & & Muart & {$[>10 \mathrm{krad}]$} & Estimated \\
\hline UA9636 & 1 & & RS423 Driver & {$[>10 \mathrm{krad}]$} & Estimated \\
\hline UA9637 & 1 & & RS422 Driver & {$[>10 \mathrm{krad}]$} & Estimated \\
\hline UA9638 & 1 & & Receiver & {$[>10 \mathrm{krad}]$} & Estimated \\
\hline ICTE-12 & 1 & & 12V Transorb & {$[>50 \mathrm{krad}]$} & Estimated \\
\hline ICTE-5 & 1 & & 5V Transorb & {$[>50 \mathrm{krad}]$} & Estimated \\
\hline
\end{tabular}

The available measured and estimated hardness limits for the piece parts on the USF ADD Board are listed in Table 6-5. Based upon manufacturers specifications, the AD7501 Analog MUX was predicted to have the lowest hardness limit of the parts on this board. To further complicate this situation, the TID hardness specified by this same manufacturer for a different part type (i.e., the AD7876) was

Table 6. 5 USF A/D Board Piece-Part/Device Hardness

\begin{tabular}{|l|l|l|l|l|l|}
\hline Part Type & \# Used & Manufacturer & Function & Hardness & Data Source \\
\hline 2N2907A & 1 & TI/MOT/NS & Transistor(BJTN) & $500 \mathrm{krad}$ & ERRIC \\
\hline 74LS04N & 1 & SIG/TI/NS & Hex Inverter & $600 \mathrm{krad}$ & ERRIC \\
\hline 74LS32N & 1 & & Quad OR & {$[200 \mathrm{krad}]$} & Family Data \\
\hline 74LS74AN & 1 & TI/FSC & Dual D-FF & $500 \mathrm{krad}$ & ERRIC \\
\hline 74LS125 & 1 & & Quad Trist Driver & {$[>200 \mathrm{krad}]$} & Family Data \\
\hline 74LS154 & 1 & & 4 TU 16-Bit Encoder & {$[>200 \mathrm{krad}]$} & Family Data \\
\hline 74LS273 & 1 & & Octal D-FF & {$[>200 \mathrm{krad}]$} & Family Data \\
\hline AD574AK & 1 & ADV/HAR & ADC & $300 \mathrm{krad}$ & Manufacturer \\
\hline AD585AQ & 1 & ADV & Hi Speed Prec. S\&H & $25 \mathrm{krad}$ & Manufacturer \\
\hline AD7501AN & 1 & ADV & Analog Mux & $20 \mathrm{krad}$ & AD7503/Manuf. \\
\hline 4N33 & 1 & & Opto Isolator & {$[>25 \mathrm{krad}]$} & Similar Type \\
\hline ICTE-5 & 1 & & 5V Transorb & {$[>50 \mathrm{krad}]$} & Estimate \\
\hline ICTE-15 & 1 & & 15V Transorb & {$[>50 \mathrm{krad}]$} & Estimate \\
\hline
\end{tabular}

experimentally determined to be significantly high at an exposure dose rate of interest for this work (i.e., greater than or about $4 \mathrm{krad}[\mathrm{Si}] / \mathrm{hr}$ ). As a result of these considerations, TID test data was obtained for the replacement (i.e., the AD7503) to the discontinued AD7501(see Appendix G). Except for the AD7501AN this board looks to be much harder than the previous two. 
The available measured and estimated hardness limits of the piece parts on the USF Amplifier Board are listed in Table 6-6. From this information, it was concluded that this board would not be the limiting factor in the hardness of this subsystem.

Table 6. 6 USF Amplifier Board Piece-Part/Device Hardness

\begin{tabular}{|l|l|l|l|l|l|}
\hline Part Type & \# Used & Manufacturer & Function & Hardness & Data Source \\
\hline LAS723B & 1 & & Voltage Reg. & {$[>25 \mathrm{krad}]$} & Estimate \\
\hline LM348 & 1 & & Quad Op. Amp. & {$[\sim 20 \mathrm{krad}]$} & Similar Type \\
\hline AD624AD & 1 & ADV & Instrumentation Amp. & $50 \mathrm{krad}$ & Manufacturer \\
\hline AD589LH & 1 & ADV & Voltage Reg. & $25 \mathrm{krad}$ & Manufacturer \\
\hline 1N4148/1N914 & 1 & FSC/UNI & Diode & $500 \mathrm{krad}$ & ERRIC \\
\hline JWD-171-23 & 1 & & Relay & {$[>500 \mathrm{krad}]$} & Estimate \\
\hline ICTE-15 & 1 & & $15 \mathrm{~V}$ Transorb & {$[>50 \mathrm{krad}]$} & Estimate \\
\hline
\end{tabular}

From the results presented in these tables, it was concluded that the USF Processor Board would control the hardness limit of the JR3 Intelligent Force Sensor.

The Minilab Sensor included electronics which made use of a "sunset technology" MUX for which the proposed replacement is the ADG506 MUX. Based upon the previously mentioned results obtained for the AD7876, the ADG506 was also selected for TID testing (see Appendix G).

Therefore, the hardness limit of the SNL Gantry Robot should be determined by the OPTO22 Mystic Controller as can be seen from Table 6-7.

Table 6. 7 Gantry Robot Subsystem/Sensor Hardness Estimates

\begin{tabular}{|l|l|l|}
\hline Subsystem/Sensor & Function & Estimated Hardness \\
\hline OPTO 22 Mystic Controller & control electronics & $3 \mathrm{krad}$ \\
\hline JR3 Intelligent Force Sensor & arm force sensor & $\sim 10 \mathrm{krad}$ \\
\hline Capacitive Proximity Sensor & proximity sensor & $>100 \mathrm{krad}$ \\
\hline Toshiba IK-C40A CCD Camera & vision sensor & $250 \mathrm{krad}$ \\
\hline Riegl LD 90-3 Laser Rangefinder & distance, level \& speed sensor & $>10 \mathrm{Mrad}$ \\
\hline Ultrasonic Sensor & distance mapping sensor & $>1 \mathrm{Mrad} \mathrm{w} / 0 \mu \mathrm{P}$ \\
\hline Minilab Sensor & & $>25 \mathrm{krad}$ \\
\hline Bar-code Reader & item identification & N/A \\
\hline Pneumatic Air Hammer & mechanical end effector & N/A \\
\hline Pipecutter & mechanical end effector & N/A \\
\hline
\end{tabular}

This hardness limit of about $3 \mathrm{krad}[\mathrm{Si}]$ means that this Gantry Robot falls far short of that required for the MRS application. Even with the inclusion of shielding to extend the "effective" life of the OPTO22 Mystic Controller, an extensive number of changeouts of the B1 Brain Board would be required over a year of operation. Indeed, without shielding this subsystem would not survive through a single loading. This does not appear to be a practical alternative and so the use of a hardened alternate to the CAT24COP should be considered. 
Also, this hardness limit is slightly less than that required to satisfy the D\&D application. Therefore, either changeout or shielding can be considered for extending the operational life of the robotic system in order to satisfy the D\&D TID requirement.

\subsection{RETRVIR Robotic System}

The RETRVIR Robot was described in Section 3.1. The application considered for RETRVIR was that of a transport accident scenario. This is described in detail in Appendix I where the scenario is modeled and the simulation of it is used to determine the dose to various parts of this robot. The TID received for the hypothetical operation was predicted to be (1) 3400 rads at the electronics bay and (2) 4300 rads at the video camera on the wrist of the Titan II manipulator.

The subsystems and sensors that are part of the RETRVIR Robot are listed in Table 6-8. Hardness considerations for each of these constituents of the robot was addressed separately.

Table 6. 8 RETRVIR Robot Subsystem/Sensors

\begin{tabular}{|l|l|l|}
\hline Subsystem/Sensor & Component & Function \\
\hline Force 30/33 Computer Board & VME-bus Board & Robot Control \\
\hline Force SYS68K/SIO-2 Board & VME-bus Board & Robot Control \\
\hline Force PIO Board & VME-bus Board & Robot Control \\
\hline Ethernet Board & VME-bus Board & Robot Control \\
\hline Arlan 620 & Ethernet Link & Communications Link \\
\hline Dell Star Subsystem & Analog Video Link & Vision Subsystem \\
\hline UOAS & Ultrasonic Sensor & Distance Mapping Sensor \\
\hline Elmo Camera & Video Camera & Vision Sensor \\
\hline Galil Inc. DMC-530 & Motor Controller & Robot Control \\
\hline Schilling Titan II & Manipulator & Object Manipulation \\
\hline
\end{tabular}

There were two separate VME computer boards evaluated, i.e., the Force 30 and Force 33. Either of these could be used in RETRVIR. There were separate boards used for vehicle, navigation and manipulator control. As was the case for the Gantry Robot, the hardness was addressed on a device-bydevice basis for the VME boards. The hardness limit information for the VME computer boards can be found in Tables 6-9 and 6-10. As can be seen from these two tables the MC68230 Parallel Interface Timer is the most sensitive to TID with the EPROM projected to be only slightly harder. 
Table 6. 9 Force 30 Computer Board Piece-Part/Device Hardness

\begin{tabular}{|c|c|c|c|c|c|}
\hline Part \# & \#Used & Manufacturer & Function & Hardness & Data Source \\
\hline 74F08-SO & 1 & MOT/FAIR & Quad 2-in AND & {$[>200 \mathrm{krad}]$} & Family Data \\
\hline $74 \mathrm{FCT} 240-\mathrm{SO}$ & 4 & IDT & Octal inv buff 3 -st & [>100 krad] & Family Data \\
\hline 74F164-SO & 2 & MOT/FAIR & 8-bit ser-in, par-out & {$[>200 \mathrm{krad}]$} & Family Data \\
\hline 27512 & 5 & TOSH/INTEL & 64kX8 EPROM & {$[-10 \mathrm{krad}]$} & Similar Type \\
\hline 74FCT244-SO & 11 & IDT & Octal buffer 3-state & {$[>100 \mathrm{krad}]$} & Family Data \\
\hline $74 \mathrm{~F} 27-\mathrm{SO}$ & 2 & MOT/FAIR & Triple 3-input NOR & [>200 krad] & Family Data \\
\hline MDU 4-20 & 1 & MOT & & [>10krad] & Estimated \\
\hline 74F74-SO & 9 & MOT/FAIRO & Dual D FF w/pr\&cl & [>200 krad] & Family Data \\
\hline 74F543-SO & $\overline{6}$ & MOT/FAIR & Oct trans n-inv 3-st & [>200 krad] & Family Data \\
\hline $74 \mathrm{~F} 373-\mathrm{SO}$ & 1 & MOT/FAIRO & Octal Transp Latch & {$[>200 \mathrm{krad}]$} & Family Data \\
\hline 74F1241-SO & 3 & VALVO & & {$[>200 \mathrm{krad}]$} & Family Data \\
\hline 74F280-SO & 4 & MOT/FAIR & 9-b O/E parity gen & [>200 krad] & Family Data \\
\hline DRAM 1Mx1 ZZ- & 4 & NEC/MOT & 1Mx1 Dyn. RAM & [>5 krad] & Estimate \\
\hline 74FCT245-SO & 12 & IDT & Octal Trans 3-state & {$[>100 \mathrm{krad}]$} & Family Data \\
\hline 74F641-SO & 3 & MOT/FAIR & Octal Bus Trans & {$[>200 \mathrm{krad}]$} & Family Data \\
\hline PAL 22V10-25 & 2 & FRC 526/7/9 & Prog Array Logic & [>20 krad] & Similar Type \\
\hline MC68230 & 2 & MOT & Parallel Int/Timer & $3 \mathrm{krad}$ & Published Data \\
\hline RTC 72421 & 1 & SEIKO & Real Time Clk (CMOS) & {$[\sim 10 \mathrm{krad}]$} & Estimate \\
\hline SRAM 32kx8 & 1 & TOSH/NEC & 32kx8 Static RAM & [>10 krad] & Similar Type \\
\hline $74 \mathrm{HCO0}-0$ & 1 & IDT & Quad 2-in NAND & {$[>100 \mathrm{krad}]$} & Family Data \\
\hline FGA002 & 1 & FORCE & Gate Array & [>20 krad] & Similar Type \\
\hline FHO01 & 1 & FORCE & Hybrid & {$[>25 \mathrm{krad}]$} & Manufacturer \\
\hline WD1772 & 1 & TOSH & FD Form/Contr(MOS) & {$[\sim 5 \mathrm{krad}]$} & Estimate \\
\hline $74 \mathrm{~F} 642-\mathrm{SO}$ & 3 & MOT/FAIR & Oct Bus Trans/Inv & {$[>200 \mathrm{krad}]$} & Family Data \\
\hline MB87031 & 1 & MOT & SCSI Prt Contr(CMOS) & {$[\sim 10 \mathrm{krad}]$} & Estimate \\
\hline $74 \mathrm{~F} 38-\mathrm{SO}$ & $\overline{1}$ & MOT/FAIR & Quad 2-in NAND & {$[>200 \mathrm{krad}]$} & Family Data \\
\hline 68562 & 2 & MOT/FAIR & DUSCC & {$[\sim 10 \mathrm{krad}]$} & Estimate \\
\hline FH002 & 4 & FORCE & Hybrid & [>25k krad] & \begin{tabular}{|l|} 
Manufacturer \\
\end{tabular} \\
\hline DDU 50A-10500 & 1 & ESAN & Disk Drive Unit & $\mathrm{n} / \mathrm{a}$ & - \\
\hline 1 N5817 & 2 & MOT & Power rectifier & {$[>500 \mathrm{krad}]$} & Similar Type \\
\hline $\begin{array}{l}\text { QUARTZ } \\
11.7456 \mathrm{MHz}\end{array}$ & 2 & JVC & $\begin{array}{l}\text { Crystal Oscillator- } \\
11.7456 \mathrm{MHz} \\
\end{array}$ & {$[>20 \mathrm{krad}]$} & Estimated \\
\hline QUOM 64MHz & 1 & JVC & Crystal Osc-64MHz & [>20 krad] & Estimated \\
\hline LED 550-3006 & 1 & DIALIGHT & LED-bicolor & [>20 krad] & Family Data \\
\hline LED 550-2206 & 1 & DIALIGHT & LED-green & {$[>20 \mathrm{krad}]$} & Family Data \\
\hline CR31/3N & 1 & VARTA & Battery & [>1 Mrad] & Estimated \\
\hline PAL 16R8-7 & 1 & FORCE 521 & AND/OR Inverter & [>20 krad] & Similar Type \\
\hline PAL 20L8-10 & 2 & FRC 523/525 & AND/OR Inverter & [>20 krad] & Similar Type \\
\hline MC68030 & 1 & MOT & Microprocessor & [>25 krad] & Family Data \\
\hline MC68881 & 1 & MOT & FP Math co-proc & [>25 krad] & Family Data \\
\hline QUOM 50MHz & 1 & JVC & Crystal Osc-50MHz & {$[>20 \mathrm{krad}]$} & Estimated \\
\hline SCB64107 & 1 & PULS. ENG. & & [>50krad] & Estimated \\
\hline $74 \mathrm{~F} 175-\mathrm{SO}$ & 1 & MOT/FAIR & Quad D flip-flop & {$[>200 \mathrm{krad}]$} & Family Data \\
\hline PAL 16L8-15 & 1 & FRC 528 & AND/OR Inverter & {$[>20 \mathrm{krad}]$} & Similar Type \\
\hline QUOM 40MHz & 1 & JVC & Crystal Osc-40MHz & {$[>20 \mathrm{krad}]$} & Estimated \\
\hline
\end{tabular}


Table 6.10 Force 33 Computer Board Piece-Part/Device Hardness

\begin{tabular}{|c|c|c|c|c|c|}
\hline Part \# & \#Used & Manufacturer & Function & Hardness & Data Source \\
\hline $74 \mathrm{~F} 08$ & 2 & MOT/FAIRO & Quad 2-in AND & [>200 krad] & Family Data \\
\hline 74FCT240 & 2 & IDT & Octal inv buff 3-st & [>100 krad] & Family Data \\
\hline 74F164 & 1 & MOT/FAIR & 8-b ser-in paral-out & {$[>200 \mathrm{krad}]$} & Family Data \\
\hline $271001 / 200 \mathrm{~ns}$ & 2 & TOSH/INTEL & EPROM & [ 10 krad] & Similar Type \\
\hline PAL20L8A & 1 & FRC 683 & AND/OR Inverter & [>20 krad] & Similar Type \\
\hline$\overline{74 F 244}$ & 10 & MOT/FAIR & Octal buffer 3-state & {$[>200 \mathrm{krad}]$} & Family Data \\
\hline $74 \mathrm{~F} 02$ & 2 & MOT/FAIR & Quad 2-inp NOR & [>200 krad] & Family Data \\
\hline $74 \mathrm{~F} 74$ & 8 & MOT/FAIR & Dual D FF w/pr\&cl & [>200 krad] & Family Data \\
\hline 74F543 & $\overline{4}$ & MOT/FAIR & Oct trans n-inv 3-st & {$[>200 \mathrm{krad}]$} & Family Data \\
\hline $74 F 241$ & 3 & MOT/FAIR & Octal Buffer 3-st & [>200 krad] & Family Data \\
\hline PAL22V10-15 & 1 & FRC 684 & Prog Array Logic & {$[\sim 20 \mathrm{krad}]$} & Similar Type \\
\hline PAL22V10-25 & 1 & FRC 685 & Prog Array Logic & [ 20 krad] & Similar Type \\
\hline $74 \mathrm{~F} 245$ & 10 & MOT/FAIR & Octal Trans 3-state & [>200 krad] & Family Type \\
\hline$\overline{74 F 641}$ & 1 & MOT/FAIR & Octal Bus Trans, & {$[>200 \mathrm{krad}]$} & Family Type \\
\hline PAL16L8-D & 1 & FRC 686/CYP & AND/OR Inverter & {$[\sim 20 \mathrm{krad}]$} & Similar Type \\
\hline MC68230 & 2 & MOT & Parallel Int/Timer & $\sim 3 \mathrm{krad}$ & Published Data \\
\hline RTC 62421 & $\overline{1}$ & SEIKO & Real Time Clck(CMOS) & {$[\sim 10 \mathrm{krad}]$} & Estimate \\
\hline SRAM/100ns & 1 & NEC/HIT & 32kx8 Static RAM & [>10 krad] & Similar Type \\
\hline $27512 / 200 \mathrm{~ns}$ & 1 & NEC/SIGN/TI & 64kx8 Static RAM & {$[\sim 10 \mathrm{krad}]$} & Similar Type \\
\hline $74 \mathrm{HCOO}$ & 1 & TI/MOT & Quad 2-in NAND & [>100 krad] & Family Data \\
\hline FG002 & 1 & FORCE GA & Hybrid microcircuit & {$[>25 \mathrm{krad}]$} & Manufacturer \\
\hline FH001 & 1 & FORCE & Hybrid microcircuit & [>25krad] & Manufacturer \\
\hline 68562 & 1 & SIGNETICS & DUSCC & [ 10 krad] & Estimate \\
\hline FH002 & 2 & FORCE & Hybrid microcircuit & [>25krad] & Manufacturer \\
\hline$\overline{D D U} 50 A-10500$ & 1 & $\overline{\text { ESAN }}$ & Disk Drive Unit & $n / a$ & - \\
\hline \multirow[t]{5}{*}{ IN5817 } & 3 & $\overline{\text { MOT }}$ & Power rectifier & [>500 krad] & Similar Type \\
\hline & 1 & DIALIGHT & LED-Bicolor & [>20 krad] & Similar Type \\
\hline & 1 & $\overline{\text { DIALIGHT }}$ & LED-Red & [>20 krad] & Similar Type \\
\hline & 3 & $\overline{\text { DIALIGHT }}$ & LED-Green & [>20 krad] & Similar Type \\
\hline & 6 & DIALIGHT & LED-Yellow & {$[>20 \mathrm{krad}]$} & Similar Type \\
\hline $\begin{array}{l}\text { QUARTZ } \\
14.7456 \mathrm{MHz}\end{array}$ & 1 & JVC & $\begin{array}{l}\text { Crystal Oscillator- } \\
14.7456 \mathrm{MHz}\end{array}$ & {$[>20 \mathrm{krad}]$} & Estimated \\
\hline QUOM 64MHz & 1 & JVC & Crystal Osc-64MHz & [>20 krad] & Estimated \\
\hline CR31/3N & 1 & VARTA & Battery & [>1 Mrad] & Estimated \\
\hline FH003 & 2 & FORCE & Hybrid microcircuit & & \\
\hline PAL 16R8-7 & 1 & FORCE & AND/OR Inverter & [ 20 krad] & Similar Type \\
\hline PAL 20L8-15 & 2 & FORCE & AND/OR Inverter & [ 20 krad] & Similar Type \\
\hline MC68030 & $T$ & MOT & Microprocessor & {$[>25 \mathrm{krad}]$} & Family Data \\
\hline MC68882 & 1 & $\overline{M O T}$ & FP Math co-proc & [>25 krad] & Family Data \\
\hline QUOM 33.4MHz & 1 & JVC & Cryst Osc 33.4MHz & [>20 krad] & Estimated \\
\hline DRAM 256x4-10 & 8 & NEC/HIT & 256x4 Dyn RAM- & [>5 krad] & Estimated \\
\hline QUOM 50MHz & 1 & JVC & Crystal Osc-50MHz & [>20 krad] & Estimated \\
\hline
\end{tabular}


The detailed piece part listing for the Force SYS68K/ISIO VME Board is presented in Table 6-11. As with most of the other subsystems evaluated, there is little part-specific hardness data available for the constituents of this board. Once again, the 68230 and EPROM piece parts should be the most radiation sensitive of the parts on this board.

Table 6. 11 SYS68K/ISIS-2 Board Piece-Part/Device Hardness

\begin{tabular}{|c|c|c|c|c|c|}
\hline Part \# & \#Used & Manufacturer & Function & $\begin{array}{l}\text { Hardness } \\
\text { Level }\end{array}$ & Data Source \\
\hline $4361-45$ & 16 & NEC/TNMOS & Static RAM (45ns) & [>10 krad] & Estimated \\
\hline $74 \mathrm{~F} 373$ & 4 & MOT/FAIR & Octal Transp Latch & {$[>200 \mathrm{krad}]$} & Family Data \\
\hline $74 \mathrm{~F} 257$ & 5 & MOT/FAIR & Quad 2in MUX 3-st & {$[>200 \mathrm{krad}]$} & Family Data \\
\hline 74ALS645-1 & 3 & TI & Oct bus trans 3-st & {$[>200 \mathrm{krad}]$} & Family Data \\
\hline $74 \mathrm{~F} 646$ & 4 & MOT/FAIR & Oct trans/reg 3-st & [>200 krad] & Family Data \\
\hline $68010 Y 10$ & 1 & MOT & Microprocessor & [>25 krad] & Family Data \\
\hline $27128-150$ & 2 & NEC/SEEQ & EPROM (16Kx8) & [ 10 krad $]$ & Similar Type \\
\hline 74ALS113 & 2 & TI & $\begin{array}{l}\text { Dual JK edge trig } \mathrm{f}-\mathrm{f} \text {, } \\
\text { w/preset }\end{array}$ & {$[>200 \mathrm{krad}]$} & Family Data \\
\hline PAL16L8B & 5 & $\begin{array}{l}\text { FRC } 140 \\
/ 45 / 49 / 50 / 51\end{array}$ & AND/OR Inverter & [ 20 krad] & Similar Type \\
\hline 68153 & 1 & MOT & Bus Inter Mod (bipolar) & [>50 krad] & Estimate \\
\hline 74ALS641-1 & 2 & $\mathrm{TI}$ & $\begin{array}{l}\text { Oct Bus Trans, open- } \\
\text { collector }\end{array}$ & {$[>200 \mathrm{krad}]$} & Family Data \\
\hline DDU50A-10500 & 1 & ESAN & Disk Drive Unit & $n / \mathbf{a}$ & - \\
\hline 20L8B PAL & 6 & $\begin{array}{l}\text { FRC 141- } \\
44 / 47 / 48\end{array}$ & AND/OR Inverter & [ 20 krad] & Similar Type \\
\hline 74ALS682 & 1 & TI & 8-bit comparator & {$[>200 \mathrm{krad}]$} & Family Data \\
\hline 74ALS244 & 1 & $\mathrm{TI}$ & Octal buffer 3-state & {$[>200 \mathrm{krad}]$} & Family Data \\
\hline 74ALS164 & 1 & TI & $\begin{array}{l}\text { 8-b ser-in, par-out shift } \\
\text { register }\end{array}$ & [>200 krad] & Family Data \\
\hline FRC & 1 & FORCE & PAL12L10 & {$[\sim 20 \mathrm{krad}]$} & Similar Type \\
\hline 68562 & 4 & SIGNETICS & DUSCC & $\sim 10 \mathrm{krad}$ & Estimate \\
\hline 75188 & 8 & TI/MOT & Quad line driver & {$[>200 \mathrm{krad}]$} & Estimate \\
\hline 75189 & 8 & TI/MOT & Quad line receiver & {$[>200 \mathrm{krad}]$} & Estimate \\
\hline $68230(\mathrm{P} 8)$ & 1 & MOT/THOMS & Paral Inter/Timer & $\sim 3 \mathrm{krad}$ & Published Data \\
\hline 74LS423 & 1 & TIMOT & & {$[>200 \mathrm{krad}]$} & Family Data \\
\hline $74 \mathrm{~F} 74$ & 1 & MOT/FAIR & Dual D FF w/pr\&cl & {$[>200 \mathrm{krad}]$} & Family Data \\
\hline 74LS393 & 1 & TI & Dual 4-b binary ctr & {$[>200 \mathrm{krad}]$} & Family Data \\
\hline 74AS1034 & 1 & $\mathrm{TI}$ & Hex Drivers & {$[>200 \mathrm{krad}]$} & Family Data \\
\hline
\end{tabular}


The detailed piece part listing for the Parallel IO VME Board is presented in Table 6-12. Again, there is little part-specific hardness data available for the constituents of this board. Although this board does not contain an EPROM piece part, it does contain the 68230 Parallel Interface Timer so that the hardness limit of this board should be essentially the same as for the other boards.

Table 6. 12 Force PIO board Piece-Part/Device Hardness

\begin{tabular}{|l|c|l|l|l|l|}
\hline \multicolumn{1}{|c|}{ Part \# } & \#Used & \multicolumn{1}{c|}{ Manufacturer } & \multicolumn{1}{c|}{ Function } & \multicolumn{1}{c|}{ Hardness } & \multicolumn{1}{c|}{ Data Source } \\
\hline 68230 & 4 & MOT & Parallel Interface/Timer & $\sim 3 \mathrm{krads}$ & Published Data \\
\hline 74S244 & 4 & TI, MMI & Octal Buffer & {$[>200 \mathrm{krad}]$} & Family Data \\
\hline 74LS126A & 1 & TI, MOT & Quad Buffer & {$[>200 \mathrm{krad}]$} & Family Data \\
\hline 74LS125A & 2 & TI, NSC & Quad Buffer & {$[>200 \mathrm{krad}]$} & Family Data \\
\hline HCPL-2630 & 24 & HP & Dual Optocoupler & {$[>25 \mathrm{krad}]$} & Similar Type \\
\hline 74LS138 & 2 & TI, MOT & 3 to 8 Decoder & {$[>200 \mathrm{krad}]$} & Family Data \\
\hline 74LS09 & 1 & TI, MOT & AND Gates & {$[>200 \mathrm{krad}]$} & Family Data \\
\hline 74LS373 & 1 & TI, MOT & Octal Latch & {$[>200 \mathrm{krad}]$} & Family Data \\
\hline 74LS148 & 1 & TI, HIT & Priority Encoder & {$[>200 \mathrm{krad}]$} & Family Data \\
\hline 74LS00 & 1 & TI, MOT & NAND Gates & {$[>200 \mathrm{krad}]$} & Family Data \\
\hline 74LS641-1 & 1 & TI & O. C. Bus Transceiver & {$[>200 \mathrm{krad}]$} & Family Data \\
\hline 74LS74A & 1 & TI, MOT & Dual D flip-flop & {$[>200 \mathrm{krad}]$} & Family Data \\
\hline 74LS32 & 1 & TI, MOT & OR Gates & {$[>200 \mathrm{krad}]$} & Family Data \\
\hline 74LS04 & 1 & TI, MOT & Inverters & {$[>200 \mathrm{krad}]$} & Family Data \\
\hline
\end{tabular}

The rf Analog Video Link, operating at $2.2952 \mathrm{GHz}$ and $30 \mathrm{fps}$, is a one-of-a-kind subsystem designed and fabricated by Dell Star Technologies. It was not possible to get design detail from them, since this unit was relatively old. It was only possible to get general design information including that concerning the generic types of piece parts used. Table 6-13 contains the information that was obtained. In general, rf piece parts possess very short minority carrier lifetimes and, as a result, are relatively radiation resistant. As a result, this subsystem is the hardest of those used in RETRVIR.

Table 6. 13 rf Analog Video Link Piece-Part/Device Hardness

\begin{tabular}{|l|l|l|l|l|l|}
\hline Part Type & \#Used & Manufacturer & Function & Hardness & Data Source \\
\hline GaAs FETs & - & & & {$[>1$ Mrad $]$} & Similar Type \\
\hline TTL Chip & & & Scalar-Divide By & {$[>200 \mathrm{krad}]$} & Family Data \\
\hline Oscillator & & HP & If Oscillator & {$[>100 \mathrm{krad}]$} & Similar Type \\
\hline MC1374 & & MOT & Video Processor & {$[>10 \mathrm{krad}]$} & Estimate \\
\hline $145151 \mathrm{P} 2$ & & MOT & Phase Lock Lp (CMOS) & {$[>10 \mathrm{krad}]$} & Estimate \\
\hline
\end{tabular}


The Ethernet system used on board RETRVIR consists of two distinct parts, the VME Ethernet card and the Arlan 620 Ethernet Link. The hardness estimates and/or data for the constituent piece parts of the Ethernet Board are presented in Table 6-14. The Arlan 620 Ethernet Link is an rf-link operating at 919 $\mathrm{MHz}$ and has been estimated by the manufacturer to have a hardness of 25 to $50 \mathrm{krad}$ [Si]. Proprietary considerations limited our ability to make an independent assessment of the hardness of this subsystem. It is unlikely that rf-type electronic parts would be as soft as some of the other parts on the VME boards. Table 6. 14 Ethernet VME-Board Piece-Part/Device

\begin{tabular}{|l|c|l|l|l|l|}
\hline Part Type & \# Used & Manufacturer & Function & Hardness & Data Source \\
\hline 54FCT543 & 13 & & Octal Reg Trans N-I & {$[>100 \mathrm{krad}]$} & Family Data \\
\hline 54FCT245 & 3 & & Octal Bidirec Trans & {$[>100 \mathrm{krad}]$} & Family Data \\
\hline 54F257A & 1 & & Quad 2-In MUX & {$[>200 \mathrm{krad}]$} & Family Data \\
\hline 54F573 & 5 & & Octal D-Type Latch & {$[>200 \mathrm{krad}]$} & Family Data \\
\hline 27AM7992 & 1 & AMD & Ser Inter Adapt & {$[\sim 10 \mathrm{krad}]$} & Estimate \\
\hline 601045C & 1 & XICOR & & {$[>10 \mathrm{krad}]$} & Estimate \\
\hline 54AS646 & 1 & & Octal Trans $/ \mathrm{reg} 3-\mathrm{st}$ & {$[>200 \mathrm{krad}]$} & Family Data \\
\hline 9233 & 1 & & & {$[>10 \mathrm{krad}]$} & Estimate \\
\hline VIC068PG & 1 & VTC & VME Interface & {$[>10 \mathrm{krad}]$} & Estimate \\
\hline MOT 68020 & 1 & MOT & HProcessor & {$[>25 \mathrm{krad}]$} & Family Data \\
\hline 54LS374 & 3 & & Octal D flip-flop 3-st & {$[>200 \mathrm{krad}]$} & Family Data \\
\hline MOT68455 & 1 & & & {$[>20 \mathrm{krad}]$} & Family Data \\
\hline 88C681M/28 & 1 & & & {$[>10 \mathrm{krad}]$} & Family Data \\
\hline 27AM7990DC & 1 & AMD & LAN Contr (CMOS) & {$[\sim 5 \mathrm{krad}]$} & Estimate \\
\hline
\end{tabular}

Table 6-15 summarizes the hardness limit data for the subsystems/sensors of the RETRVIR Robot. It is obvious that all the subsystems which contain the 68230 Parallel Interface Timer and EPROM piece parts have the potential to control the hardness limit of this robot. Statistically speaking, one of the VME boards should fail first and this should occur at about $3 \mathrm{krad}[\mathrm{Si}]$.

Table 6. 15 RETRVIR Robot Subsystem/Sensor Hardness

\begin{tabular}{|l|l|l|}
\hline Subsystem/Sensor & Function & Estimated Hardness \\
\hline Force 30/33 Computer Board & VME-bus Board & $\sim 3 \mathrm{krad}$ \\
\hline Force SYS68K/ISIO-2 Board & VME-bus Board & $\sim 3 \mathrm{krad}$ \\
\hline Force PIO Board & VME-bus Board & $\sim 3 \mathrm{krad}$ \\
\hline Ethernet Board & VME-bus Board & $25 \mathrm{krad}$ \\
\hline Arlan 620 & Ethernet Link & $>25 \mathrm{krad}$ \\
\hline Dell Star Subsystem & Analog Video Link & $>1 \mathrm{Mrad}$ \\
\hline & Ultrasonic Sensor & $>250 \mathrm{krad}$ \\
\hline Elmo Camera & Video Camera & $>25 \mathrm{krad}$ \\
\hline Galil Inc. DMC-530 & Motor Controller & $>10 \mathrm{Mrad}$ \\
\hline Schilling Titan II & Manipulator & $>10 \mathrm{Mrad}$ \\
\hline
\end{tabular}

This means that the RETRVIR Robot might survive through the entire transport accident scenario since the electronic-bay dose was predicted to be $3400 \mathrm{rad}[\mathrm{Si}]$. 


\section{Radiation Hardened Robotic Design Approach.}

When considering the application of robotic equipment in radiation environments, the approach can be very complex. At a minimum, it should include the following steps:

1. Perform a preliminary assessment of the radiation hardness of the components being considered for use in the robotic system.

2. Establish the extent of the potential radiation exposure, including any operations, configurations, or shielding that would minimize the total ionizing dose (TID). Reliability predictions for system components will be based on both radiation dose rates and total dose.

3. Determine the design based on required function and available hardening alternatives. Radiation dose monitoring capability should be included in the hardware design so real-time determination of dose can be made as the robotic system performs it's operations.

4. Perform a detailed evaluation of the hardness of the final design, with or without the assistance of a radiation effects expert. This evaluation may require that additional TID testing be carried out on select parts.

5. In high risk applications (i.e., those applications where failure of the robotic system has the potential of leading to disastrous results), a proof test of the more radiation-sensitive subsystems/components may be in order.

6. Plan preventive maintenance based on system hardness and the environment.

7. Monitor system conditions during operation.

8. Withdraw from the environment in a timely manner when simulation or monitored conditions indicate exposure rates approach the failure range.

\section{Radiation Dose Establishment}

In some environments, radiation dose rates may be relatively constant over time and within a robot's work volume. This may be the case, for example, for characterization efforts within an underground storage tank as described in Section 2.1.2. However, in many of the applications considered in Section 2, work environments will change, quantities and strengths of radiation sources will change, and the machines themselves will move through paths that may be varied as operations are executed. This is clearly the case in D\&D operations such as those expected for the underground storage tanks, since the active sludge and crystalline structures will be steadily removed by robot-borne tools. Such situations can make assumptions regarding equipment exposure rates difficult, yet significant differences between estimated and actual exposure could result in substantial changes in the effort and costs to harden these systems.

To help predict more closely what radiation doses may be imparted to critical areas of a robot, a simulation analysis procedure was developed. The procedural steps were to model the situation of interest, model radiation sources present, simulate necessary operations, and track the doses imparted to the equipment by the sources. Three scenarios representing various applications of robotics in the nuclear environment were analyzed using this approach: models of fuel handling at an MRS, example D\&D operations at a nuclear power plant, and a hypothetical transportation accident recovery (Appendix I).

Commercial graphical simulation packages such as IGRIP42 are capable of modeling robots, obstacles and other objects within an environment of interest, and animating them as needed with kinematic models of the mechanisms. IGRIP was used to simulate the MRS, D\&D and transportation accident scenarios described in Appendix 1. 
Dose maps were separately generated as described in Appendix I. For each scenario, a grid was superimposed on the environment of interest, radiation sources were placed into the grid, the dose rates were calculated using Monte Carlo methods for each source at each grid point, and the sum of the effects from all sources determined for each of the points.

A software package called doseServer, described in Appendix $\mathrm{H}$, was developed to track the positions of user-defined dose-critical points in the simulation relative to the radiation sources, compare the positions to the available dose maps, and sum the dose for each simulation time step at each critical point. The doseServer provided continuous updates to the operator during graphical simulation, and when a userdefined limit was reached, a warning was transmitted for display on the simulation screen. Further, dose rate and total dose data at the end of operations were available to determine the constraining dose values. 43

Additional steps to minimize doses may be taken through optimization of task planning and execution. Tasks such as installing shielding or removing large radiation sources from a work area first could substantially reduce imparted doses. For robotic equipment, path planners have been used to provide optimized motion based on some desired characteristics such as minimal movement or straight-line motion. Planning paths of motion based on the minimum product of time and dose rate could significantly reduce doses during operation, resulting in extended mean-time-between-failures.

Design Definition

As called out above, during the preliminary design of a robotic system for application in a hazardous radiation environment, the radiation hardness requirements for the components of the system should be addressed. The designer can obtain device-specific TID radiation hardness data from the sources presented in Appendix $\mathrm{C}$ of this report or, alternatively, radiation effects expertise within the designers organization, available commercial sources and/or government laboratories çan be consulted concerning parts performance in radiation environments.

A general "rule of thumb" to obtain TID-hard electronic designs is to use only discrete bipolar parts and bipolar small scale integrated circuits (SSICs). LSI and VLSI bipolar circuits exhibit some of the same sensitivities to TID as MOS-type ICs. Examples of families of potentially acceptable part types are ALS, ECL, LSTTL, STL, TTL, etc. (see Section 3). However, the design of complex electronic circuitry today almost certainly means the use of digital CMOS ICs. As presented in Section 3, this means a greater radiation sensitivity. In most cases CMOS ICs can be obtained in a radiation-hard product but at a substantially higher cost. For example, a rough categorization of available electronic part types would be as follows;

\begin{tabular}{ccc} 
Grade of Part Type & Approx. Cost & Hardness Range \\
\cline { 2 - 2 } Commercial & $<1$ to $20 \$$ & $<10$ to $<100 \mathrm{krad}[\mathrm{Si}]$ \\
Industrial & 10 to $200 \$$ & $\approx 10$ to $>100 \mathrm{krad}[\mathrm{Si}]$ \\
Hardened & 100 to $2000 \$$ & 0.1 to $<10 \mathrm{Mrad}[\mathrm{Si}]$
\end{tabular}

where there are many exceptions to such a rough grouping structure. Such a range in hardness levels makes it difficult to quantify parts type usage without more application-specific detail.

Final design of a robotic system, including both the electronic and mechanical components, should not proceed until after the model simulation, described above, has been completed. This will provide the 
exposure dose that must be survived. The designer will then have to get more specific about the radiation hardness of the candidate part types. Again, this can be done using the sources presented in this report or by seeking radiation effects expertise. It is now even more likely that additional experimental data will be required in order to assure reliable operation of the robotic system in the modeled application.

The designer is almost certain to face a tradeoff in cost versus hardness; i.e., for suitably selected part types, it is likely to be less expensive to replace non-hardened, but radiation tolerant, parts many times over the life of the system than to buy radiation hardened parts. This is especially true if only a few devices are required of a part type that is a special order in the radiation hardened version. Such tradeoffs are further complicated by the fact that localized, or unit-wide, shielding might be used to increase the "effective" hardness. However, this approach does increase weight and potentially the cost.

In the event that a designer chooses a design requiring the regular replacement of radiation-sensitive parts, a modular design, especially for those circuits containing the "soft" parts, will help to facilitate these "life-extending" replacement procedure. An approach of this type is likely to increase cost also. A combination of shielding and replaceable-element modular design could be employed to further extend the life of a robotic system and in some instances may be the most cost effective.

Finally, in those cases where the failure of a robotic system could lead to serious consequences, TID testing of the final-design hardware may be called for. This results from the fact that there may be incircuit, synergistic, effects between degrading piece parts that could produce a small, but none the less significant, decrease in failure threshold of the subsystem as compared to the constituent parts.

\section{Monitoring and Maintenance}

In order to ensure that the replacement of "soft" parts and/or modules is carried out at the correct interval, monitoring and maintenance should be considered. Initial maintenance schedules can be estimated from the radiation dose simulations and design components. Monitoring will provide real-time feed-back on exposures to verify estimated maintenance schedules and include off-normal event exposure. Radiation monitors 44 called RADFETs can be used for this purpose. These RADFETs are continuous readout devices that directly measure dose to silicon. Devices of this type could be placed in the vicinity of the devices scheduled for regular replacement; indeed they could be a part of the replaceable modules. The use of these dosimeters add a cost increment to the design. RADFETs are commercially available but usually have specified sensitivity ranges. They can be specially fabricated to meet specific customer requirements but this adds additional cost to the use of this type of a real time TID monitor. 


\section{Summary and Recommendations}

Many of the possible applications of robots in radiation environments were discussed. Three of the possible applications were selected for detailed analysis; i.e., MRS, D\&D and radiation accidents. Simulation and modeling techniques were applied in these cases.

It was found that a large number of robotic systems have been developed for, or have the potential for, applications in ionizing radiation environments. A large fraction of these systems are one of a kind and have been developed by, and at, the facilities where they are used. There are only a limited number of commercial manufacturers of robotic systems and very few who provide radiation hardened products.

Contemporary robotic systems use a wide variety of sensors and electronic parts which have been designed with little or no concern for radiation hardness. A great deal of radiation hardness data is available for the different electronic technologies used in robotic systems so that the impact of these components on the hardness of a given robotic system can be assessed. The majority of this TID and displacement damage data can be found in the E.R.R.I.C. data base of D.A.S.I.A.C. There is also data available via the online Radata data base of NASA, the SNL White Star data base and data that can be found in manufacturers publications. The situation is not as good in the case of sensors and since the vast majority of the sensors are commercially available, fabrication details are in some cases proprietary which has made the estimation of their radiation hardness difficult.

Since the start of this multi-year project, a compendium has been published dealing with the radiation hardness properties of components and materials used in the nuclear power industry 45 and a survey of the radiation hardness of sensors and components used in robotic systems carried out at Oak Ridge. This later survey is very similar to a part of this work. In addition Sias and Tulenko have addressed the availability of rad-hard microcomputers for robotic applications 46 . Although there are some differences of opinion and interpretation concerning the hardness and availability of the various components, the information in all the sources, including this report, is generally consistent. During the conduct of this project, hardening of one of the REMOTEC commercially available robots was initiated 47 .

Radiation hardness requirements placed upon robotic systems are dependent upon the application (i.e., they are application specific). In light of the specific radiation requirements and available piece-part hardness levels and associated costs, cost-performance trade-off studies can be performed in order to arrive at an optimal design.

One means of establishing a first order estimate of the radiation doses imparted to operating robotic equipment is to use simulation of the operations in the presence of calculated radiation fields, and to track the doses within the simulation. Graphical programming of robotic equipment is used extensively at SNL 48,49 utilizing a simulation package known as IGRIP (see Reference 41). IGRIP has been used to model the work cell of interest, including machines, structures, tools and work pieces. Objects are programmed on the screen, operations reviewed and approved, then downloaded to the hardware for immediate execution. During the simulation, positions of critical points on the robotic equipment can be tracked relative to radiation sources. Software known as doseServer receives these position vectors, compares them to dose maps generated off-line for particular source types, sums the doses at each point, and warns the operator through the simulation interface when a dose limit has been reached. The operator can then accept the simulated tasks or reject them in favor of lower-dose-producing options. 
Using these simulation and modeling techniques in combination with the available radiation-effects data bases, including new data obtained as a part of this project, two specific robotic systems were selected for radiation hardness evaluation. The systems chosen were the SNL Gantry Robot and the RETRIVR. The gantry robot was found to contain one electronic subsystem that had a projected failure level of about $3 \mathrm{krad}[\mathrm{Si}]$ due to the measured test data obtained on one of its constituent piece parts. All the rest of the sensors and electronics had, or were estimated to have, failure levels in the range of 25 to $50 \mathrm{krad}[\mathrm{Si}]$ or greater. The RETRIVR did not have any sensors or electronics with measured or estimated failure levels below $25 \mathrm{krad}[\mathrm{Si}]$.

The ultimate applicability of electronic piece parts, sensors and selected materials to robotic systems depends upon the specifics of the design and the particular application.

The approach to radiation hard design can be very complex, and should, at a minimum, include the following steps. First, preliminary assessment of the radiation hardness of the robotic system components being considered for use in the system should be performed. Second, the extent of the potential exposure should be established, including any minimization of TID. Third, determine the design based on required function and available hardening alternatives. Radiation dose monitoring capability should be included in the hardware for real-time determination of dose. Fourth, a detailed evaluation of the hardness of the final design, with or without the assistance of a radiation effects expert, which may require that additional TID testing be carried out on select parts. Fifth, preventive maintenance based on system hardness and the environment should be planned. Sixth, system conditions should be monitored during operation. Finally, withdraw from the environment in a timely manner when simulation or monitored conditions indicate exposure rates are approaching the failure range.

As an extension of this work it is recommended that an electronic radiation-hardening data base for sensors and other components be developed for robotic system designers to use when developing designs. Finally, it is recommended that the procedure outlined in this report be used to develop a prototype hardened robotic system in order to evaluate the utility of the procedure developed in this work. 


\section{Acknowledgments}

The authors wish to acknowledge the invaluable assistance of C.B. Selleck, for the development of doseServer; J.A. Dedig for the development of the MRIP user interface with doseServer and for the accident simulation development, R.G. Dedig for the development of the reactor D\&D simulation; to L.M. Desjarlais and G. Lo for initial hot cell dose tracking code development; to B.E. Jones for simulation of the hot cell, the RETRVIR robot, and associated activities; and to G. A. Harms and P.J. Griffin for radiation field analysis and dose map generation.

We also would like to thank C. Dieterle, Portland General Electric, for design and decommissioning information relating to the Trojan power plant used in the D\&D simulation.

We also wish to acknowledge the assistance of T. J. Sheridan who carried out the hardness testing of all the video cameras and the CONTAQ ISU 4000 Proximity Sensor, D. E. Beeson (Ktech) who carried out the hardness testing of the ADG506 and ADG7503 Multiplexers and P. G. Micono who carried out the hardness testing of the CSI CAT24CO4P. We also thank R. Romero for his contributions to these testing activities as well as for the preparation of some of the material contained in this report.

We wish to express our appreciation to E. F. Hartman for his part in the development of this project and his continued contributions and encouragement during the conduct of the work. We also thank R. D. Palmquist for his advice and encouragement during the course of this work.

A very special thanks goes to T. J. Sheridan for his significant contribution to the preparation of this final report. Without his dedication and commitment the final product would not have been as comprehensive and complete. Finally, we wish to express our gratitude to the Laboratory Directed Research and Development Office for making this work possible. 


\section{Appendix-A Radiation Hardness of Electronic Components}

The radiation hardness of electronic piece parts is dependent upon the technology, fabrication process and function, and complexity of the part type. Commercial (non-hardened) parts are generally the most sensitive to radiation effects although some can be as hard as "hardened" parts of another technology. For robotic systems, the most important radiation effect is total ionizing dose (TID), although displacement damage is also of importance for the space and possibly the fusion applications. Single event effects (SEE) can also be important in the space environment. Hardness ranges for various electronic-part technologies are presented in Figure 5-1 of Section 5.1 for TID and displacement damage. As can be seen from this figure, the TID hardness level can vary from less than $10 \mathrm{krad}[\mathrm{Si}]$ to greater than $10 \mathrm{Mrad}[\mathrm{Si}]$.

A complete presentation of all TID, displacement damage and SEE test data is beyond the scope of this report. Most of the available data can be found in the following four data bases:

1. The JPL/NASA electronic data bank called "RADATA" which contains TID and SEE test data.

2. The ERRIC Device Inventory of DASIAC.

3. The SNL "Whitestar" data base.

4. The A.E.A. Technology Report (see Reference 45).

Tables A.1, A.2, A.3, and A.4 reference the part type and the test data per part that are available from these four sources. The first two include examples of the type of data that can be obtained from these sources. A major part of the SEE test data has been summarized in four journal articles and these have been included at the end of this appendix as Table A.5.

The specific robotic application will dictate whether commercial or hardened piece parts will have to be used in a given design as determined from cost-effectiveness considerations (i.e., will it be possible to change-out piece parts at selected intervals of exposure in such a way that the use of multiple sets of commercial parts during the useful life of the robotic system can affect a significant savings over the cost of using hardened parts?) 
'Handbook of Industrial Robotics, ed Nof, S.Y, John Wiley \& Sons, 1985.

2 "A Compendium on Mobile Robots Used in Hazardous Environments," EPRI Report No. NP5060, May 1987.

3 "A Compendium of Robotic Equipment Used in Hazardous Environments," EPRI Report No. NP-6697, February 1990.

${ }^{4}$ Bennett, P. C., and J. B. Stringer, "MRS/MPC Analysis: Simulation and Economics of Automation" Proceedings of the International High Level Radioactive Waste Management Conference, Las Vegas, NV; 1994

'C.P. Gertz and S. Teitlebaum, "1992: When Things Began to Move at Yucca Mountain", Proceedings of Waste Management '93, Tucson, Arizona, 1197 (1993)

6 "A Description of the Hanford Single-Shell Tanks and Their Contents", WHC-SD-TD-TI-001, Westinghouse Hanford Company, Richland, WA (1992)

${ }^{7}$ Shen, E.J., "Retrieval of Underground Storage Tank Wastes: The Hanford Challenge," Proceedings of the ANS 6th Topical Meeting on Robotics and Remote Systems, Monterey, CA, Feb. 1995, Vol. II pp. 549-553

${ }^{8}$ Rahn, F.J., Adamantiades, A.G., Kenton, J.E., and C. Braun, A Guide to Nuclear Power Technology, John Wiley \& Sons, 1984, pp.194-196.

'Borovoi, A.A., A.I. Ivanov, A.R. Sich, "Use of Robotic Technologies and Remotte Systems for Diagnostics and Research within the Chernobyl Sarcophagus," Proceedings ofthe ANS Fifth Topical Meeting on Robotics and Remote Systems, Knoxville, TN. April 1993. pp. 211-216

${ }^{10}$ TMII II EPRI reports "The Cleanup of Three Mile Island Unit 2, A Technical History: 1979 to 1990" EPRI NP 6931s

"F.C. Davis, et.al., "New Remote Maintenance Approach for IPX", Proceedings of the Fifth Topical meeting on Robotics and Remote Systems, Knoxville, TN, p 669, April 1993

${ }^{12}$ R. Hancox, et. al., "Remote Maintenance in a Fusion Reactor, and its Implications for Availability", Proceedings of the Fifth Topical meeting on Robotics and Remote Systems, Knoxville, TN, p 681, April 993

${ }^{13}$ M.W. Frei, et. al., "System Integration for the Disposal of Defense Transuranic Waste" Proceedings of Waste Management '93, Tucson, AZ, p 409, 1993 
${ }^{14}$ H. B. Meieran, "Meieran: A View of Robotics in Nuclear," Nuclear News, Vol. ,p 51 , April 1992

${ }^{15}$ Rahn, F.J., Adamantiades, A.G., Kenton, J.E., and C. Braun, A Guide to Nuclear Power Technology, John Wiley \& Sons, 1984, p. 628

${ }^{16} \mathrm{G}$. Harrop "The Integration of Advanced Technology: Robotics and Remote Handling," IAEA TECDOC, Technical Committee Meeting on Remote Technology Related To The Handling, Storage and/or Disposal of Spent Fuel, 12/94

${ }^{17}$ Personal Communication, Mr. D. Webster, British Nuclear Fuels Limited, Risley, UK, 8/95

${ }^{18}$ Personal Communication, Colin Robson, BNFL, Sellafield, UK, 8/95

19 Gain, O., H. Hacard and L. Baillif, "Hands On Versus Remote Techniques in Casks Unloading Facilities", IAEA TECDOC, Technical Committee Meeting on Remote Technology Related To The Handling, Storage and/or Disposal of Spent Fuel, 12/94

${ }^{20}$ Makarchuk, T., "Remote Handling of Spent Fuel and High-Level Wastes in Back-End Operations of Nuclear Fuel Cycle", IAEA TECDOC Technical Committee Meeting on Remote Technology Related To The Handling, Storage and/or Disposal of Spent Fuel, 12/94

${ }^{21}$ R. I. Crutcher and M. R. Moore, "An RF Communications System for the West Valley Transfer Cart", Proceedings of the ANS Fifth Topical Meeting on Robotics and Remote Systems, Knoxville, TN, p 569, April 1993

${ }^{22}$ REMOTEC, 114 Union Valley Road, Oak Ridge, TN 37830, 615-483-0228

${ }^{23}$ W. Rahim, "Feedback Limited Control System on a Skid-Steer Vehicle", Proceedings of the ANS Fifth Topical Meeting on Robotics and Remote Systems, Knoxville, IN, p 37, April 1993

${ }^{24}$ P.T.Boissiere, et. al.,"Selective Retrieval of Buried Waste Using Mobile Robot Manipulator Systems", Proceedings of the Fifth Topical Meeting on Robotics \& Remote Systems, Knoxville, Tennessee, April 26-29, 1993,p.517.

${ }^{25}$ S. M. Sze, "Physics of Semiconductor Devices", John Wiley \& Sons, 1984

${ }^{26}$ Personal Communication, T. F. Luera, SNL, Dept. 9363

27, Personal Communication, E. L. Petersen 
${ }^{2 s}$ G. P. Summers, et. al., "Energy Dependence of Proton Displacement Damage Factors for Biploar Transistors", IEEE Trans. On Nucl. Science, NS-33, No. 6, p. 1282, December 1986

${ }^{29}$ R. I. Vandermolen, et. al., "Radiation Hardened Control System", Proceedings of the ANS Fifth Topical Meeting on Robotics and Remote Systems, Knoxville, TN, p. 555, April 1993

${ }^{30}$ R. B. Malhot and K. L. Morris, "Infrared Imaging System for the Ferrocyanide Waste Tanks at the U.S. Department of Energy's Hanford Site", Proceedings of the Symposium on Waste Management '93, Tucson, AZ, p. 1075, March 1993.

${ }^{31}$ B. Christensen, et. al., "Model Based, Sensor Directed Remediation of Underground Storage Tanks", Proceedings of the Fourth ANS Topical Meeting on Robotics and Remote Systems, Albuquerque, NM, p. 227, February 1991

${ }^{32}$ L. E. Efferding, "Infrared Scanner Parametric Test Using Heated-Simulant Tank Waste", Proceedings of the Symposium on Waste Management '93, Tucson, AZ, p. 1063, March 1993

${ }^{33}$ Figaro, USA, Inc. P.O. Box 357, 1000 Skokie Blvd., Room 575, Winette, IL, 60091

${ }^{34}$ B. A. Crawford, et. al., "Application of Remote Raman Screening to Processing of Mixed Wastes in Drums", Proceedings of the Symposium on Waste Management '93, Tucson, AZ, p.1379, March 1993

${ }^{35}$ The six-around-one fiber-optic configuration provides a single center fiber for the delivery of light to the sample surface and the scattered light is collected by the six peripheral fibers.

${ }^{36}$ C. R. Tallman, "Review and Status of Radiation Effects Studies on Strain Gauges", LANL, unpublished.

${ }^{37}$ J. L. Novak and J. T. Feddema, "Whole Arm Collision Avoidance Using Capacitive Sensors on a Puma 560", Proceedings of the ANS Fifth Topical Meeting on Robotics and Remote Systems, Knoxville, TN, p. 649, April 1993

${ }^{38}$ R. V. Steele and W. P. Wallace, Metal Progress, Vol.68, 114(1955)

${ }^{39}$ C. A. Bruch, et. al., Journal of Metals, 1362 (1956)

${ }^{40}$ C. E. Bames and J. J. Wiczer, "Transient Damage Effects" in Radiation Effects in Optoelectronic Devices, Sandia National Laboratory, SAND 84-0771, 1984

${ }^{41}$ Personal Communication, J. A. Tauscher, SNL, Dept. 9661 
${ }^{42}$ IGRIP is a trade mark of Deneb Robotics, Inc., Auburn Hills, MI.

${ }^{43}$ This procedure also lends itself to dose minimization techniques. Using manual iteration or advanced path planners, the simulation can be altered to reduce radiation doses to critical components. Sandia National Laboratories has integrated IGRIP into GISC-based robotic control systems for gantry, pedestal and mobile robots, demonstrating rapid programming and execution capability. Similarly, automated path planners have been integrated as modules into these control systems. In most situations, several options are available to move from one point to another. Path planners seek to find the "best" path for such movement by applying some set of rules, such as minimum joint movement or straight-line motion. By adding a rule that minimizes total dose (dose rate $x$ time) every move, the robot availability can be optimized.

${ }^{44}$ Personal Communication D. J. Moreno, SNL Dept. 1315

${ }^{45}$ R. E. Sharp and D. R. Garlick, "Radiation Effects on Electronic Equipment: A Designers' Users' Guide for the Nuclear Power Industry" AEA Technology, Harwell, Didcot, Oxfordshire, OX11, ORA, United Kingdom, 1994

${ }^{46}$ F.R.Sias, Jr. and J.S.Tulenko, "Radiation-Hardened Microcomputers for Robotics and Teleoperated Systems" Trans. of ANS Vol.69, Nov. 1993

${ }^{47}$ S.L.Jones,etal., "Environmental Hardening of a Mobile-Manipulats System for Nuclear Environments", Trans. of ANS Vol.69, Nov.1993.

${ }^{48}$ McDonald, M.J., and R. D. Palmquist, "Graphical Programming: On-Line Robot Simulation for Telerobotic Control." Sandia National Laboratories, International Robots and Vision Automation Show and Conference Proceedings, Detroit, MI. April 1993.

${ }^{49}$ McDonald, M.J., and R. D. Palmquist, "Graphical Programming: On-Line Robot Simulation for Telerobotic Control." Sandia National Laboratories, International Robots and Vision Automation Show and Conference Proceedings, Detroit, MI. April 1993.

\footnotetext{
${ }^{50}$ J. Janesick, et. al., "Scientific Charge-Coupled Devices", Optical Engineering, Vol.26, No.8, p.692, August 1987
}

S1 J. Janesick, et. al., "Radiation Damage in Scientific Charge-Coupled Devices", IEEE Trans. On Nucl. Science, Vol.36, No.1, p.572, February 1989

52 G. R. Hopkinson, " $\mathrm{CO}^{60}$ and Proton Radiation Effects on Large Format, 2-D, CCD Arrays for an Earth Imiaging Application", IEEE Trans. on Nucl. Science, Vol. 39, No.6, p.2018, December 1992 
${ }^{53}$ Chori America, Inc., One Penn Plaza, 54 $4^{\text {th }}$ Floor, New York, NY 10119

${ }^{54}$ Hitachi Denshi, Ltd., 5910 North Central Expressway, Suite 1000, Dallas, Tx, 75206

ss "Monitored Retrievable Storage (MRS) Facility Conceptual Design Report," U.S. Department of Energy, Office of Civilian Radioactive Waste Management, M\&O Document No. TSO92-0323.0257. May 1992.

${ }^{56}$ Bennett, P.C., L.M. DesJarlais, B.E. Jones and J. Pinkerton, MRS Simulation Results Report: Spent Nuclear Fuel and MPC Handling. Submitted to TRW Environmental Safety Systems, July 1993.

${ }^{57}$ Harms, G.A., "MRS Cell Dose Calculations", Sandia National Laboratories, Intemal Memorandum RS6514/93/00010, July 1993.

${ }^{58}$ Designed by General Atomics under contract to the U.S. Deparment of Energy 


\section{Distribution}

\begin{tabular}{|c|c|c|}
\hline 3 & $\begin{array}{ll}\text { MS } & 1176 \\
\text { MS } & 0188\end{array}$ & $\begin{array}{l}\text { P. C. Bennett, } 9651 \\
\text { LDRD Office, } 4523 \\
\text { Attn: D. L. Chavez }\end{array}$ \\
\hline & $\begin{array}{ll}\text { MS } & 1167 \\
\text { MS } & 1008\end{array}$ & $\begin{array}{l}\text { E. F. Hartman, } 9351 \\
\text { ISRC Library, } 9621 \\
\end{array}$ \\
\hline & $\begin{array}{ll}\text { MS } & 1176 \\
\text { MS } & 1167 \\
\text { MS } & 0727\end{array}$ & $\begin{array}{l}\text { R. D. Palmquist, } 9651 \\
\text { L. D. Posey, } 9351 \\
\text { T. L. Sanders, } 6406\end{array}$ \\
\hline & $\begin{array}{ll}\text { MS } & 9018 \\
\text { MS } & 0899 \\
\text { MS } & 0619\end{array}$ & $\begin{array}{l}\text { Central Technical Files, } 8940-2 \\
\text { Technical Library, 4916 } \\
\text { Review \& Approval Desk, } 12690 \\
\text { For DOE/OSTI }\end{array}$ \\
\hline
\end{tabular}

